\title{
TOMOKO SEKIYA
}

\section{Análise do gene $C D K N 1 B / p 27^{k i p 1}$ em pacientes com neoplasia endócrina múltipla tipo 2}

\author{
Tese apresentada à Faculdade de Medicina da \\ Universidade de São Paulo para obtenção do título de \\ Doutor em Ciências
}

Programa de: Endocrinologia

Orientador: Prof. Dr. Sérgio Pereira de Almeida Toledo

São Paulo

2013 
Dados Internacionais de Catalogação na Publicação (CIP)

Preparada pela Biblioteca da

Faculdade de Medicina da Universidade de São Paulo

Creprodução autorizada pelo autor

Sekiya, Tomoko

Análise do gene $C D K N 1 B / p 27^{\text {kip1 }}$ em pacientes com neoplasia endócrina múltipla tipo 2 / Tomoko Sekiya. -- São Paulo, 2013.

Tese(doutorado)--Faculdade de Medicina da Universidade de São Paulo. Programa de Endocrinologia.

Orientador: Sérgio Pereira de Almeida Toledo.

Descritores: 1.Inibidor de quinase dependente de ciclina p27 2.Neoplasia endócrina múltipla tipo 2a/genética 3.Neoplasia endócrina múltipla tipo 2b/genética 3.Proteína proto-oncogênicas c-ret 4.Polimorfismo de nucleotídeo único 5.Carcinoma medular 6.Neoplasias da glândula tireoide/genética 7.Feocromocitoma/genética 8.Hiperparatireoidismo primário/genética 9.Inibidor de quinase dependente de ciclina p18 10.Transformação celular neoplásica 11.Transdução de sinal 12. Fosforilação 13.Imunoistoquímica

USP/FM/DBD-300/13 


\section{DEDICATÓRIA}


À Deus, que nunca me abandonou e sempre me deu forças para seguir em frente e nunca desistir.

Aos meus queridos pais, que me ensinaram os valores da vida que me transformaram na pessoa que sou. Em especial ao meu pai, que não está aqui comigo, mas com certeza deve estar muito orgulhoso.

Aos meus queridos irmãos que estiverem presentes nos momentos mais importantes da minha vida.

Ao meu orientador e amigo professor. Sérgio P.A. Toledo. Sempre com muita sabedoria me orientou na tese e também me ensinou muito sobre a vida. 


\section{AGRADECIMENTOS}


Uma das coisas maravilhosas da vida são as pessoas que encontramos pelo caminho. Elas podem passar como estrelas ou cometas, mas de uma maneira ou outra sempre deixam um pouco de si em nós. Não somos nada se não tivermos companheiros, amigos para compartilhar momentos, ideias e ensinamentos. Por isso, ficam meus profundos agradecimentos às pessoas que participaram no desenvolvimento e conclusão da tese.

À Deus pelas bênçãos alcançadas durante a minha vida sem sua presença nada seria possível.

Ao meu orientador professor Sérgio P.A. Toledo, uma pessoa muito sábia, pela orientação e conhecimentos transmitidos. Sou muito agradecida por todos os momentos e conversas compartilhadas.

Ao amigo Rodrigo Toledo pelo auxílio no desenvolvimento e conclusão da tese. Ele sempre demonstrou grande paixão pela pesquisa e pela busca do conhecimento, e por isso foi sempre um exemplo para todos os alunos do LIM-25.

Aos queridos amigos Jorge Menezes, Viviane Longuini e Roxanne Hatanaka, que sempre foram muito companheiros, me apoiando em todos os momentos. Conheci vocês durante essa jornada e sei que levarei a amizade de vocês para o resto da vida.

Às queridas Victoria Denck e Tatiana Denck, mãe e filha que são exemplo de pessoas. Sempre nos lembraremos de nossa viagem. Vocês são muito especiais.

À amiga Kátia Tessima, que tornou o início dessa jornada possível

À Dra. Ester Sabino, fica minha admiração pela pessoa que é e também pela sua inteligência e por todo conhecimento transmitido.

As queridas companheiras da Life Technologies: Ana Fraga, Cinthia Bacchir, Eliane Laurentino, Fabiana Yasuhara e Tatiana Ortolan. Obrigada pelos ensinamentos e pela companhia nesses últimos meses. 
Aos médicos Delmar Lourenço Muniz Jr., Flávia Coutinho, Joya Emilie Correia-Deur pelo auxílio com os dados clínicos dos pacientes do projeto.

À pesquisadora Luciana Isaki do Departamento de Biologia Celular (ICB-USP) pelo auxílio com a técnica de Western blot.

Às doutoras Camila Tomikawa e Sheila Siqueira do Laboratório de Patologia do HC-FMUSP (LIM-14) pela paciência e auxílio com os procedimentos de imunohistoquímica.

Aos funcionários do Laboratório de Endocrinologia Genética UEG/LIM-25, Elisângela Quedas, Geni Rodrigues, Maria das Graças Cavalcanti que sempre estiveram disponíveis a auxiliar e também pela companhia agradável durante esses anos.

À Eliete Helena Santiago, que sempre pelo auxílio com documentações e burocracias. Mas, principalmente por ser uma pessoa alegre e que sempre nos recebia no laboratório com um grande e singelo sorriso.

À pesquisadora Ericka Trabach pela companhia e apoio sempre quando precisei. Fica minha admiração por sua dedicação.

Aos colegas de pós-graduação, Karine Rodrigues, Lucas Moura e Michelle Buscarilli por dividirem conhecimentos e momentos agradáveis.

Aos doutores Ana Hoff, Marcos Tavares e Antônio Carlos Lelário por contribuírem com sugestões e observações na minha banca de qualificação.

À professora Dra. Berenice Bilharino de Mendonça pelo apoio na realização do projeto.

Ao Dr. Alexander Augusto de Lima Jorge pelo apoio, e por permitir a conclusão da tese na UEG/LIM-25.

À Cida, secretária da pós-graduação da endocrinologia, pelo apoio e auxílio.

À FAPESP pelo apoio financeiro. 
"Deus disse: Eu irei com você e Ihe darei a vitória"

(Êxodo 33:14) 
Esta tese está de acordo com as seguintes normas, em vigor no momento desta publicação:

Referências: adaptado de International Committee of Medical Journals Editors (Vancouver).

Universidade de São Paulo. Faculdade de Medicina. Divisão de Biblioteca e Documentação. Guia de apresentação de dissertações, teses e monografias. Elaborado por Anneliese Carneiro da Cunha, Maria Julia de A. L. Freddi, Maria F. Crestana, Marinalva de Souza Aragão, Suely Campos Cardoso, Valéria Vilhena. 3a ed. São Paulo: Divisão de Biblioteca e Documentação; 2011.

Abreviaturas dos títulos dos periódicos de acordo com List of Journals Indexed in Index Medicus. 
SUMÁRIO 
Lista de abreviaturas, símbolos e siglas

Lista de tabelas

Lista de figuras

Resumo

Summary

1 INTRODUÇÃO

1.1 Neoplasias Endócrinas Múltiplas................................................. 2

1.2 Neoplasia Endócrina Múltipla tipo 2 ........................................... 4

1.2.1 Correlação genótipo-fenótipo ................................................ 8

1.2.2 Aspectos Clínicos da NEM2 ………………..................... 9

1.2.2.1 Carcinoma Medular de Tireoide ...................................... 9

1.2.2.2 Feocromocitoma...................................................... 11

1.2.2.3 Hiperparatireoidismo Primário ..................................... 12

1.2.2.4 Outros fenótipos menos frequentes associados à NEM2 …........................................................... 13

1.2.2.4.1 Megacólon congênito ............................................ 13

1.2.2.4.2 Liquen amiloide cutâneo (CLA) ............................... 14

1.2.3 Aspectos moleculares da NEM2 ....................................... 14

1.2.3.1 Proto-oncogene RET ................................................... 14

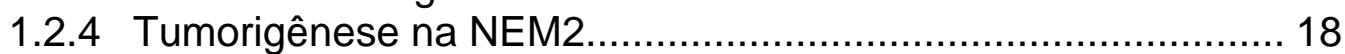

1.2.4.1 Duplas mutações no gene RET ...................................... 19

1.2.4.2 Polimorfismos no RET .................................................. 20

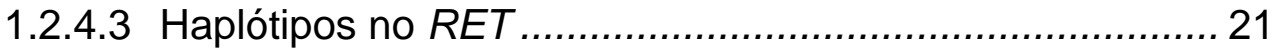

1.3 Evidências do envolvimento de Inibidoras de quinases dependente de ciclinas (CDKIs) na tumorigênese NEM2 ................. 22

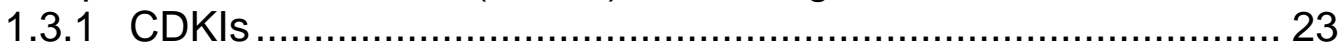

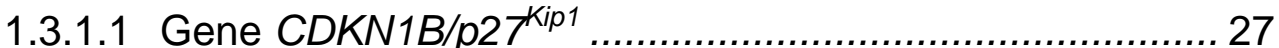

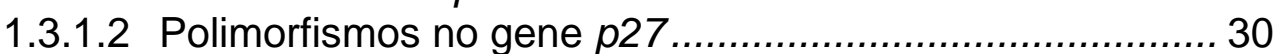

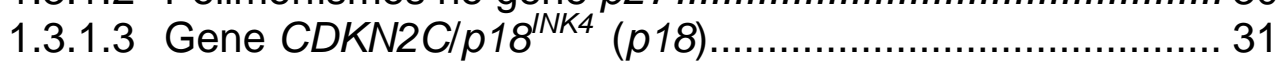

1.3.1.4 Interação de p18 e p27 ............................................... 33

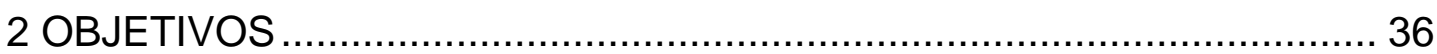

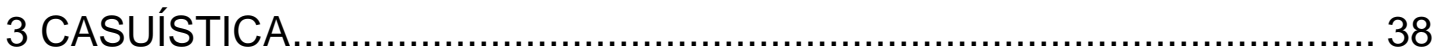

3.1 Pacientes e tumores.................................................................... 39

3.2 Análise de polimorfismos do gene p27 em uma grande família

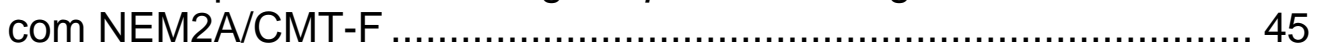

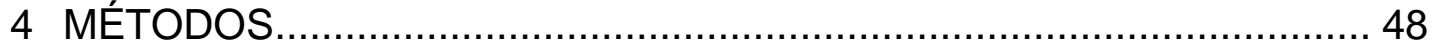

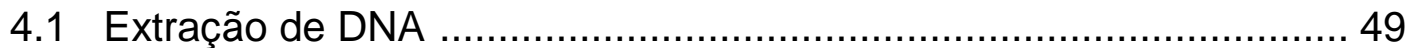

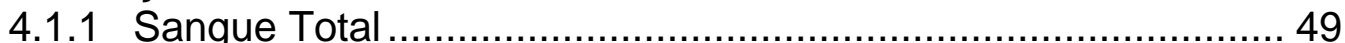

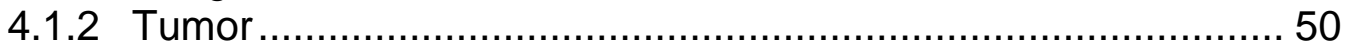

4.2 Rastreamento de mutação e/ou variantes polimórficas nos

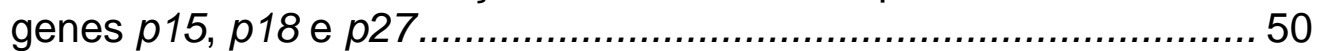

4.3 Análise somática de RET nos tumores NEM2 ............................... 51

4.4 Reação em Cadeia da Polimerase - PCR …..................................... 52 
4.5 Purificação e quantificação do produto amplificado ....................... 53

4.6 Reação de Sequenciamento .................................................... 54

4.7 Purificação do produto da reação de sequenciamento ...................... 54

4.8 Análise das sequências......................................................... 55

4.9 Análise dos polimorfismos p.V109G no gene p27 por PCRRFLP e c.-79C>T por sequenciamento - Grupo controle ................ 56

4.10 Análise in silico ................................................................. 57

4.11 Análise de microssatélites do gene p27 ...................................... 58

4.12 Análise de expressão proteica de p27 e Skp2 ..............................6 60

4.12.1 Extração de proteína e análise de Western blot para p27 ..... 60

4.12.2 Extração da proteína p27 ............................................... 61

4.12.3 Western blot (WB) ................................................ 61

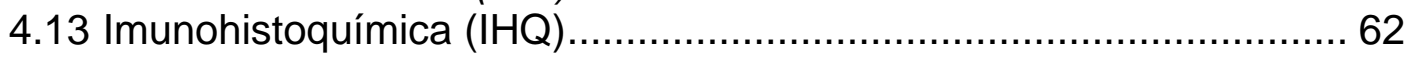

4.14 Análise Estatística ....................................................... 64

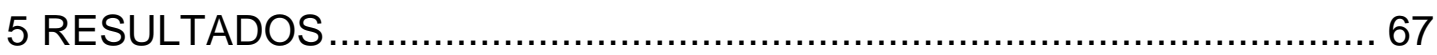

5.1 Análise geral dos dados ..................................................6 68

5.2 Rastreamento de mutações nos tumores nos genes $p 15, p 18 \mathrm{e}$

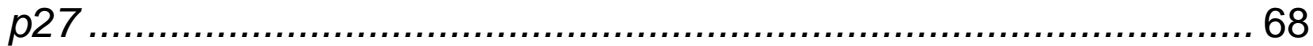

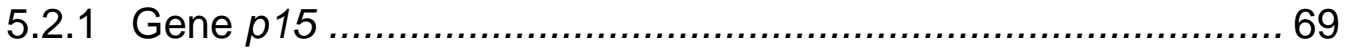

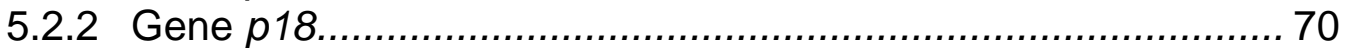

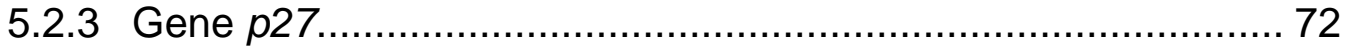

5.2.3.1 Frequência dos genótipos de $p 27$ no grupo controle ....... 77

5.2.3.2 Análise da associação de polimorfismos no gene $p 27$ sobre o fenótipo NEM2A/CMT-F de uma grande família.............................................................. 77

5.2.4 Análise somática de RET nos tumores ........................... 78

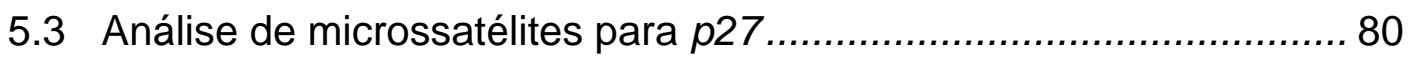

5.4 Expressão e localização celular de p27 .................................... 80

5.4.1 Western blot de p27 e Skp2 .......................................... 81

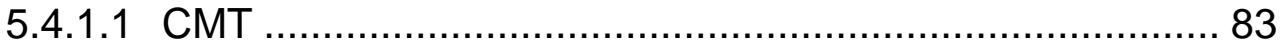

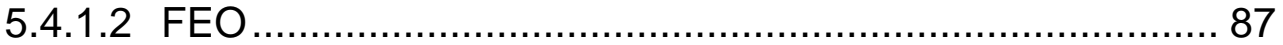

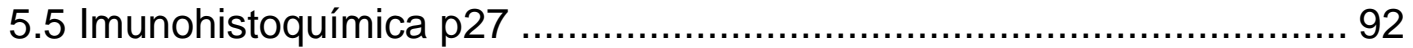

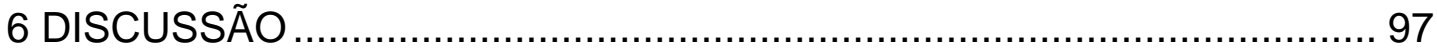

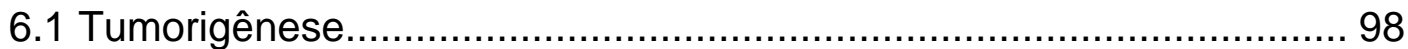

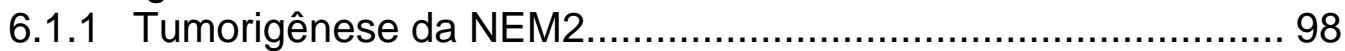

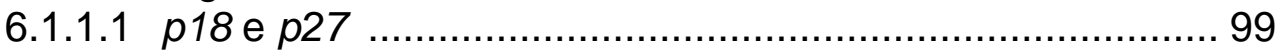

6.1.1.2 Polimorfismos no gene p27 como modulares de fenótipo em uma grande família com NEM2 ................ 104

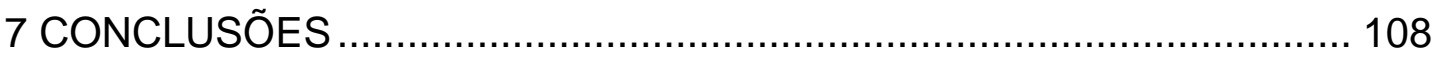

8 ANEXOS ............................................................................. 110

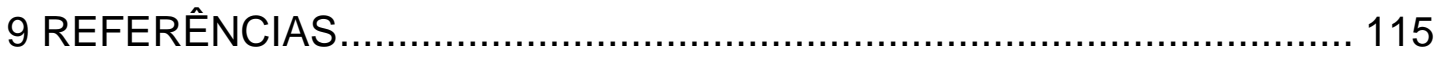


LISTAS 


\section{LISTA DE ABREVIATURAS, SIGLAS E SÍMBOLOS}

\begin{tabular}{|c|c|}
\hline 3'UTR & - $3^{\prime}$ região não traduzida \\
\hline 5'UTR & - 5' região não traduzida \\
\hline ATA & - American Thyroid Association \\
\hline CDKI & - Inibidora de quinase ciclina-dependente \\
\hline $\mathrm{CGH}$ & - Hibridização genômica comparativa \\
\hline CLA & - Liquen amiloide cutâneo \\
\hline CMT & - Carcinoma Medular de Tireóide \\
\hline $\mathrm{Ct}$ & - Calcitonina \\
\hline DNA & - Ácido Desoxiribonucleico \\
\hline dNTP's & - deoxyribonucleotide triphosphates \\
\hline DO & - Densidade ótica \\
\hline $\mathrm{E} 2 \mathrm{~F}$ & - fator de transcrição E2 \\
\hline FAPESP & - Fundação de Amparo à Pesquisa do Estado de São Paulo \\
\hline FEO & - Feocromocitoma \\
\hline $\mathrm{HCC}$ & - Hiperplasia de célula-C da tireoide \\
\hline HC-FMUSP & $\begin{array}{l}\text { - Hospital das Clínicas da Faculdade de Medicina da Universidade de } \\
\text { São Paulo }\end{array}$ \\
\hline HPT & - Hiperparatireoidismo primário \\
\hline HSCR & - Doença de Hirschsprung \\
\hline IB-USP & - Instituto de Biociência da Universidade de São Paulo \\
\hline ICESP & - Instituto do câncer do estado de São Paulo \\
\hline IHQ & - Imunohistoquímica \\
\hline LIM-14 & - Laboratório de Investigação Médica 14 \\
\hline LIM-25 & - Laboratório de Investigação Médica 25 \\
\hline $\mathrm{LOH}$ & - Perda de heterozigose \\
\hline
\end{tabular}




\begin{tabular}{|c|c|}
\hline MAF & - Minor allele frequency \\
\hline MENX & - Neoplasia Endócrina Múltipla em linhagem de ratos \\
\hline $\min$ & - minuto \\
\hline mRNA & - RNA mensageiro \\
\hline NEM & - Neoplasia Endócrina Múltipla \\
\hline NEM1 & - Neoplasia Endócrina Múltipla tipo 1 \\
\hline NEM2 & - Neoplasia Endócrina Múltipla tipo 2 \\
\hline NEM4 & - Neoplasia Endócrina Múltipla tipo 4 \\
\hline NIH 3TC & - Linhagem celular padrão de fibroblasto \\
\hline OMS & - Organização Mundial da Saúde \\
\hline p18 & - proteína codificada pelo gene p18 \\
\hline p27 & - proteína codificada pelo gene p27 \\
\hline PCR & - Reação em Cadeia da Polimerase \\
\hline PCR-RFLP & - Restriction Fragment Lengh Polymorphism \\
\hline $\mathrm{pRb}$ & - proteína retinoblastoma \\
\hline PTH & - Paratormônio \\
\hline RET & - Rearranged during transfection \\
\hline RTK & - Receptor de tirosina quinase \\
\hline seg & - segundo \\
\hline SNC & - Sistema Nervoso Central \\
\hline SNP & - Polimorfismo de um único nucleotídeo \\
\hline TK & - Tirosina quinase \\
\hline TK2 & - Domínio tirosina quinase 2 \\
\hline TTx & - Tireoidectomia profilática \\
\hline UV & - Ultra-violeta \\
\hline WB & - Westen blot \\
\hline
\end{tabular}




\section{LISTA DE TABELAS}

Tabela 1 - Caracterização clínica e genética das Neoplasias

Endócrinas Múltiplas

Tabela 2 - Classificação da Neoplasia Endócrina Múltipla (NEM2) e ocorrência do CMT, tumores associados e outras 5

Tabela 3 - Correlação genótipo-fenótipo, níveis de risco e monitoramento dos pacientes com diferentes mutações no gene RET, de acordo com o consenso de CMT/NEM2 de 2009

Tabela 4 - Comparação dos fenótipos NEM com os tecidos neoplásicos envolvidos na MENX

Tabela 5 - $\quad$ Mutações somáticas identificadas em humanos no p18 em CMT e FEO associada à mutação ativadora no gene RET

Tabela 6 - Incidência de tumores em animais knockout p18, p27 e p18/p27

Tabela 7 - Comparação da incidência de tumores em ratos p18 -//p27 -/- em pacientes com síndromes NEM1 e NEM2.

Tabela 8 - Dados clínicos de 36 pacientes com NEM2 e mutação no gene RET na qual foram analisados tecidos tumorais.

Tabela 9 - Dados clínicos da família de Arapiraca com NEM2A/CMT-F e mutação germinativa C620R no gene RET

Tabela 10 - Sequências dos primers e tamanhos dos produtos amplificados para os genes $p 15, p 18$ e $p 27$

Tabela 11 - Sequências dos primers e tamanhos dos produtos amplificados para os éxons 10,11, 13, 14 e 16 do gene RET

Tabela 12 - Sequências referências utilizadas nas análises do sequenciamento direto dos genes p27, p18, p15 e RET

Tabela 13 - Programas preditivos de computador utilizados para análise in silico das regiões codificadoras 
Tabela 14 - Sequência dos marcadores de microssatélites utilizados para análise de LOH do gene p27 locus 12p13.

Tabela 15 - Correlação entre as características clínico-patológicas e bioquímicas dos pacientes apresentando NEM2 e os genótipos do polimorfismo c.-79C>T do gene p27

Tabela 16 - Correlação das características clínico-patológicas e bioquímicas de pacientes apresentando NEM2 com os genótipos do polimorfismo p.V109G no gene $p 27$.

Tabela 17 - Resultado da expressão relativa de p27, Skp2 e relação p27/Skp2 nuclear em amostras de CMT, nos três grupos estudados

Tabela 18 - Análise comparativa dos grupos estudados em relação à expressão relativa de p27 e Skp2 nuclear, utilizando-se o Teste-T, em amostras de CMT

Tabela 19 - Resultado da expressão relativa de p27, Skp2 e relação p27/Skp2 nuclear dos grupos estudados em amostras de FEO

Tabela 20 - Análise comparativa dos grupos estudados em relação à expressão relativa de p27 e Skp2 nuclear, utilizando-se o teste-T

Tabela 21 - Genótipos polimorfismos c.-79C>T e p.V109G no gene p27, características clinico-patológicas e bioquímicas e resultados da análise da expressão proteica de p27 por imunohistoquímica em amostras de CMT 


\section{LISTA DE FIGURAS}

Figura 1 - Vias de transdução mediadas pelo proto-oncogene RET ...... 15

Figura 2 - Representação esquemática do receptor RET ……................ 16

Figura 3 - Mutações germinativas identificadas no proto-oncogene RET associadas com a síndrome NEM2A, NEM2B e CMT-

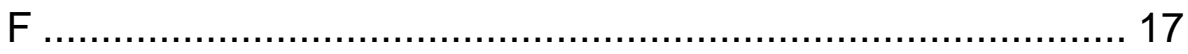

Figura 4 - Possíveis meios de ativação genética do proto-oncogene RET durante o processo de tumorigênese …….................... 19

Figura 5 - Genes envolvidos na regulação do ciclo celular ..................... 24

Figura 6 - Vias de sinalização da p27 durante a regulação da proliferação e migração celular.............................................. 28

Figura 7 - Eletroferograma mostrando variante polimórfica em homozigose c. 43-27C>A (rs2069426) na região intrônica do gene $p 15$

Figura 8 - Eletroferograma mostrando a variante sinônima G114G (rs1043141) em heterozigose no éxon 2 do gene $p 18$.......... 71

Figura 9 - Eletroferograma mostrando a variante intrônica 3'UTR $\mathrm{c}^{\star} .151 \mathrm{C}>\mathrm{T}$ (rs12855) em heterozigose no gene $\mathrm{p} 18$. 71

Figura 10 - Eletroferogramas mostrando a variante, c.-79C $>$ T (rs34330) localizado na região $5^{\prime}$-UTR do gene $p 27$ 73

Figura 11 - Eletroferogramas mostrando a variante c.326T $>\mathrm{G}$ p.V109G, rs2066827) localizada no éxon 1 do gene p27. 73

Figura 12 - Eletroferogram de região do éxon 10 gene RET. Evidência de perda somática do alelo normal do códon 620 em um caso de CMT (caso 26)

Figura 13 - Eletroferograma de região éxon 11 gene RET. Evidência de perda somática do alelo normal do códon 611 em dois tumores do caso 10 .

Figura 14 - Expressão de p27 e Skp2 por Western blot (WB) em CMT.... 82

Figura 15 - Expressão de p27 e Skp2 por Western blot (WB) em FEO .... 82

Figura 16 - Expressão relativa de p27 nuclear em cada um dos grupos estudados, em amostras de CMT 
Figura 17 - Expressão relativa Skp2 nuclear em cada um dos grupos estudados, em amostras de CMT

Figura 18 - Relação p27 e Skp2 nuclear em cada um dos grupos estudados em amostras de CMT.

Figura 19 - Expressão relativa de p27 nuclear em cada um dos grupos analisados em amostras de FEO.

Figura 20 - Expressão relativa Skp2 nuclear em cada dos grupos analisados em amostras de FEO.

Figura 21 - Relação das proteínas p27 e Skp2 nuclear em cada um dos grupos analisados em amostras de FEO

Figura 22 - Expressão e localização de p27 em CMT. Fotomicrografia dos casos representativos

Figura 23 - Sinergismo molecular da proteina RET ativada com as proteínas p18 e p27 na tumorigênsese da NEM2 
RESUMO 
Sekiya T. Análise do gene CDKN1B/p27 $7^{k i p 1}$ em pacientes com neoplasia endócrina múltipla tipo 2 [Tese] São Paulo: Faculdade de Medicina, Universidade de São Paulo; 2013.

INTRODUÇÃO: Na Neoplasia Endócrina Múltipla tipo 2 (NEM2), o desenvolvimento do Carcinoma Medular de Tireoide (CMT), Feocromocitoma (FEO) e Hiperparatireoidismo primário (HPT) está associado à mutações germinativas ativadoras no proto-oncogene $R E T$. Casos de CMT esporádico podem apresentar mutações somáticas no RET $(\sim 40 \%)$. A variabilidade fenotípica observada em casos de CMT e FEO familiais associados à NEM2 indica o envolvimento de eventos genéticos adicionais que seriam responsáveis pelas diferenças clínicas observadas nos indivíduos afetados (idade de desenvolvimento, progressão e agressividade do tumor). Outras alterações genéticas no RET como duplas mutações, SNPs e haplótipos específicos podem influenciar na susceptibilidade, agressividade e modulação do fenótipo NEM2. Entretanto, os estudos de outros genes envolvidos no processo da tumorigênese NEM2 ainda estão em andamento. Recentemente foi mostrado que RET ativado controla a expressão de proteínas inibidoras do ciclo celular (p18 e p27). Mutações germinativas no gene p27 foram recentemente associadas à susceptibilidade de tumores neuroendócrinos e estão associadas à síndrome NEM4 (Neoplasia endócrina múltipla tipo 4). Mutações somáticas, inativadoras de p27, são raramente encontradas em vários tipos de tumores. Entretanto, diversos estudos documentaram que a redução na expressão e a sublocalização citoplamática de p27 são controladas por alterações pós-transducionais e/ou epigenéticas. OBJETIVOS: o estudo teve como objetivos avaliar a participação de genes, recentemente associados ao RET ativado, em tumores de pacientes com NEM2 e também verificar se polimorfismos no gene p27 estariam atuando como moduladores de fenótipo em uma grande família com NEM2. CASUÍTICA: foram analisadas 66 amostras tumorais advindas de 36 pacientes com diagnóstico clínico e genético de NEM2 e 28 indivíduos pertencentes a uma grande família com NEM2A-CMTF e mutação C620R no gene RET. MÉTODOS: As análises somáticas do p27 e também de p15, p18 e RET foram realizadas por PCR e sequenciamento direto de DNA e análise de microssatélites para p27 foi realizada por PCR e eletroforese capilar. Análises de expressão e localização da proteína p27 celular foram realizadas por Western blot e imunohistoquímica. A análise da modulação de fenótipo na família com NEM2A foi realizada por meio da amplificação do éxon 1 do gene p27 na amostra de sangue total. RESULTADOS: Não foram encontradas mutações somáticas no gene p27 e também nos genes p15 e p18. Entretanto, verificamos baixa expressão proteica de p27 em tumores CMT e FEO, a qual se encontrava relacionada com o tipo e agressividade do códon mutado no RET, principalmente em tumores que apresentavam mutação RET no códon 634 (controle x $634 \mathrm{p}=0,05$; controle $\times 634 / 791 \mathrm{p}=0,032 ; 620 \times 634 \mathrm{p}=0,045 ; 620$ $\times 634 / 791 p=0,002 ; 620 \times 634+634 / 791 p=0,036)$. Notou-se também correlação positiva entre os níveis de expressão de p27 na localização nuclear, analisada por imunohistoquímica, e o genótipo TT do SNP p27 p.V109G $(p=0,03)$. CONCLUSÕES: Alterações moleculares somáticas no gene p27 nos tumores NEM2 não são frequentes. Entretanto, a redução na expressão e a localização citoplasmática de p27 provavelmente estão associadas a alterações somáticas em outros genes que controlam os processos de fosforilação da proteína p27 (eventos pós-transducionais).

Descritores: Inibidor de quinase dependente de ciclina p27; Neoplasia endócrina múltipla tipo 2a/genética; Neoplasia endócrina múltipla tipo 2b/genética; Proteína protooncogênicas c-ret; Carcinoma medular; Polimorfismo de nucleotídeo único; Neoplasias da glândula tireoide/genética; Feocromocitoma/genética; Hiperparatireoidismo primário/genética; Inibidor de quinase dependente de ciclina p18; Transformação celular neoplásica; Transdução de sinal; Fosforilação; Imunoistoquímica. 
SUMMARY 
Sekiya T. CDKN1B/p27 $7^{k i p 1}$ gene analysis in patients with multiple endocrine neoplasia type 2 (MEN2) [Thesis] São Paulo: "Faculdade de Medicina, Universidade de São Paulo"; 2013.

INTRODUCTION: In Multiple Endocrine Neoplasia type 2 (MEN2) the development of medullary thyroid carcinoma (MTC), pheochromocytoma (PHEO) and primary hyperparathyroidism (HPT) are associated with activating germline mutations in RET proto-oncogene. Cases of sporadic MTC may have somatic RET mutations ( $40 \%)$. The phenotypic variability observed in cases with familial MTC/MEN2 and PHEO/MEN2 indicates the probable involvement of additional genetic events that could be responsible for the clinical differences observed in the affected individuals (age development, progression and aggressiveness of the tumor). Other genetic alterations such as RET double mutations, SNPs and specific haplotypes may influence susceptibility, aggressiveness and MEN2 phenotype modulation. However, studies of other genes involved in the tumorigenesis of MEN2 are still in progress. Recently, it was shown that the activated RET controls the expression of cell cycle inhibitory proteins (p18 and p27). Germline mutations in the p27 gene have recently been associated with the susceptibility to neuroendocrine tumors and are associated with the MEN4 syndrome (Multiple endocrine neoplasia type 4). Somatic inactivating mutations p27 are rarely found in many types of tumors. However, several studies have documented that reduced expression and subcellular location of p27 is controlled by post-transductional changes and/or epigenetic factors. OBJECTIVES: This study aimed to evaluate the role of genes recently associated with RET activated in tumors from MEN2 patients and also check whether polymorphisms in the p27 gene would be acting as modulators of phenotype in a large MEN2 family. PATIENTS: We analyzed 66 tumor samples from 36 patients with clinical and genetic diagnosis of MEN2 and from 28 individuals belonging to a large family with FMTC/MEN2A and RET C620R mutation. METHODS: The analyses of somatic p27, p15, p18 and RET were performed by PCR and direct sequencing of DNA and microsatellite analysis was performed for p27 by PCR and capillary electrophoresis. Expression analysis and subcellular localization of p27 protein were performed by Western blot and immunohistochemistry. The analysis of phenotype modulation in MEN2A families was performed by the amplification of exon 1 of the p27 gene in a whole blood sample. RESULTS: There were no somatic mutations in the p27 gene and also in the $p 15$ and p18 genes. However, we verified a low p27 protein expression in MTC/MEN2 and PHEO/MEN2 that showed a definite correlation with the type and aggressiveness of the mutated RET codon, mainly in those tumors from cases with germline RET codon 634 mutations (control vs $634, p=0,05$; control vs 634/791, $p=$ $0,032 ; 620$ vs $634, p=0,045 ; 620$ vs $634 / 791, p=0,002 ; 620$ vs $634+634 / 791, p=0,036)$. It was also verified a positive correlation between the immunohistochemistry expression of nuclear p27 subcellular location and the p27 p.V109G TT genotype $(p=0,03)$. CONCLUSIONS: The reduction in the expression of p27 and its subcellular localization are likely to be associated with somatic changes in other genes that control the processes of phosphorylation of p27 protein through post-transductional events.

DESCRIPTORS: Cyclin-dependent kinase inhibitor p27; Multiple endocrine neoplasia type 2a/genetics; Multiple endocrine neoplasia type 2b/genetics; Proto-oncogene proteins c-ret; Carcinoma, medullary; Polymorphism, single nucleotide; Thryroid neoplasms/genetics; Pheochromocytoma/genetics; Hyperparathyroidism primary/genetics; Cyclin-dependent kinase inhibitor p18; Cell transformation, neoplasic; Signal transduction; Phosphorylation; Immunohistochemistry. 
1 INTRODUÇÃO 


\subsection{Neoplasias Endócrinas Múltiplas}

As Neoplasias Endócrinas Múltiplas (NEMs) são síndromes de caráter autossômico dominante caracterizado pela ocorrência de tumores benignos e/ou malignos envolvendo pelo menos duas glândulas endócrinas. Duas principais síndromes NEMs são bem conhecidas e caracterizadas: a Neoplasia Endócrina Múltipla tipo 1 (NEM1) e tipo 2 (NEM2), que são causadas por mutações germinativas nos genes MEN1 e RET, respectivamente (Marx, 2005). Essas duas síndromes são caracterizadas pelos diferentes tipos de tumores relacionados (Eng, 1999) (Tabela 1).

Em 2002 foi descrita em uma linhagem de ratos com NEM, denominada NEMX. Esses animais desenvolviam espontaneamente múltiplos tumores endócrinos relacionados com NEM1 (tumor de paratireóide, tumor hipofisário, tumor pancreático endócrino) e NEM2 (Hiperplasia de célula C, Feocromocitoma bilateral) em humanos, além de paraglanglioma e catarata (Fritz, 2002). Estudos genéticos identificaram mutações germinativas no gene $C d k n 1 b$, que codifica a proteína inibidora do ciclo celular p27 como responsável pelo desenvolvimento dessa síndrome em ratos. Diante desse achado, foram identificadas mutações germinativas em heterozigose no gene homólogo em humanos $C D K N 1 B / p 27 k^{1}{ }^{1}$ em pacientes com tumores NEM-relacionados, mas que não apresentavam mutação nos genes MEN1 ou RET. Esses dados permitiram a descoberta de 
um novo gene de susceptibilidade a desenvolvimento de tumores endócrinos

em humanos, e esta síndrome foi denominada NEM4 (Pellegata et al., 2006).

Tabela 1 - Caracterização clínica e genética das Neoplasias Endócrinas Múltiplas (Marx et al., 2005; Pellegata et al., 2006)

\begin{tabular}{|c|c|c|}
\hline Síndrome & Principais Manifestações Clínicas & $\begin{array}{l}\text { Anormalidades genéticas } \\
\text { Gene/ locus }\end{array}$ \\
\hline NEM1 & $\begin{array}{l}\text { - Adenomas hipofisários } \\
\text { - Hiperparatireoidismo primário } \\
\text { - Tumores das ilhotas } \\
\text { pancreáticas/duodeno endócrino } \\
\text { - Tumores do córtex da adrenal } \\
\text { - Angiofibroma cutâneo } \\
\text { - Lipomas }\end{array}$ & $\begin{array}{l}\text { Mutação inativadora do } \\
\text { gene MEN1 (11q13) que } \\
\text { codifica a proteína MENIN }\end{array}$ \\
\hline NEM2 & $\begin{array}{l}\text { - Carcinoma Medular de Tireoide } \\
\text { - Feocromocitoma } \\
\text { - Hiperparatireoidismo primário } \\
\text { - Líquen amiloide cutâneo } \\
\text { - Megacólon congênito } \\
\text { - Problemas de formação óssea }\end{array}$ & $\begin{array}{l}\text { Mutação ativadora no proto- } \\
\text { oncogene } R E T \text { que codifica } \\
\text { o receptor tirosina quinase } \\
\text { RET }\end{array}$ \\
\hline NEM4 & $\begin{array}{l}\text { - Tumores hipofisários } \\
\text { - Hiperparatireoidismo primário }\end{array}$ & $\begin{array}{l}\text { Mutação inativadora no } \\
\text { gene } C D K N B / p 27^{k i p 1} \text { que } \\
\text { codifica a ciclina inibidora } \\
\text { de quinase p27 }\end{array}$ \\
\hline $\begin{array}{l}\text { Neurofibromatose } \\
\text { tipo } 1\end{array}$ & $\begin{array}{l}\text { - Tumores endócrinos associados: } \\
\text { - Feocromocitoma } \\
\text { - Carcinoma medular de tireóide } \\
\text { - Hiperparatireoidismo primário } \\
\text { - Tumor carcinóide produtor de } \\
\text { somatostatina }\end{array}$ & $\begin{array}{l}\text { Mutação inativadora no } \\
\text { gene NF-1 (17q11.2) que } \\
\text { codifica a proteína } \\
\text { Neurofibromina }\end{array}$ \\
\hline von Hippel-Lindau & $\begin{array}{l}\text { - Feocromocitoma } \\
\text { - Tumores das ilhotas pancreáticas } \\
\text { - Hemangioblastoma do SNC } \\
\text { - Angiomas da retina } \\
\text { - Hipernefromas } \\
\text { - Cistos viscerais } \\
\text { - Neurofibromas }\end{array}$ & $\begin{array}{l}\text { Mutação inativadora do } \\
\text { gene VHL (3p25-26) que } \\
\text { codifica a proteína Elongina }\end{array}$ \\
\hline $\begin{array}{l}\text { Complexo de } \\
\text { Carney }\end{array}$ & $\begin{array}{l}\text { - Pigmentação cutânea puntiforme } \\
\text { - Mixoma cardíaco } \\
\text { - Mixoma cutâneo } \\
\text { - Doença adrenocortical pigmentar } \\
\text { - nodular primária } \\
\text { - Tumor de células de Sertoli } \\
\text { - Acromegalia } \\
\text { - Schawanoma }\end{array}$ & $\begin{array}{l}\text { Mutação inativadora do } \\
\text { gene PRKAR1A (17q22-24) } \\
\text { identificada em algumas } \\
\text { famílias }\end{array}$ \\
\hline
\end{tabular}




\subsection{Neoplasia Endócrina Múltipla tipo 2}

A Neoplasia Endócrina Múltipla tipo 2 (NEM2) é uma síndrome hereditária transmitida por herança autossômica dominante causada por mutações do tipo missense no proto-oncongene RET (Mulligan et al., 1993). Os tumores associados são o carcinoma medular de tireóide (CMT), hiperparatireoidismo primário (HPT) e feocromocitoma (FEO) (Eng, 1996; Frank-Raue, 2010).

Apesar da prevalência da NEM2 na população em geral ser baixa (1 em 30.000), o número de indivíduos afetados por família pode ser expressivo, uma vez que a penetrância do Carcinoma medular de tireoide (CMT) é virtualmente completa ao longo da vida ( 100\%). Indivíduos afetados inicialmente desenvolvem a hiperplasia das células-C (HCC - fase pré-malígna) que pode progredir para CMT invasivo. Assim, diante de cada paciente com CMT, FEO ou HPT primário diagnosticado abaixo de 30 anos de idade, deve-se investigar possível presença de mutação germinativa no gene RET (Brandi et al., 2001; Frank-Raue e Raue, 2008). Familiares sobrisco apresentam $50 \%$ de possibilidade de herdar o gene mutado, e, portanto a doença (Raue e Frank-Raue, 2010).

Os tumores envolvidos na NEM2 estão relacionados à proliferação tumoral das células derivadas da crista neural, como células $C$ da tireoide, células cromafins da medula das suprarrenais, células principais e oxifílicas das paratireóides, gânglios simpáticos, parassimpáticos e entéricos, além do trato urogenital (Eng et al., 1999; Nunes et al., 2002). Aproximadamente 75\% 
dos casos de CMT são esporádicos e 25\% hereditários (Eng et al., 1999; Brandi et al., 2001; Marx, 2005).

As formas hereditárias são divididas em três subtipos clínicos, tomando como base a combinação das manifestações clínicas: NEM2A, NEM2B e Carcinoma Medular Familial de Tireoide (CMT-F) (Eng, 1999; Brandi et al., 2001; Frank-Raue, 2009). De acordo com os consensos de NEM2 (Brandi et al., 2001; Kloos et al., 2009), os três subtipos de NEM2 apresentam diferenças na incidência, genética, idade de desenvolvimentos dos tumores, associação com outras doenças, agressividades do CMT e prognóstico (Tabela 2).

Tabela 2 - Classificação da Neoplasia Endócrina Múltipla (NEM2) e ocorrência do CMT, tumores associados e outras doenças (Kloos et al., 2009; Frank-Raue, 2012)

\begin{tabular}{ccccccc}
\hline Subtipo & $\begin{array}{c}\text { Incidência } \\
(\%)\end{array}$ & $\begin{array}{c}\text { Idade } \\
\text { (anos) }\end{array}$ & $\begin{array}{c}\text { CMT } \\
(\%)\end{array}$ & $\begin{array}{c}\text { FEO } \\
(\%)\end{array}$ & $\begin{array}{c}\text { HPT } \\
(\%)\end{array}$ & Doenças associadas \\
\hline NEM2A & 56 & 10 & 100 & 50 & 25 & $\begin{array}{c}\text { Liquen amiloidótico } \\
\text { cutâneo, HSCR }\end{array}$ \\
NEM2B & 9 & 2 & 100 & 50 & -- & $\begin{array}{c}\text { Ganglioneuromatose, } \\
\text { habitus marfanoide }\end{array}$ \\
CMT-F & 35 & 30 & 100 & -- & -- & -- \\
\hline
\end{tabular}

NEM2A, Neoplasia Endócrina Múltipla tipo 2A; NEM2B, Neoplasia Endócrina Múltipla tipo 2B; CMT-F, Carcinoma medular de tireoide familial; CMT, Carcinoma medular de tireoide; FEO, Feocromocitoma; HPT, Hiperparatireodismo primário; HSCR, megacólon congênito.

A NEM2A representa aproximadamente $75 \%$ dos casos de NEM2 e é caracterizada pela presença do CMT em combinação com FEO e/ou múltiplos tumores das glândulas paratireóides em um único indivíduo; ou a presença de dois ou mais tumores em diversos membros de uma única 
família (Marx, 2005). A frequência do CMT é de $\sim 100 \%$, enquanto que a do FEO e o HPT correspondem a $50 \%$ e $25 \%$ dos casos, respectivamente (Brandi et al., 2001; Drosten et al., 2004). O CMT é geralmente a primeira manifestação da NEM2A, e quando presente surge entre 5-25 anos de idade. Existem algumas variantes fenotípicas raras de NEM2A: a) com desenvolvimento do líquen amiloidótico cutâneo e, b) associação de NEM2A/CMT-F com doença de Hirschsprung (HSCR), que é o megacólon congênito (Frank-Raue, 2012) (Tabela 2).

As mutações do RET mais frequentes na NEM2A promovem a substituição das cisteínas no domínio extracelular nos códons 609, 611, 618, 620 do éxon 10; e dos códons 630,634 do éxon 11, com trocas de diversos resíduos. A maioria dos pacientes com NEM2A apresentam a mutação no códon 634, que é um fator preditivo para o desenvolvimento de FEO e hiperplasia de paratireóide. Mais raramente ocorrem duplicações de 9-12 pares de bases no domínio rico em cisteína (Höppner et al., 1997 e 1998).

A síndrome NEM2B é a forma mais rara e agressiva e correspondem cerca de $5-10 \%$ dos casos de NEM2. É caracterizada pela presença do CMT, FEO e ausência de HPT. Ocorrem também neuromas cutâneos nos lábios e língua, ganglioneuromas no intestino e também malformações ósseas (habitus marfanóides) (Brandi et al., 2001; Frank-Raue, 2012) (Tabela 2). Indivíduos com NEM2B desenvolvem o tumor no primeiro ano de vida e apresentam uma forma muito agressiva de CMT, com altas taxas de morbidade e mortalidade comparados com os pacientes que apresentam a NEM2A e o CMT-F (Brandi et al., 2001; Kloos et al., 2009). Geralmente os 
casos de NEM2B não apresentam histórico familial da doença, e em aproximadamente $50 \%$ dos casos ocorre por mutação do tipo de novo no gene RET (Frank-Raue, 2010).

Em $95 \%$ dos pacientes e famílias com NEM2B a mutação mais comum localiza-se no códon 918 no éxon 16, região onde o domínio TK2 intracelular é encontrado. Em cerca de $50 \%$ dos casos de NEM2B a mutação no códon 918 ocorreu de novo (Brandi et al., 2001).

O CMT-F é a forma menos agressiva e compreende $35-40 \%$ dos casos de NEM2 (Berndt et al., 1998; Elisei et al., 2007; Frank-Raue et al., 2012). É caracterizado pela presença de CMT em pelo menos quatro ou mais membros de uma mesma família, e de ausência de quaisquer achados clínicos e laboratoriais de FEO e HPT no caso índice (Brandi et al., 2001). Atualmente o CMT-F é visto como uma variante fenotípica da NEM2A que possui menor penetrância gênica do FEO e HPT (Frank-Raue, 2012) (Tabela 2).

Em geral, o prognóstico do CMT em pacientes com CMT-F é melhor que os de NEM2A e NEM2B, e alguns portadores da CMT-F apresentam desenvolvimento tardio das manifestações clínicas. Entretanto, já foram descritos alguns casos e CMT-F com CMT agressivo em portadores da mutação V804M no RET (Frank-Raue, 2012).

Um histórico familial inadequado pode levar a erro na identificação do fenótipo da doença. Por isso, é imprescindível a realização de exames bioquímicos e genéticos adequados (análise de mutação no $R E T$ ), no sentido de se investigar possível histórico familial de CMT nos indivíduos 
que inicialmente foram classificados como apresentando aparentemente a forma esporádica da doença. Cerca de 1-7\% dos casos aparentemente esporádicos de CMT apresentam mutação germinativa no gene RET, incluindo aproximadamente $2-9 \%$ com mutação de novo germinativa (Kloos et al., 2009).

As mutações responsáveis pelo $\mathrm{CMT}-\mathrm{F}$ são as mesmas que o descrito para NEM2A, mas são mais homogeneamente distribuídos entre os resíduos de cisteína 609, 618 e 620. Mutações nos resíduos 768, 790, 791 (éxon 13), 804, 844 (éxon 14), ou 891 (éxon 15) também foram descritos em casos de CMT-F (Arighi et al., 2005).

\subsubsection{Correlação genótipo-fenótipo}

Existe uma forte correlação genótipo-fenótipo na NEM2 (Mulligan et al., 1995; Eng et al., 1995). Dessa forma, mutações em determinados códons estão diretamente associadas a manifestações fenotípicas específicas e ao grau de risco para CMT, FEO ou HPT (Tabela 3). A caracterização dessa correlação genótipo-fenótipo é muito importante para avaliação do prognóstico, assim como para indicação do tratamento cirúrgico profilático (tireoidectomia total) em idade adequada (Eng, 1996; Brandi et al., 2001; Marx, 2005; Groot et al., 2006) (Tabela 3). Recentes recomendações detalhadas foram publicadas quanto ao manejo diagnóstico e terapêutico do CMT pela Sociedade Americana de Tireóide (Kloss et al., 2009). 
Tabela 3 - Correlação genótipo-fenótipo, níveis de risco e monitoramento dos pacientes com diferentes mutações no gene RET, de acordo com o consenso de CMT/NEM2 de 2009 (Adaptado de: Kloos et al., 2009 ; Frank-Raue, 2012)

\begin{tabular}{|c|c|c|c|c|}
\hline \multirow[b]{2}{*}{$\begin{array}{l}\text { Características/ } \\
\text { Monitoramento }\end{array}$} & \multicolumn{4}{|c|}{ Códon } \\
\hline & $\begin{array}{l}321,515,533, \\
600,603,606, \\
635,649,666, \\
768,776,790, \\
791,804,819, \\
833,844,861, \\
891,912\end{array}$ & $\begin{array}{l}609,611,618 \\
620,630,631\end{array}$ & 634 & $\begin{array}{l}918,883 \\
922\end{array}$ \\
\hline Nível de risco ATA (2009) & A & B & C & $\mathrm{D}$ \\
\hline Subtipo NEM2 & CMT-F & $\begin{array}{l}\text { CMT- } \\
\text { F/NEM2A }\end{array}$ & NEM2A & NEM2B \\
\hline Agressividade do CMT & Moderado & Alto & Muito alto & Altíssimo \\
\hline $\begin{array}{l}\text { Idade de desenvolvimento } \\
\text { do CMT }\end{array}$ & adulta & 5 anos & $\begin{array}{l}\text { antes dos } 5 \\
\text { anos }\end{array}$ & $\begin{array}{l}\text { Primeiro } \\
\text { ano de vida }\end{array}$ \\
\hline $\begin{array}{l}\text { Idade para TTx profilática } \\
\text { (anos de idade) }\end{array}$ & $\begin{array}{l}\text { quando } \mathrm{Ct}> \\
\text { níveis basais/ } \\
\text { ou } 5-10 \text { anos }\end{array}$ & 5 anos & $\begin{array}{l}\text { antes dos } 5 \\
\text { anos }\end{array}$ & $\begin{array}{l}\text { antes dos } 5 \\
\text { meses de } \\
\text { vida }\end{array}$ \\
\hline Rastreamento para FEO & $\begin{array}{l}\text { início aos } 20 \\
\text { anos, } \\
\text { periodicamente }\end{array}$ & $\begin{array}{l}\text { Início aos } 20 \\
\text { anos, } \\
\text { anualmente }\end{array}$ & $\begin{array}{l}\text { início aos } 8 \\
\text { anos, } \\
\text { anualmente }\end{array}$ & $\begin{array}{l}\text { início aos } 8 \\
\text { anos, } \\
\text { anualmente }\end{array}$ \\
\hline Rastreamento para HPT & $\begin{array}{l}\text { início aos } 20 \\
\text { anos, } \\
\text { periodicamente }\end{array}$ & $\begin{array}{l}\text { Início aos } 20 \\
\text { anos, } \\
\text { periodicamente }\end{array}$ & $\begin{array}{l}\text { início aos } 8 \\
\text { anos, } \\
\text { anualmente }\end{array}$ & -- \\
\hline
\end{tabular}

ATA, American Thyroid Association; CMT-F, Carcinoma medular de tireoide familiar; HPT, Hiperparatireoidismo primário; CMT, Carcinoma medular de tireóide; FEO, Feocromocitoma; TTx, tireoidectomia total; Ct, calcitonina.

\subsubsection{Aspectos Clínicos da NEM2}

\subsubsection{Carcinoma Medular de Tireoide}

O Carcinoma Medular de Tireóide (CMT) é um tumor maligno raro originário das células- $C$ parafoliculares da tireoide, produtora e secretora de calcitonina e corresponde aproximadamente $5-10 \%$ de todos os tumores de 
tireoide (Horn, 1951; Brandi et al., 2001). Foi descrito pela primeira vez por Hazard et al. em 1959 como sendo uma estrutura histopatológica de baixo ou intermediário grau de malignidade e presença de depósitos amilóides no estroma desses tumores. Aproximadamente $70 \%$ de todos os casos são esporádicos e 30\% hereditários (Kloos et al., 2009).

O CMT geralmente é a primeira e mais importante manifestação clínica da NEM2 sendo que as metástases de CMT estão relacionadas com as altas taxas de mortalidade em pacientes com essa síndrome (Sipple et al., 1961).

A forma hereditária do CMT apresenta-se inicialmente como processo multifocal com hiperplasia das células C (HCC), que é a lesão precursora do CMT. O tempo de progressão da hiperplasia das células $C$ até atingir o estágio de microcarcinoma na NEM2 ainda é desconhecido. Avalia-se que pode levar anos e a idade desta transformação neoplásica varia de acordo com o tipo específico e da agressividade de cada mutação germinativa no RET. O CMT em pacientes com NEM2 é tipicamente multicêntrico, concentrado no terço superior da glândula tireoide e apresenta desenvolvimento precoce (abaixo de 20-30 anos de idade). Já na forma esporádica, os tumores são geralmente unicêntricos e tem desenvolvimento mais tardio (por volta dos 40-50 anos de idade) (Brandi et al., 2001; Kloos et al., 2009).

A média de sobrevida por 5 anos de um paciente com CMT é de $83 \%$, sendo bem menor que em casos de carcinoma papilífero ou folicular da tireoide. A identificação precoce do CMT antes da apresentação dos 
sintomas clínicos resulta em um melhor prognóstico e alto índice de cura. Aproximadamente $50-70 \%$ dos casos de CMT com diâmetros maiores que $1.0 \mathrm{~cm}$ já apresentam metástases nos linfonodos cervicais nas regiões central, lateral, cervical e mediastinal. As metástases à distância desenvolvem-se durante o curso da doença e podem ser encontradas no fígado, pulmões e ossos (Kloos et al., 2009; Frank-Raue, 2010).

O diagnóstico laboratorial do CMT é baseado na dosagem dos níveis séricos basais de calcitonina $(\mathrm{Ct})$, ou após teste de estímulo com cálcio ou pentagastrina, realizada ou, a) em pacientes com nódulos na tireoide ou, b) durante o rastreamento familiar de mutações do proto-oncogene $R E T$. $O$ exame de imagem recomendado é o ultrassom (US) de tireoide, mas a tomografia cervical (TC) é também utilizada na pré-cirúrgia por revelar informações importantes. Em casos de familiares sob risco de NEM2, o rastreamento genético é extremamente importante para o diagnóstico precoce. Isto porque o único tratamento eficaz para o CMT é o cirúrgico, uma vez que este tumor é resistente a tratamentos quimioterápicos e radioterápicos (Kloos et al., 2009).

\subsubsection{Feocromocitoma}

O Feocromocitoma (FEO) é um tumor originário das células cromafins que sintetizam, armazenam, metabolizam e secretam catecolaminas. De acordo com classificação da Organização Mundial de Saúde (OMS) 2004, o FEO é um tumor localizado na medula da glândula adrenal, enquanto os 
tumores localizados nos paragânglios simpáticos e parassimpáticos extraadrenais são denominados paragângliomas (Lenders, 2002).

Aproximadamente $5-15 \%$ dos casos de FEO são associados à NEM2, e podem ser encontrados como parte de outras síndromes como von HippelLindau (VHL), Neurofibromatose tipo 1 (NF1), paragangliomatose tipos 1, 2, 3, e 4 (Eng et al., 1995). Recentemente foram descobertos novos genes que conferem susceptibilidade no desenvolvimento do FEO, como TMEM127 e MAX e a real porcentagem de FEOs por causa hereditária pode estar ao redor de 30\% (Yao et al., 2010; Burnichon et al., 2012).

Os FEO/NEM2 podem ser unilaterais ou bilaterais e na maior parte dos casos são benignos. A possibilidade de desenvolvimento de FEO bilateral deve ser cuidadosamente avaliada devido a sua alta frequência nos casos hereditários (60\%). A penetrância depende do tipo da mutação no gene RET. O FEO geralmente aparece 10 anos após a manifestação do CMT. Exames bioquímicos e de imagem devem ser realizados anualmente em indivíduos com NEM2 (Arum et al., 2005; Toledo et al., 2006).

\subsubsection{Hiperparatireoidismo Primário}

O Hiperparatireoidismo primário (HPT) é encontrado em aproximadamente $25-30 \%$ dos casos de NEM2A, mas é raramente a primeira manifestação clínica dessa síndrome. O diagnóstico é estabelecido pela detecção de altas concentrações de $\mathrm{PTH}$ na presença de hipercalcemia, geralmente depois da terceira década de vida. Achados patológicos mostram hiperplasia celular envolvendo múltiplas áreas das 
glândulas e às vezes múltiplos adenomas. Sua apresentação clínica é geralmente lenta e leve, podendo dificultar o seu diagnóstico (de Groot et al., 2006) .

\subsubsection{Outros fenótipos menos frequentes associados à NEM2}

\subsection{Megacólon congênito}

O megacólon congênico, também conhecido como doença de Hirschsprung (HSCR) é uma malformação congênita caracterizada pela agangliose do megacólon em tamanhos variáveis do intestino apresentando uma incidência da doença é de 1:5000 nascidos vivos (Amiel e Lyonnet, 2001). Origina-se pela falha na migração das células da crista neural durante o processo de embriogênese, levando a defeitos na inervação entérica, obstrução intestinal e constipação crônica. A doença é caracterizada pela ausência de células ganglionares dos plexos intermusculares e submucosos, profundo e superficial (Parisi e Kapur, 2000).

O megacólon congênito é encontrado frequentemente na forma esporádica (70\%), e aproximadamente $15-30 \%$ são casos familiares e usualmente ocorrem em associação com outras síndromes como a NEM2. Recentemente um consenso sobre a doença verificou que aproximadamente $50 \%$ dos casos familiares e $15-20 \%$ dos casos esporádicos apresentam mutações germinativas no proto-oncogene RET (Amiel et al., 2008). 


\subsection{Liquen amiloide cutâneo (CLA)}

Trata-se de uma lesão cutânea liquenóide pruriginosa, usualmente localizada na região interescapular (Menko et al., 2002).

\subsubsection{Aspectos moleculares da NEM2}

\subsubsection{Proto-oncogene RET}

O proto-oncogene RET (Gene ID 5979) está localizado próximo ao centrômero, no braço longo do cromossomo 10, na região 11.2 e apresenta um tamanho de aproximadamente $69 \mathrm{~kb}$ contendo 21 éxons, todos codificantes (Eng, 1999; Groot et al., 2006). Esse gene foi identificado em 1985 por Takahashi et al. ao estudarem a atividade alterada da linhagem celular NIH 3T3 após um processo de transfecção com DNA de linfoma humano. Nesse estudo, foi localizado um gene quimérico que surgiu da recombinação entre duas sequências de DNA diferentes, por isso o nome "Rearranjado durante Transfecção" (RET) (Arighi et al., 2005).

O gene RET codifica um receptor transmembrana da família de proteínas receptoras de tirosino-quinase (RTK) chamado RET. Essa proteína está envolvida na regulação de crescimento, sobrevida, diferenciação e migração de células da linhagem da crista neural, de células $C$ da tireoide, medula adrenal, gânglios parassimpáticos, simpáticos e entéricos, paratireóides e broto ureteral (de Groot et al., 2006). Pelo menos 18 sítios de fosforilação foram descritos na região TK, cada um deles relacionado a uma determinada via de transdução. Dentre as principais vias de sinalização da 
RET estão: a RAS/MEK/ERK, que promove o progresso do ciclo celular; PI3K/AKT/NF-Kb, que leva ao aumento na motilidade, sobrevivência e progressão do ciclo celular; p38, MAPK, JAK/STAT, e proteína quinase C (Arighi, 2005) (Figura 1).

A proteína RET é composta de três domínios: um extracelular, que é o domínio de ligação que apresenta quatro repetições semelhantes às caderinas; região hidrofóbica transmembrana; e um domínio intracelular citoplasmático tirosino-quinase (TK1 e TK2), que está envolvido na ativação de numerosos sinais intracelulares e de vias de transdução de sinal através do processo de fosforilação (Eng et al., 1996 e 1999) (Figura 2).

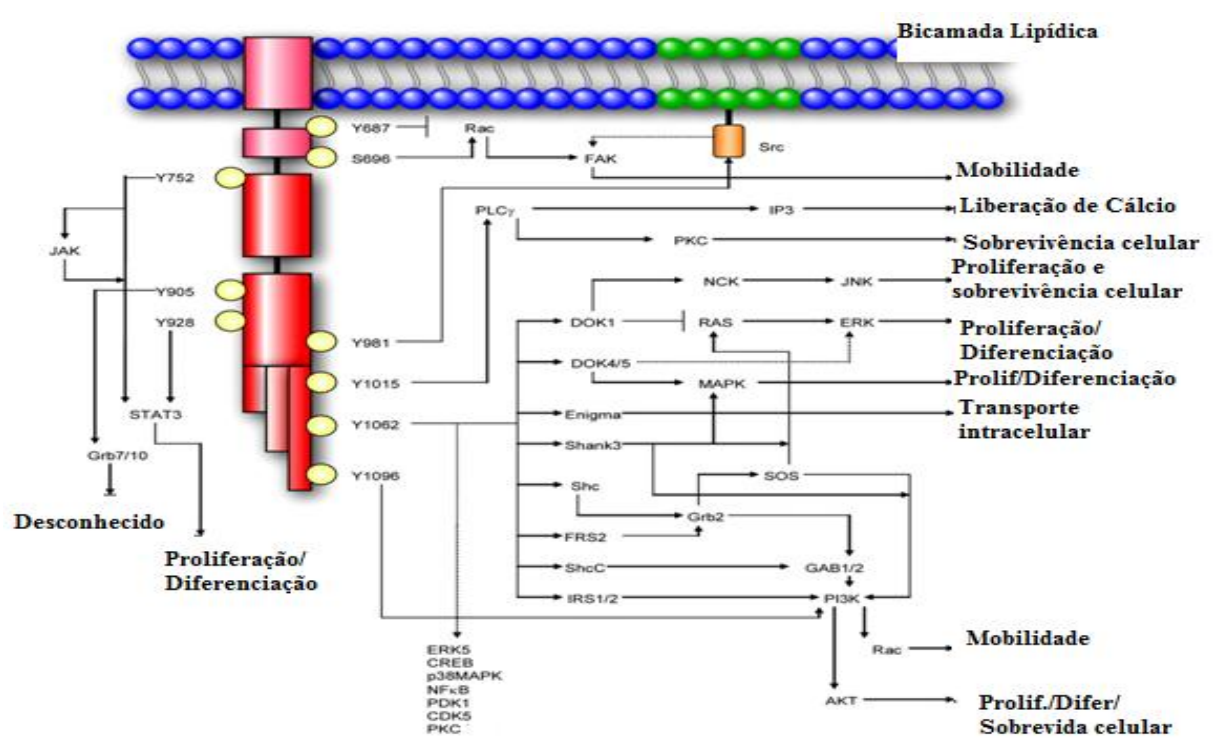

Figura 1 - Vias de transdução mediadas pelo proto-oncogene RET (de Groot et al., 2006) 


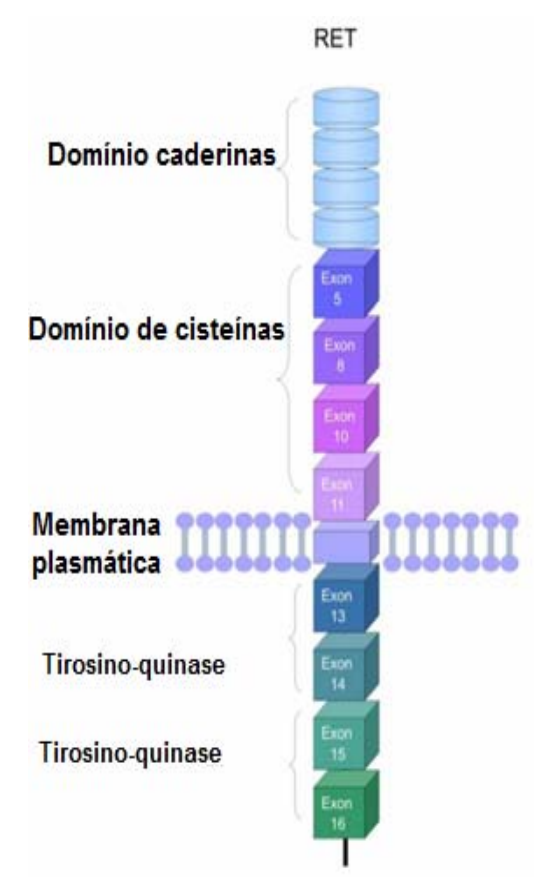

Figura 2 - Representação esquemática do receptor RET. A região extracelular compreende os domínios caderinas e a região rica em cisteínas, domínio transmembrana, e a região intracelular que apresenta dois domínios tirosina-quinase (TK1 e TK2) (Ceolin et al., 2012)

Estima-se que em aproximadamente $95 \%$ dos casos de NEM2 apresentem mutações germinativas no proto-oncogene RET havendo predominância nos éxons 10,11, 13,14, 15 e 16 (Brandi et al., 2001). No Brasil e Grécia foram relatadas mutações germinativas no éxon 8 (da Silva et al., 2003; Kaldrymides, 2006). As principais mutações germinativas encontradas nos éxons hotspot do proto-oncogene $R E T$, que estão associadas com as síndromes NEM2 e CMT-F estão descritas na figura 3. 


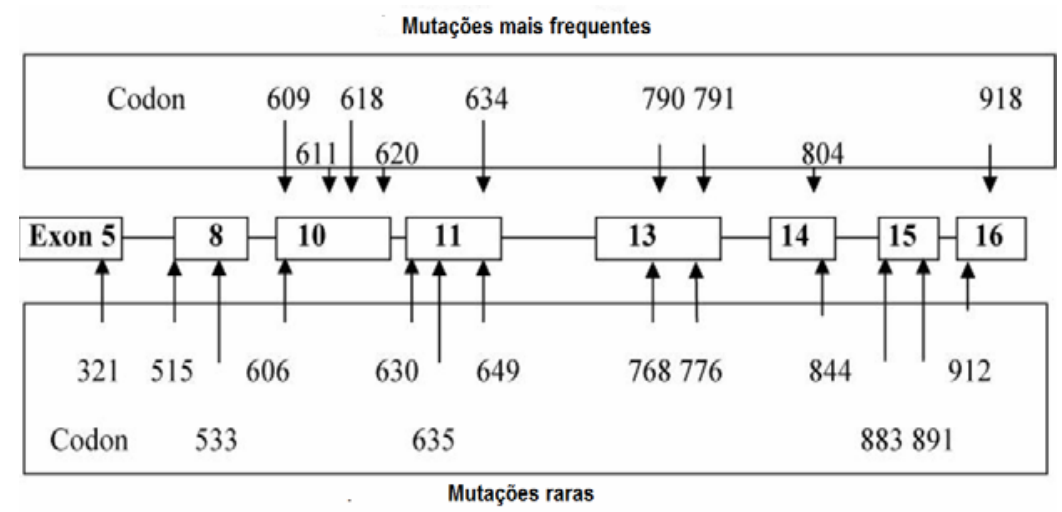

Figura 3 - Mutações germinativas identificadas no proto-oncogene $R E T$ associadas com a síndrome NEM2A, NEM2B e CMT-F. Os números indicam as posições dos códons mutados no gene (Frank-Raue, 2012)

Após a identificação de mutações no RET como sendo a causa genética da NEM2, essa síndrome passou a ser diagnosticada de forma mais precoce por meio de análises genéticas (Mulligan, 1993). O diagnóstico molecular apresentou um grande impacto na conduta clínica e cirúrgica da NEM2, pois o reconhecimento de portadores de mutação germinativa RET tem a possibilidade e realizar a cirurgia profilática preventiva (tireoidectomia total) em fase anterior ao início ou em estágios precoces da doença (Santos et al., 2006; Toledo et al., 2006; Kloos et al., 2009).

Segundo o Consenso Internacional sobre NEMs, recomenda-se que seja realizada tireoidectomia total preventiva em todos os portadores de mutação germinativa no $R E T$, independente do quadro clínico apresentado (Brandi et al., 2001) (Tabela 3). Recentemente um novo consenso sobre CMT foi realizado, complementando o anterior (Kloos et al., 2009). 


\subsubsection{Tumorigênese na NEM2}

A participação do proto-oncogene RET no desenvolvimento de tumores NEM2 já está bem estabelecida tanto nos casos esporádicos quanto nos hereditários. Entretanto, pouco se conhece sobre os eventos genéticos adicionais que ocorrem durante o processo de tumorigênese. Essas alterações genéticas graduais que o tumor adquire poderiam explicar porque em uma mesma família com uma mesma mutação no RET apresenta manifestações clínicas distintas do CMT, FEO e HPT, quanto à penetrância, agressividade e idade do surgimento tumoral (van Veelen et al., 2008 e 2009).

Outras alterações genéticas no RET, além da mutação ativadora, podem estar envolvidas no desenvolvimento e progressão da doença, entretanto são eventos bastante raros (Marsh et al., 2003). Por isso, o estudo de outros genes, principalmente os envolvidos no controle do ciclo celular ou que aqueles que fazem parte da mesma via de sinalização molecular, são de grande importância para o estudo do processo de tumorigênese nos casos de NEM2 (Arighi et al., 2005, de Groot et al., 2006).

Estudos em diversos tumores advindos de casos com NEM2 evidenciaram que um segundo evento genético no próprio $R E T$, que promove um desequilíbrio na expressão dos alelos do gene, pode promover ganho de função do oncogene (Marx, 2005). Estes eventos podem ocorrer por duplicação do alelo mutante ou perda do alelo selvagem (Huang, 2000). Ainda não é claro se são necessários dois eventos genéticos no locus de 
RET como parte do processo de tumorigênese NEM2 (Marsh, 2003) (Figura 4).

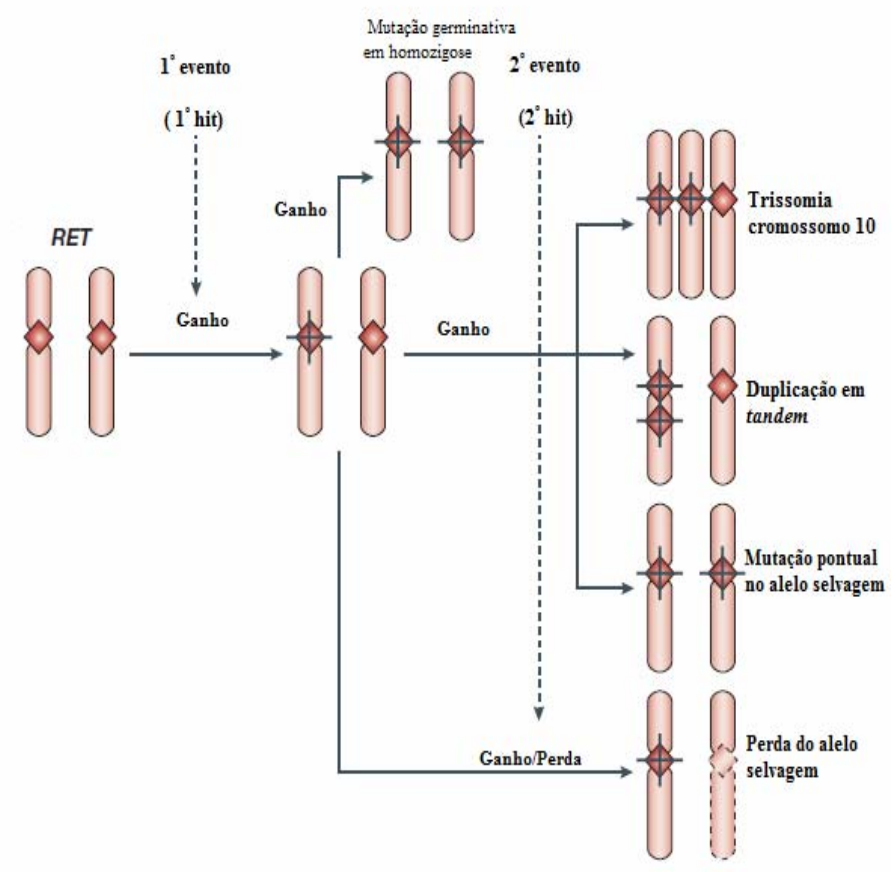

Figura 4 - Possíveis meios de ativação genética do proto-oncogene RET durante o processo de tumorigênese (Modificado de Marx, 2005)

\subsubsection{Duplas mutações no gene RET}

A presença de duplas mutações germinativas no RET é um exemplo de modulação da expressão fenotípica de casos de NEM2 (Tessitore et al., 1999; Bartsch et al., 2000, Kasprzak et al., 2001; Menko et al., 2002; Dvorakova et al., 2006).

Poucos casos de duplas mutações somáticas ou germinativas já foram descritos. Dvoráková et al. (2006) identificaram um paciente com NEM2 que apresentava três mutações somáticas em missense no mesmo 
alelo: Gly911Asp, Met918Thr, e Glu921Lys no éxon 16 e uma nova dupla somática Val591lle no éxon 10 e Met918Thr no éxon 16 do gene RET. A combinação de mutações no proto-oncogene $R E T$ pode modular a atividade transformadora, catalítica e a especificidade do substrato da proteína RET de maneira diferente ao que ocorre quando há uma simples mutação.

Em 2010, estudos do nosso grupo relataram a ocorrência da dupla mutação C634Y/Y791F em cis em quatro famílias brasileiras com NEM2A, sendo que os afetados apresentavam FEOs bastante mais agressivos que os usualmente observados na NEM2A. Dados advindos de estudo in vitro demonstraram que a dupla mutação apresentava maior poder de fosforilação, quando comparado com o controle e com células portadoras somente da mutação no códon 634 (Toledo et al., 2010).

\subsubsection{Polimorfismos no RET}

Variações genicas de um único nucleotídeo (Single Nucleotide Polymorphisms, SNPs) no RET têm sido associadas com a patogênese e progressão do CMT (Ceolin et al., 2012). Há cinco polimorfismos comuns nesse gene com frequências alélicas menores que $1 \%$ e que estão localizados nas regiões dos éxons hotspots, que estão associados com a doença CMT/NEM2: p.G691S, p.L769L, p.S836S, p.S904S, e c.2608-24G>A (Ceccherini et al., 1994; Gimm et al., 1999; Elisei et al., 2004; BaumgartnerParzer et al., 2005).

Diversos autores sugerem que os polimorfismos estão associados às mutações no RET, e estariam atuando como moduladores de fenótipo da 
NEM2. Isto poderia explicar a variabilidade da clínica e da agressividade dos tumores (CMT, FEO) entre os indivíduos de uma mesma família com uma mesma mutação germinativa no RET. Apesar disto, este assunto ainda é controverso e há necessidade de mais estudos em grandes populações que validem os achados iniciais em amostras com número limitado de indivíduos (Weber e Eng, 2005).

Em 2002, nosso grupo relatou uma família com NEM2A associada à mutação no RET p.C634R, que estava associada a uma variantes polimórfica (SNP), também no éxon 11, a p.V648I. É provável que combinação mutação/SNP tenha levado a uma modulação fenotípica de NEM2A, pois o paciente portador das variantes $634 / 648$ desenvolveu um quadro clínico raro que incluía FEO produtor ectópico de $\mathrm{ACTH}$, levando a síndrome de Cushing (Nunes et al., 2002). Ressaltando a hipótese de que a variante V648I seja um SNP, dois indivíduos portadores dessa variante, hoje com 30-35 anos de idade, não desenvolveram CMT, FEO ou HPT. Assim, a variante polimórfica no códon 648 tem sido descrita como SNP com potencial capacidade de modular o fenótipo NEM2A. Recentemente, a variante p.V648I foi analisada por um grupo italiano por meio de estudos in vitro que confirmaram sua incapacidade de transformação neoplásica, confirmando-se assim que esta variante é um SNP (Cosci et al., 2011).

\subsubsection{Haplótipos no RET}

A identificação de diversos polimorfismos no RET proporcionou a caracterização de alelos que co-segregam juntos com um fenótipo, os 
haplótipos. Estes podem agir como moduladores de fenótipo e estarem associados à variabilidade clínica em indivíduos familiares portadores de uma mesma mutação no RET.

Qi et al. (2011), utilizando a técnica de sequenciamento do exoma, descreveram o haplótipo p.V292/R67H/R982C na predisposição para o CMT-F.

Um recente trabalho de nosso grupo relatou a influência de haplótipos na caracterização do fenótipo NEM2A. Esse estudo descreveu uma família que apresentava a mutação C620R no gene RET, na qual alguns indivíduos apresentavam um fenótipo HSCR/CMT (megacólon congênito + CMT) enquanto que outros, apenas o CMT. Todos os casos com fenótipo HSCR/CMT apresentavam um mesmo haplótipo, concluindo-se que ele poderia ser utilizado como marcador molecular para indivíduos dessa família (Quedas et al., 2012).

\subsection{Evidências do envolvimento de Inibidoras de quinases dependente de ciclinas (CDKIs) na tumorigênese NEM2}

A presença de mutações ativadoras no proto-oncogene RET é responsável por aproximadamente $95 \%$ dos casos de NEM2, tanto nos casos aparentemente esporádicos como nos hereditários de CMT. Entretanto, os mecanismos genéticos do processo de tumorigênese na NEM2 ainda não estão bem estabelecidos. Além disto, há ainda que melhor se estudar os aproximadamente $5 \%$ dos casos RET-negativos que apresentam fenótipo NEM2-simile (casos familiares com tumores NEM2- 
relacionados). Nestes últimos casos, alterações em outros genes podem estar potencialmente envolvidas, como segue abaixo.

\subsubsection{CDKIs}

A progressão do ciclo celular da fase $\mathrm{G} 1$ para $\mathrm{S}$, em mamíferos, é regulada de forma cooperativa por várias classes de quinase-dependentes de ciclinas (CDKs - cyclin-dependent kinases), cujas atividades são controladas negativamente por moléculas inibidoras de quinasesdependentes de ciclinas (CDKIs). As CDKls estão agrupadas em duas famílias, que tomam como base a sua estrutura química e as moléculas de CDK com as quais interage: INK4 e Cip/Kip (Sherr e Roberts, 1999) (Figura $5)$.

O complexo ciclina/CDK tem a capacidade de fosforilar a proteína retinoblastoma $(\mathrm{pRb})$, que quando fosforilada, libera o fator de transcrição E2F. Este último é responsável pela indução da transcrição dos genes necessários para progressão do ciclo celular da fase G1 para S (Sherr e Roberts, 1999) (Figura 5).

A desregulação do controle do ciclo celular pela perda da função de proteínas envolvidas esse processo contribuem para o desenvolvimento e progressão de muitos tipos de câncer (Hanahan e Weinberg, 2010). 


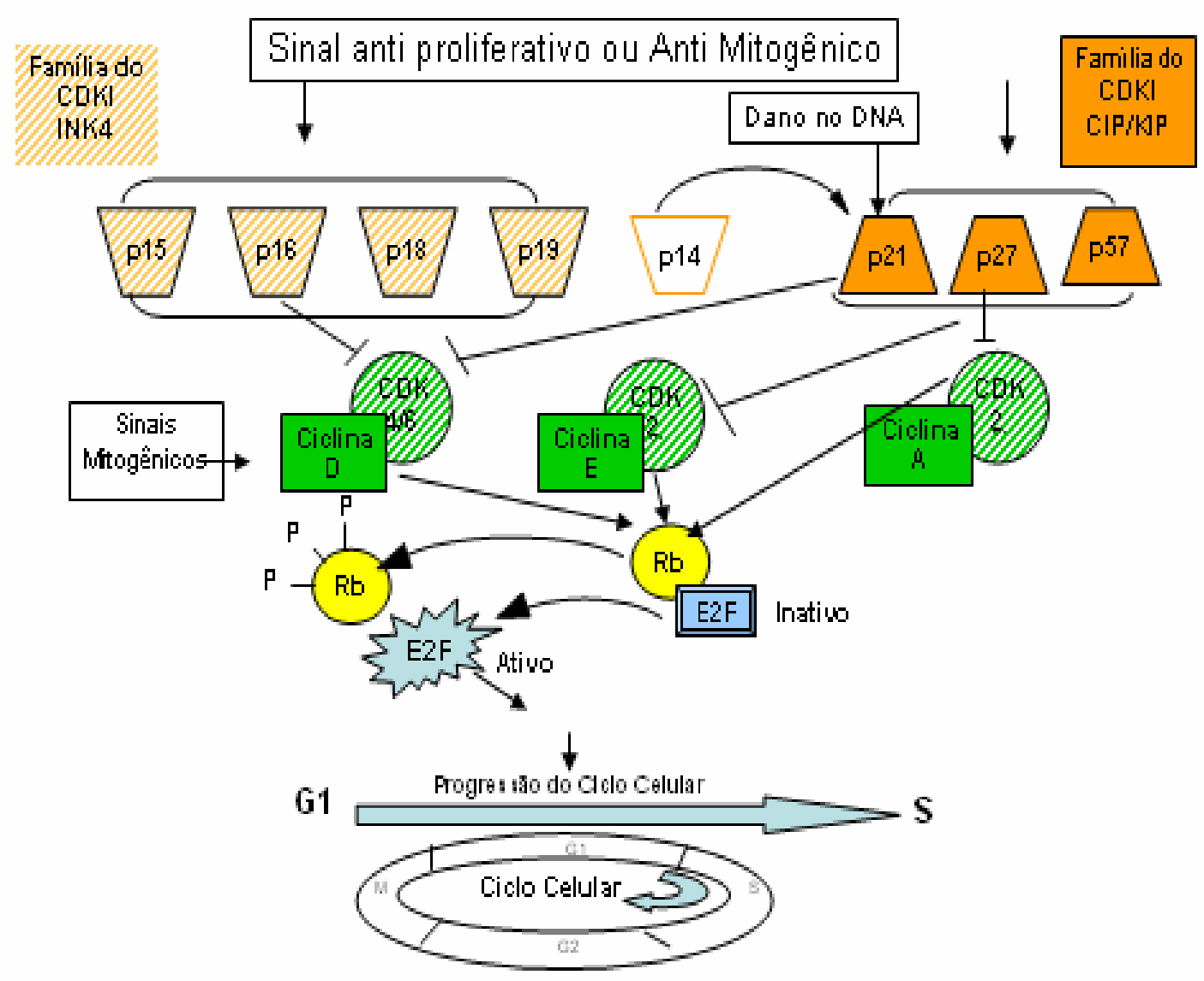

Figura 5 - Genes envolvidos na regulação do ciclo celular (Agarwal et al., 2009)

Ye et al. (2008), utilizando a técnica de Hibridização Genômica Comparativa $(\mathrm{CGH})$, relataram que em $\mathrm{CMT}$ advindos de pacientes com ou sem mutação no gene RET (esporádicos e hereditários), apresentavam frequentes perdas e ganhos de alelos. As regiões com frequentes perdas alélicas, nos CMT tanto esporádicos como hereditários, ocorreram em quatro loci gênicos 7q36.1, 12p13.31, 13q12.11 e 19p13.3-11, sendo que no lócus 12p13.31 houve a maior incidência de perda somática (43 \%) (Takeuti et al., 1996). Sendo que nessa região localiza-se o gene supressor de tumor $C D K N 1 B / p 27^{K i p 1}$. 
Especificamente, nos casos esporádicos foi evidenciada uma grande perda de $25-30 \%$ da região do braço curto do cromossomo 1 (1p), sendo que nesta região encontra-se outro gene supressor de tumor, o CDKN2C/p18 $8^{I N K 4}$. Yang (1990), Takai (1987), Mulligan (1993) e Marsh (2003) também relataram a ocorrência de frequente perda de marcadores polimórficos nos região 1p em CMT e FEO associados à NEM2.

Experimentos em modelos animais transgênicos e knockout evidenciaram que os genes $p 27^{K i p 1}$ e $p 18^{\text {INK4 }}$ estão envolvidos na predisposição e desenvolvimento de múltiplos tumores endócrinos. Estudo com duplo knockouts de p27 ou p21 com perda de p18 apresentaram tumores endócrinos característicos tanto de NEM1 como de NEM2 (Franklin et al., 2000). Dados obtidos por van Veelen et al. (2008) e Joshi et al. (2007) indicaram que a perda de função destes genes contribuem na tumorigênese da NEM2. Joshi et al. (2007) relataram que ratos knockout p27 $\%$ desenvolviam tumores em combinação com a perda ou diminuição de função da proteína p18.

Nos últimos anos, uma nova visão sobre a etiopatogenia dos tumores endócrinos hereditários surgiu a partir de estudos realizados nos modelos animais MENX, que é uma neoplasia endócrina múltipla que ocorre em ratos. Esta nova síndrome foi descoberta ao acaso em linhagens de ratos que viviam em colônia e desenvolviam espontaneamente múltiplos tumores neuroendócrinos. O espectro fenotípico variava entre os tumores NEM1simile e os NEM2-simile (feocromocitoma bilateral, paragangliomas, CMT bilateral, hiperplasia das paratireóides e adenomas de pituitária). Entretanto, 
estes animais não revelaram mutação em seus genes relacionados MEN1 e RET, respectivamente (Fritz et al., 2002) (Tabela 4).

A análise por mapeamento de ligação (linkage) permitiu a identificação da região do cromossomo 4 que correspondia ao locus do gene Cdkn1b, o qual codifica a proteína inibidora do ciclo celular p27. Piotrowska et al., 2004 identificaram mutação neste gene como sendo responsável pela síndrome MENX.

Tabela 4 - Comparação dos fenótipos NEM com os tecidos neoplásicos envolvidos na MENX (Fritz el al., 2002)

\begin{tabular}{lcc}
\hline Tumor & Frequência (\%) & Síndrome Associada \\
\hline HPT & 65 & NEM1/ NEM2 \\
Tumor hipofisário & 77 & NEM1 \\
Feocromocitoma bilateral & 95 & NEM2 \\
Paraganglioma & 85 & NEM2 \\
CMT & 78 & NEM2 \\
\hline CMT, Carcinoma medular de & tireoide; HPT, Hiperparatireoidismo; NEM1, Neoplasia \\
endócrina múltipla tipo 1; NEM2, Neoplasia endócrina múltipla tipo 2; MENX, Neoplasia \\
endócrina múltipla em ratos.
\end{tabular}

Em 2006 Pellegata et al., identificaram mutações germinativas em pacientes que apresentavam tumores NEM1 relacionados, mas sem mutação no gene MEN1. Como consequência dessas observações, uma nova síndrome NEM foi definida em humanos, a NEM4 que é causada por mutações germinativas no gene $p 27$.

A descoberta de mutações no gene p27 abriu caminho para o estudo de outros genes que codificam proteínas inibidoras de quinase dependentes de ciclinas do ciclo celular, tais como p15, p18 e p21. Agarwal et al. (2009) 
identificaram mutações nestes genes em amostras de pacientes com fenótipo NEM1, mas sem mutação no gene NEM1. Entretanto, há ainda poucos relatos da participação desses genes na tumorigênese da NEM2 e também das suas participações nos casos de pacientes com fenótipos NEM2-relacionados.

\subsubsection{Gene CDKN1B/p27 ${ }^{K i p 1}(p 27)$}

O gene $C D K N 1 B / p 27^{K i p 1}$ - que será a partir de agora identificado no texto como p27 - codifica a proteína p27 uma inibidora de quinase ciclinadependente. A p27 é uma proteína regulatória que controla a progressão da fase G1 para S do ciclo celular pela interação com complexos ciclina E/Cdk2 e ciclina A/Cdk4 (Polyak et al., 1994; Sherr e Roberts, 1999). Está localizado no braço curto do cromossomo 12 na região 12-13.1 (12p13.1-p12).

Na fase G0 e início da G1, a expressão e estabilidade de p27 são máximas. Durante a fase G1 ocorre a degradação gradual de p27 e um aumento da atividade dos complexos ciclina E/Cdk2 e ciclina A/Cdk4 que estimulam a progressão do ciclo celular (Reed et al., 1994). Diversas vias de transduções mitogênicas (ativação das vias MAPK, PI3K/AKT) e antiproliferativos (TGFß/SMAD) regulam a atividade e expressão de p27, e essa integração é um dos pontos centrais para manutenção da proliferação celular normal (Chu et al., 2008). Essas vias podem regular p27 por diferentes níveis, incluindo transcricionais, translacionais, localização intracelular ou degradação proteolítica mediada por ubiquitinas (Borriello et al., 2007; Molatore, 2010) (Figura 6). 


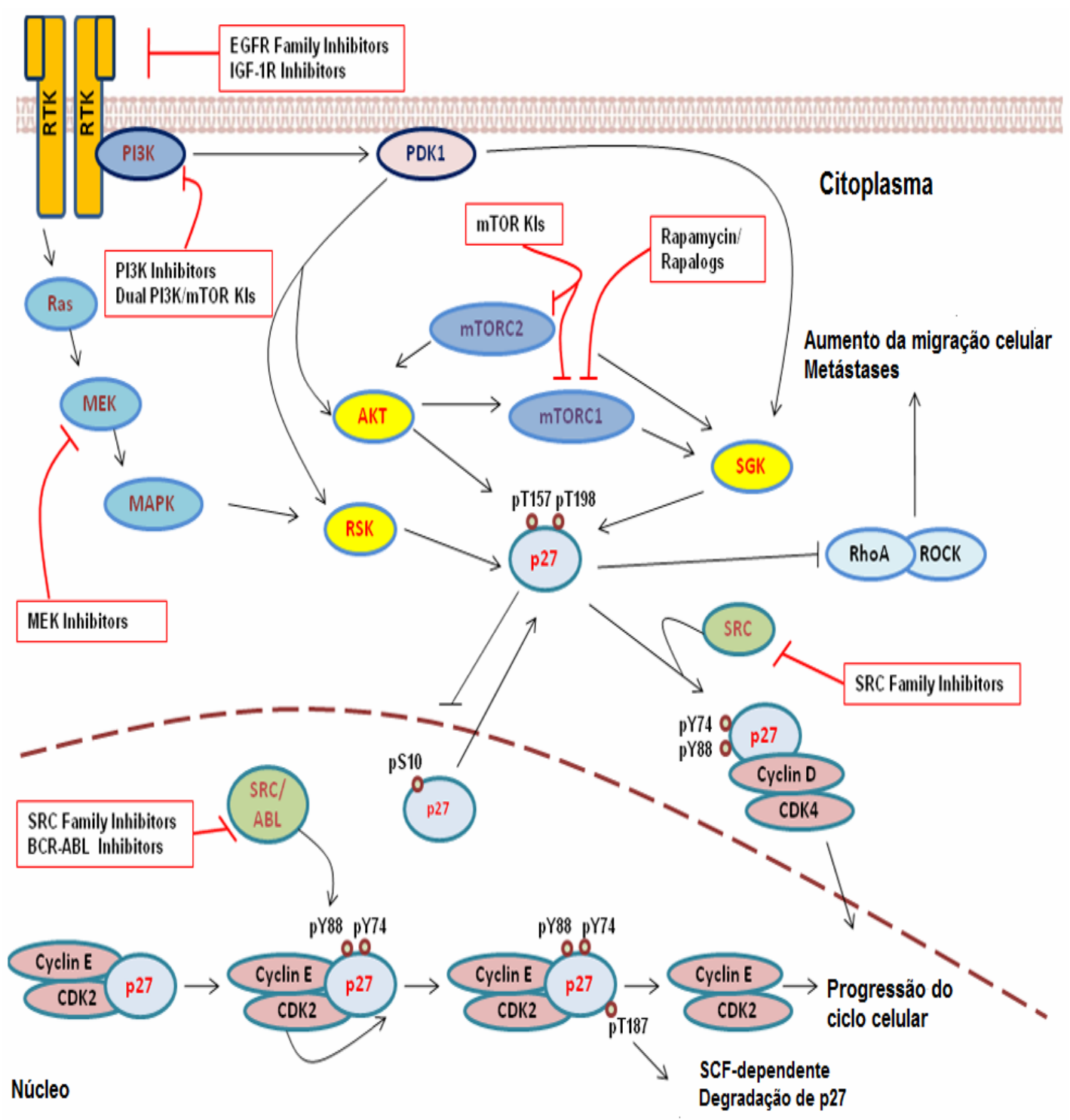

Figura 6 - Vias de sinalização da p27 durante a regulação da proliferação e migração celular. O esquema mostra a regulação e funções de p27 de acordo com a sua localização intracelular. No núcleo, p27 liga-se ao complexo ciclina E-CDK2 e inibe a progressão do ciclo celular $(\mathrm{G} 1 \rightarrow \mathrm{S})$, quando ocorre a fosforilação do sítio T187 mediado por SRC/ABL p27 é degradado pelo completo SCF/Skp2, permitindo assim a progressão do ciclo celular. Fosforilação no sítio S10 promove a exportação nuclear para o citoplasma. No citoplasma, p27 executa diferentes funções: sinais de transdução promovidos pela via PI3K/PDK1 ou Ras/MAPK resultam na hiperativação de diversos membros da família AGC quinases (incluindo AKT, SGK e RSK), que promove a fosforilação dos sítios T157 e T198. A fosforilação destes sítios coopera para sequestrar e estabilizar p27 no citoplasma, onde promove a proliferação pela ligação com o complexo ciclina D-CDK4 e a motilidade, via inibição da via de sinalização RhoA/ROCK. Em destaque (amarelo) estão os possíveis alvos terapêuticos (Wander et al., 2011) 
Estudos anteriores tinham analisado o gene p27 e verificado que, apesar de possuir baixa expressão em diversos tumores em relação à tecidos normais, ele não era comumente mutado em tumores, sugerindo inativação por outras vias, como eventos epigenéticos, pós-transcricionais e pós-transducionais. Em 1995, Kawamata e colaboradores realizaram um grande estudo de rastreamento de mutações no p27 em 432 tumores, sendo: 36 células non-small do fígado, 20 ovário, 39 testicular, 15 endomedrial, 18 próstata, 31 gástrico, 68 cervical, 48 osteosarcoma, 25 outros sarcomas, 132 leucemias, 50 leucemias mielóide aguda e 82 leucemias linfocíticas. Nesse estudo não foi encontrada nenhuma variante patogênica, verificando que mutações nesse gene são muito raras.

Estudos em animais knockout para esse gene evidenciaram associação da inativação de p27 com tumorigênese hipofisária. Esses animais desenvolviam hiperplasia/tumor hipofisário aos três meses de idade e gigantismo (Fero et al., 1996; Kiyokawa et al., 1996).

A perda da expressão da proteína p27 foi descrita como evento frequente em diversos tipos de câncer humano (Chu et al., 2008), aparentemente conferindo uma vantagem proliferativa que pode levar a formação do tumor. Esses dados evidenciam que p27 não é um gene supressor tumoral clássico, uma vez que se encontra raramente mutado em tumores (Kawamata et al., 1995; Lindberg et al., 2007). Por isso, sugeriu-se que $p 27$ poderia ser controlado por mecanismos alternativos que atuam em nível pós-transcricional, incluindo: uma menor taxa de tradução de mRNA de p27 (Hengst e Reed, 1996), um aumento na degradação proteolítica, 
especificamente pelo complexo SCF/Skp2E3 ubiquitina ligase (Pagano et al., 1995, Chiappetta et al., 2007) e a translocação citoplasmática de p27 (Viglietto et al., 2002).

O p27 tem papel importante na etiologia do câncer de tireóide. Evidências obtidas em estudos clínicos e in vitro demonstram que a perda somática, baixa expressão (Khoo et al., 2002) ou translocação citoplasmática (Baldassarrre et al., 1999) de p27 podem contribuir no processo de tumorigênese dos cânceres de tireóide. Em adição, foi demonstrado que as vias PI3K/AKT controlam a proliferação das células da tireóide pela regulação da expressão e localização subcelular de p27 (Khoo et al., 2002).

\subsubsection{Polimorfismos no gene p27}

Foram descritos 15 polimorfismos no p27 de acordo com o banco de dados Internacional do Projeto HapMap (http://www.hapmap.org). Baseado em dados da literatura e de estudos preditivos funcionais (estudos in silico), três destes polimorfismos se mostraram consistentes: $-838 \mathrm{C}>\mathrm{A}$ (rs36228499), -79C>T (rs34330) e 326T>G (V109G, rs2066827). Segundo dados do HapMap, existe algum desequilíbrio de ligação ao longo da região entre rs36228499 e rs34330, mas que não demonstra uma correlação elevada. Assim, os três SNPs representam fatores de risco genéticos independentes.

Uma abordagem que aumenta a probabilidade de encontrar fatores de riscos genéticos relacionados com a NEM2 é a seleção de polimorfismos 
de nucleotídeo único (SNPs) em genes candidatos ou loci envolvidos na modulação de fenótipo em uma doença.

O polimorfismo $-838 \mathrm{C}>\mathrm{A}$ está localizado na região promotora de $p 27$ e tem sido associado com aumento de risco de enfarte do miocárdio devido à diminuição da atividade da região promotora (Gonzalez et al., 2004). Esse SNP também está associado ao risco de re-estenose depois de processo cirúrgico, mas a diferença é que os pacientes que apresentam o genótipo 838A em homozigose tem uma diminuição do risco de re-estenose intrastend com o aumento da atividade do promotor do alelo $A$, o que pode explicar a diminuição da proliferação de células do músculo liso (van Tiel et al., 2009).

O polimorfismo -79C>T está localizado na região $5^{\prime}$ não traduzida (5'UTR) do p27 e apresenta atividade promotora (Minami et al., 1997, Ito et al., 1999) e está associado a um aumento de risco de câncer de tireóide devido a alteração dos níveis de transcrição de p27 (Landa et al., 2010).

Finalmente o polimorfismo mais estudado, 326T $>C$ (V109G) que é uma variante não-sinônima localizada no éxon 1 do p27 e está associada com susceptibilidade a diversos tipos de câncer, como o de próstata e ovário (Kibel et al., 2003, Li et al., 2004, Gayther et al., 2007).

\subsubsection{Gene CDKN2C/p18 ${ }^{I N K 4}(p 18)$}

Além do gene p27, o gene p18 é outro candidato na via de tumorigênese da NEM2. Diversos estudos descreveram a perda alélica do marcador $1 p$, na região $1 \mathrm{p} 32-1 \mathrm{p} 36$, em casos de CMT/NEM2, em linhagem 
primária de cultura de células de CMT de várias espécies (Matthew et al., 1987; Khosla et al., 1991). Estudos mais recentes utilizando a técnica de CGH (Hibridização genômica comparativa) revelaram a perda da região $1 p$ em 8 de $28(8 / 28)$ casos de CMT, bem com em linhagens de células tireoidiana (TT) (Marsh et al., 2003).

Um evento frequentemente detectado em CMT e FEO é alteração cromossômica na qual ocorre a perda de parte específica ou total do braço curto do cromossomo 1. O ponto mais comum de quebra é na região onde se localiza o gene CDKN2C (1p32) (van Veelen et al., 2008 e 2009).

Não há relatos na literatura de mutações germinativas no gene p18 associadas à predisposição a tumores endócrinos. Entretanto, van Veelen et al. (2009) identificaram várias mutações somáticas inativadoras em p18, associadas à presença de mutação no RET e à progressão de CMT e FEO. Estes achados evidenciam p18 como um gene envolvido na progressão de CMT e FEO (Tabela 5).

O gene p18 (Gene ID1031) está localizado no braço curto do cromossomo 1 , na região $32(1 \mathrm{p} 32)$ e codifica a proteína supressora de tumor p18. Esta proteína pertence à família INK4 dos inibidores das quinases dependentes de ciclinas e interage com CDK4 ou CDK6 prevenindo a ativação de CDK quinases (Nelson e Cox, 2006). 
Tabela 5 - Mutações somáticas identificadas em humanos no p18 em CMT e FEO associada à mutação ativadora no gene RET (van Veelen et al., 2009)

\begin{tabular}{|c|c|c|c|c|c|}
\hline Tumor & $\begin{array}{l}\text { Fonte do } \\
\text { tecido }\end{array}$ & $\begin{array}{c}\text { Familial/ } \\
\text { Esporádico }\end{array}$ & $\begin{array}{c}\text { RET } \\
\text { (proteína) }\end{array}$ & $\begin{array}{c}p 18 \\
\text { (DNA) }\end{array}$ & $\begin{array}{c}\text { p18 } \\
\text { (proteína) }\end{array}$ \\
\hline \multirow{3}{*}{ CMT } & $\begin{array}{l}\text { Metástase } \\
\text { (linfonodos) }\end{array}$ & Esporádico & M918T & $151 G>A$ & E51K \\
\hline & Primária & Esporádico & M918T & $181 G>A$ & $\mathrm{~A} 61 \mathrm{~T}$ \\
\hline & Primária & NEM2A & C634W & $214 A>T$ & $\mathrm{~A} 72 \mathrm{~T}$ \\
\hline \multirow{3}{*}{ FEO } & $\begin{array}{c}\text { Metástase } \\
\text { (glândula } \\
\text { adrenal) }\end{array}$ & NEM2A & C634W & $235 G>A$ & R79G \\
\hline & Primária & NEM2A & C634R & $188 G>A$ & P63L \\
\hline & Primária & NEM2A & C634R & $236 C>T$ & R79K \\
\hline
\end{tabular}

CMT, Carcinoma medular de tireoide; FEO, Feocromocitoma.

\subsubsection{Interação de p18 e p27}

A presença de uma mutação no RET em combinação com a perda de p18 e/ou p18 e p27 resulta em aumento na incidência de CMT, bem como a diminuição das idades de desenvolvimento da doença em modelos animais (van Veelen et al., 2009; Joshi et al., 2007).

Estudos em camundongos knockout evidenciaram que animais com o genótipo p18 -/- desenvolveram hiperplasia das células C (HCC) e CMT, e também apresentavam perda adicional de p27 (Joshi et al., 2007; van Veelen et al., 2008). A perda de p18 e/ou p27 leva à aceleração na progressão de vários tumores endócrinos (Franklin et al., 1998 e 2000).

Resultados de van Veelen et al. (2008) evidenciaram a existência de interação entre p18 e p27, na qual camundongos knockout com genótipo 
$p 18^{-} /^{-} ; p 27^{+} /^{-}$desenvolveram CMT precocemente, antes dos 9 meses de idade. Franklin et al. (1998) e Nakayama et al. (1996) mostraram em modelos animais a incidência de tumores NEM relacionados (Tabelas 6 e 7). $\mathrm{Na}$ literatura, ainda há poucos relatos sobre mutações e/ou polimorfismos nos genes p18 e p27 que, como mostrado por van Veelen (2008 e 2009), quando associadas à mutação no gene RET podem promover a progressão dos tumores na NEM2.

Tabela 6 - Incidência de tumores em animais knockout p18, p27 e p18/p27 (Nakayama et al., 1996; Franklin et al., 1998)

\begin{tabular}{llll}
\hline \multirow{2}{*}{ Tecido } & \multicolumn{3}{c}{ Genótipos } \\
\cline { 2 - 4 } & \multicolumn{1}{c}{ p18 -/- } & \multicolumn{1}{c}{ p27 -/- } & \multicolumn{1}{c}{ p18-/- ; p27 -/- } \\
\hline Hipófise & $\begin{array}{l}\text { Hiperplasia (62\%) } \\
\text { Adenoma (27\%) }\end{array}$ & $\begin{array}{l}\text { Hiperplasia (40\%) } \\
\text { Adenoma (25\%) }\end{array}$ & $\begin{array}{l}\text { Hiperplasia (6\%) } \\
\text { Adenoma (91\%) } \\
\text { Carcinoma (3\%) }\end{array}$ \\
\hline Medula Adrenal & $\begin{array}{l}\text { Hiperplasia (33\%) } \\
\text { Feocromocitoma } \\
(8 \%)\end{array}$ & $\begin{array}{l}\text { Hiperplasia (19\%) } \\
\text { Feocromocitoma } \\
(23 \%)\end{array}$ & $\begin{array}{l}\text { Hiperplasia (6\%) } \\
\text { Feocromocitoma } \\
(91 \%)\end{array}$ \\
Tireoide (células C) & Hiperplasia (12\%) & Normal & $\begin{array}{l}\text { Hiperplasia (81\%) } \\
\text { Adenoma (6\%) }\end{array}$ \\
\hline $\begin{array}{l}\text { Testiculos (células de } \\
\text { Leydig) }\end{array}$ & Hiperplasia (95\%) & Normal & Hiperplasia (100\%) \\
Pâncreas (ilhotas) & Normal & Normal & Hiperplasia (20\%) \\
\hline $\begin{array}{l}\text { Estômago (células } \\
\text { escamosas) }\end{array}$ & Normal & Normal & Adenoma (25\%) \\
\hline \begin{tabular}{l} 
Intestino \\
\hline
\end{tabular} & Normal & Normal & $\begin{array}{l}\text { Adenoma } \\
\text { duodenal (9\%) }\end{array}$ \\
\hline
\end{tabular}


Tabela 7 - Comparação da incidência de tumores em ratos p18 -/- /p27 -/em pacientes com síndromes NEM1 e NEM2 (Nakayama et al., 1996; Franklin et al., 1998; e Hoff et al., 2000)

\begin{tabular}{llcc}
\hline \multicolumn{1}{c}{ Tecido } & p18-/-; p27 -/- & NEM1 & NEM2 \\
\hline Hipófise & $\begin{array}{l}\text { Hiperplasia } \\
\text { Adenoma } \\
\text { Carcinoma }\end{array}$ & Carcinoma & Normal \\
\hline Medula Adrenal & $\begin{array}{l}\text { Hiperplasia } \\
\text { Feocromocitoma }\end{array}$ & Normal & Feocromocitoma \\
\hline Células C da tireóide & Hiperplasia & Normal & Carcinoma \\
\hline $\begin{array}{l}\text { Paratireóide } \\
\text { Testiculos (células de }\end{array}$ & Hormal & Hiperplasia & Hiperplasia \\
Leydig) & Adenoma & Adenoma \\
\hline $\begin{array}{l}\text { Pâncreas (ilhotas) } \\
\text { Tumores não endócrinos }\end{array}$ & Sim & Normal & Normal \\
\hline
\end{tabular}

Levando em conta que todo processo de tumorigênese envolve a participação de diversos genes, além das evidências de polimorfismos estarem modulando fenótipo de uma doença, o presente estudo poderá contribuir para a análise das vias do processo de tumorigênese da NEM2, o que poderá auxiliar no melhor monitoramento e direcionamento/recomendações para o rastreamento e seguimento clínico da NEM2. 
2 OBJETIVOS 
- Analisar a presença de mutação somática dos genes p15, p18 e p27 em tumores de pacientes com NEM2 e mutação RET;

- Avaliar a associação de polimorfismos no gene p27 no prognóstico e progressão da doença em pacientes com NEM2 e mutação RET;

- Avaliar se polimorfismos no gene p27 estariam modulando o fenótipo da NEM2A em uma grande família com mutação C620R no gene RET;

- Verificar se a localização e níveis de expressão celular da proteína p27 estariam associados ao prognóstico da doença. 


\section{CASUÍSTICA}




\subsection{Pacientes e tumores}

Neste projeto foram incluídos 36 pacientes $(n=36)$ com NEM2 provenientes do programa de rastreamento genético de NEM2 do HCFMUSP/ Unidade de Endocrinologia Genética/LIM25, com diagnósticos clínicos e genéticos confirmados de NEM2 (casos com mutação no gene $R E T)$. Dos 36 casos, 34 herdaram a mutação germinativa e 2 apresentavam mutação de novo no RET.

Dentre os 36 pacientes, havia 17 mulheres (47\%) e 19 homens (53\%) com média de idade de $30,5 \pm 19$ anos. As mutações no RET presente nos tumores desses pacientes foram: C620R (58\%), C634R (11\%), C634Y/Y791F (19\%), M918T (6\%), V804M (3\%) e C611W (3\%).

O CMT estava presente em 33 casos (92\%) e a hiperplasia de células-C em 3 casos (8\%). A localização do CMT na maioria dos casos foi multicêntrica e bilateral (79\%), e nos demais casos era multicêntrica unilateral $(9 \%)$ ou unicêntrica $(12 \%)$. O estadiamento do CMT variou entre I -IV, sendo que 23 casos (64\%) estavam no estágio I/II e 13 casos (36\%) no estágio II/IV. Em 16 casos (44\%) houve a cura bioquímica da doença (calcitonina $<2 \mathrm{pg} / \mathrm{mL}$ ) e em 20 casos documentou-se recidiva do CMT $(50 \%)$

O FEO estava presente em 12 casos (34\%) sendo sua localização na maioria dos casos unilateral (73\%), e os casos de tumores bilaterais foram 3 
(27\%). Um dos casos com suspeita de FEO apresentava somente hiperplasia adrenal. O hiperparatireoidismo primário (HPT) estava presente em 6 casos com NEM2 (17\%).

No total, 66 tecidos tumorais $(n=66)$ proveniente dos 36 pacientes com NEM2 foram analisados, sendo: 37 CMT ( $n=37 ; 56 \%)$ com média de tamanho entre $1,5 \pm 1,7 \mathrm{~cm}$ e 21 FEO $(n=21 ; 32 \%)$ com média de tamanho $2,2 \pm 1,3 \mathrm{~cm}, 2$ HPT $(n=2 ; 3 \%) 2$ linfonodos cervicais $(n=2 ; 3 \%)$ e 4 metástases de pulmão $(n=4 ; 6 \%)$. As amostras tumorais foram obtidas de processos cirúrgicos realizados no HC-FMUSP e adequadamente acondicionados em nitrogênio líquido ou solução estabilizadora RNAlater (Ambion, USA) para sua conservação.

O presente estudo foi aprovado pela Comissão de Ética para Análise de Projetos de Pesquisa do HC-FMUSP (CAPPesq) sob o protocolo de pesquisa $n^{\circ}$ 1231/09 e de outros projetos do grupo: 0425/08, 0549/09 e 0050/10. Todos os pacientes leram e assinaram o Termo de Consentimento Livre e Esclarecido.

De acordo com a tabela 8, foi realizada uma breve descrição clínica dos pacientes que foram submetidos a processo cirúrgico seguido da análise genética dos tumores.

Os casos 1 e 4 são dois pacientes com NEM2B que apresentam a mutação M918T de novo. Estes casos foram diagnosticados e operados com 8 e 12 anos de idade, respectivamente, e não se encontram clinica ou bioquimicamente curados do CMT. O caso 1 apresentava múltiplas metástases cervicais e metástases à distância nos pulmões, sendo que a 
última dosagem de calcitonina era de $3.733 \mathrm{pg} / \mathrm{mL}$. Já o caso 2 apresentava metástases cervicais e em sua última dosagem de calcitonina o valor era de $32.651 \mathrm{pg} / \mathrm{mL}$. Atualmente estes dois pacientes seguem no ICESP.

Os casos 3, 5, 9, 14, 15, 24 e 29 pertencem a uma família NEM2A com dupla mutação germinativa C634Y/Y791F no RET. Os pacientes apresentavam CMTs com desenvolvimento usual para a síndrome, associados à FEOs mais agressivos e precoces. O caso 5 apresentou CMT e FEO já operados e atualmente encontra-se curada bioquimicamente do CMT (calcitonina basal $<2 \mathrm{pg} / \mathrm{mL}$ ). As características clínicas e genéticas gerais de pacientes pertencentes a esta família já foram relatadas em detalhe (Toledo et al., 2010).

O caso 28 é portador de NEM2A com a presença de CMT, FEO e HPT. Pertence a uma família de Natal, Rio Grande do Norte. Há mais três afetados na família.

O caso 10 é portador de NEM2A típico apresentando CMT e FEO bilateral. Não curado do CMT.

Os casos 11 e 19 pertencem a uma família com NEM2A típico e apresentaram CMT e FEO. Foram os primeiros casos operados preventivamente para o CMT no Hospital das Clínicas, aproximadamente há 22 anos (Santo et al., 2006). Atualmente ambas pacientes encontram-se clinica e bioquimicamente curadas do CMT (calcitonina basal $<2,0 \mathrm{pg} / \mathrm{mL}$ ). Mais recentemente, também foram operadas de FEO bilateral. 
Os casos 12, 23 e 31 pertencem a uma família com NEM2A típica (CMT, FEO e HPT), sendo que o caso 31 foi submetido à tireoidectomia total preventiva aos 2 anos de idade.

Os casos 16 e 32 pertencem a uma família com NEM2A típico (CMT, FEO e HPT). Há outros seis membros afetados na família. O caso 16 não se encontra curado do CMT.

O caso 21 é paciente que pertence a uma família de NEM2 onde ocorre somente o CMT. Dois homens afetados desta família apresentaram CMT com evolução agressiva e não estão curados do CMT. Enquanto isto, quatro mulheres afetadas desta família tiveram evolução muito lenta, inclusive o caso 21. As mulheres dessa família encontram-se curadas do CMT, apesar de terem sido operadas tardiamente.

As amostras $2,6,7,8,13,17,18,20,22,25,26,27,30,33,34,35$, 36 da tabela 9 correspondem a 17 indivíduos de uma grande família com NEM2A/CMT-F na qual foram analisados tumores. A clínica desses pacientes está descrita a seguir, na descrição da família de Arapiraca. Dados parciais sobre esta família foram relatados anteriormente (FrankRaue et al., 2010; Quedas et al., 2012). 
Tabela 8 - Dados clínicos de 36 pacientes com NEM2 e mutação no gene RET na qual foram analisados tecidos tumorais.

\begin{tabular}{|c|c|c|c|c|c|c|c|c|c|c|c|c|c|c|c|c|}
\hline \multicolumn{5}{|c|}{ Paciente } & \multicolumn{8}{|c|}{ CMT } & \multirow{3}{*}{ HPT } & \multirow{2}{*}{\multicolumn{3}{|c|}{ FEO }} \\
\hline \multirow[b]{2}{*}{ Caso $n^{\circ}$} & \multirow[b]{2}{*}{ Sexo } & \multirow{2}{*}{$\begin{array}{l}\text { Id Diag } \\
\text { (anos) }\end{array}$} & \multirow[b]{2}{*}{ Genótipo } & \multirow[b]{2}{*}{ Fenótipo } & \multirow[b]{2}{*}{ Localização } & \multirow{2}{*}{$\begin{array}{c}\text { Tamanho } \\
\text { (cm) }\end{array}$} & \multicolumn{2}{|c|}{ Estadiamento } & \multicolumn{2}{|c|}{ Calcitonina** } & \multicolumn{2}{|c|}{ Prognóstico } & & & & \\
\hline & & & & & & & Estágio & $\mathrm{TNM}^{*}$ & $\begin{array}{c}\text { Pré- } \\
\text { cirúrgico }\end{array}$ & $\begin{array}{c}\text { Pós- } \\
\text { cirúrgico }\end{array}$ & Cura & Recidiva & & Tumor & Localização & Tamanho (cm) \\
\hline 1 & $M$ & 9 & M918T & NEM2B & M bil & sem info & IVc & T3N1M1 & 64,0 & 3733,0 & $\mathrm{~N}$ & $S$ & $\mathrm{~N}$ & $\mathrm{~N}$ & sem tumor & 1 \\
\hline 2 & $\mathrm{~F}$ & 16 & C620R & NEM2A/CMTF & M uni & sem info & 1 & T1NOMO & $<5,0$ & $<2,0$ & $S$ & $\mathrm{~N}$ & $\mathrm{~N}$ & $\mathrm{~N}$ & sem tumor & 1 \\
\hline 3 & M & 23 & C634Y/Y791F & NEM2A & M uni & 0,1 e 0,3 & 1 & T1NOMO & 8,4 & $<2,0$ & $S$ & N & N & N & sem tumor & 1 \\
\hline 4 & M & 12 & M918T & NEM2B & M bil & 2,8 e 1,4 & $\mathrm{IVa}$ & T3N1bMx & 29327,0 & 32651,0 & $\mathrm{~N}$ & $S$ & $\mathrm{~N}$ & $\mathrm{~N}$ & sem tumor & 1 \\
\hline 5 & $\mathrm{~F}$ & 44 & C634Y/Y791F & NEM2A & M bil & sem info & 1 & T1NOMO & $<2,0$ & $<2,0$ & $S$ & N & N & $S$ & U & 0,5 \\
\hline 6 & M & 13 & C620R & NEM2A/CMTF & U & 0,3 & I & T1N1M0 & $<2,0$ & $<2,0$ & $S$ & $\mathrm{~N}$ & $\mathrm{~N}$ & $\mathrm{~N}$ & sem tumor & 1 \\
\hline 7 & M & 33 & C620R & NEM2A/CMTF & M uni & 2,0 e 3,5 & III & T2N1M0 & sem info & sem info & $\mathrm{N}$ & $\mathrm{N}$ & $\mathrm{N}$ & N & sem tumor & 1 \\
\hline 8 & M & 26 & C620R & NEM2A/CMTF & M bil & sem info & III & T3N1bM1 & 47,0 & 458,0 & $N$ & St & N & $N$ & sem tumor & I \\
\hline 9 & M & 51 & C634Y/Y791F & NEM2A & M bil & 0,4 e 0,4 & ॥ & T2NOMO & 14,1 & 11,9 & $\mathrm{~N}$ & $S$ & $S$ & $S$ & BA & 3,1 e 2,5 \\
\hline 10 & $\mathrm{~F}$ & 50 & C611W & NEM2A & M bil & sem info & I & T1NOMO & 23,0 & 25,1 & $\mathrm{~N}$ & $S$ & N & $S$ & $B$ & 5 e 3 \\
\hline 11 & $M$ & 38 & C634R & NEM2A & $\mathrm{HCC}$ & sem info & I & T1NOMO & $<1.9$ & $<2,0$ & $S$ & $\mathrm{~N}$ & $\mathrm{~N}$ & $\mathrm{HCC}$ & $\mathrm{HCC}$ & 0,8 \\
\hline 12 & $\mathrm{~F}$ & 28 & C620R & NEM2A & U & 0,8 & I & T1NOMO & 72,0 & $<2,0$ & $S$ & $\mathrm{~N}$ & $\mathrm{~N}$ & $S$ & $U$ & 2,3 \\
\hline 13 & $\mathrm{~F}$ & 20 & C620R & NEM2A/CMTF & M bil & 4 & III & T2N1M0 & 55 & 291,0 & $N$ & $S$ & $N$ & $N$ & sem tumor & 1 \\
\hline 14 & M & 64 & C634Y/Y791F & NEM2A & M bil & sem info & III & T2N1M0 & 306,0 & 303,0 & $\mathrm{~N}$ & $S$ & $\mathrm{~N}$ & $S$ & U & I \\
\hline 15 & $M$ & 49 & $\mathrm{C} 634 \mathrm{Y} / \mathrm{Y} 791 \mathrm{~F}$ & NEM2A & M bil & 3 e 0,5 & $\|$ & T2NOMO & 1594,0 & $>2,0$ & $S$ & $\mathrm{~N}$ & $S$ & $S$ & B & 2 e 1 \\
\hline 16 & $M$ & 55 & C634R & NEM2A & M bil & sem info & $\|$ & T2NOMO & $<10,0$ & 8,7 & $\mathrm{~N}$ & $S$ & $\mathrm{~N}$ & $S$ & U & 3 \\
\hline 17 & M & 2 & C620R & NEM2A/CMTF & $\mathrm{HCC}$ & 1 & 1 & TONOMO & 5,2 & 16,7 & $S$ & N & N & $N$ & sem tumor & 1 \\
\hline 18 & M & 8 & C620R & NEM2A/CMTF & U & 0,3 & I & T1aNOMO & 9,5 & $<2,0$ & $S$ & $N$ & $\mathrm{~N}$ & $N$ & sem tumor & 1 \\
\hline 19 & $\mathrm{~F}$ & 27 & C634R & NEM2A & M bil & sem info & I & T1NOMO & $<10,0$ & $<2,0$ & $S$ & $\mathrm{~N}$ & $S$ & $S$ & U & 4 \\
\hline 20 & $\mathrm{~F}$ & 34 & C620R & NEM2A/CMTF & M bil & 0,5 e 0,9 & I & T1NOMO & 10,5 & 9,1 & $\mathrm{~N}$ & $\mathrm{~N}$ & $\mathrm{~N}$ & $\mathrm{~N}$ & sem tumor & 1 \\
\hline 21 & $\mathrm{~F}$ & 62 & V804M & NEM2A & $\mathrm{HCC}$ & 1 & I & TONOMO & $<10,0$ & $<2,0$ & $S$ & $\mathrm{~N}$ & $\mathrm{~N}$ & $\mathrm{~N}$ & sem tumor & 1 \\
\hline 22 & $\mathrm{~F}$ & 25 & C620R & NEM2A/CMTF & M bil & 0,9 e 0,1 & I & T1NOMO & 92,0 & 27,6 & $\mathrm{~N}$ & $S$ & $\mathrm{~N}$ & $\mathrm{~N}$ & sem tumor & 1 \\
\hline 23 & $\mathrm{~F}$ & 30 & C620R & NEM2A & M bil & 1,4 e 2 & III & T1bN1aM0 & 32,8 & 80,7 & $\mathrm{~N}$ & $S$ & $S$ & $\mathrm{~N}$ & sem tumor & I \\
\hline 24 & $\mathrm{~F}$ & 61 & C634Y/Y791F & NEM2A & M bil & sem info & III & T1N1M0 & 336,0 & 620,0 & $\mathrm{~N}$ & $S$ & $S$ & $S$ & sem info & sem info \\
\hline
\end{tabular}


Tabela 8 - Dados clínicos de 36 pacientes com NEM2 e mutação no gene RET na qual foram analisados tecidos tumorais. (conclusão)

\begin{tabular}{|c|c|c|c|c|c|c|c|c|c|c|c|c|c|c|c|c|}
\hline 25 & $\mathrm{~F}$ & 17 & C620R & NEM2A/CMTF & M bil & 1,2 e 0,2 & III & T2N1M0 & $<2,0$ & sem info & $\mathrm{N}$ & $S$ & $\mathrm{~N}$ & $\mathrm{~N}$ & sem tumor & 1 \\
\hline 26 & $\mathrm{~F}$ & 84 & C620R & NEM2A/CMTF & M bil & 9 e 1,7 & ॥ & T3N1aM0 & 9869,0 & 402,0 & $\mathrm{~N}$ & SH & $\mathrm{N}$ & $N$ & sem tumor & 1 \\
\hline 27 & $\mathrm{~F}$ & 10 & C620R & NEM2A/CMTF & M bil & 0,3 e 0,18 & I & T1NOMO & 8,2 & $<2,0$ & $S$ & $\mathrm{~N}$ & $\mathrm{~N}$ & $N$ & sem tumor & 1 \\
\hline 28 & M & 35 & C620R & NEM2A & M bil & sem info & ॥ & T2N1M0 & 714,0 & 16,2 & $S$ & $S$ & $\mathrm{~N}$ & $S$ & $U$ & 1,4 \\
\hline 29 & M & 28 & C634Y/Y791F & NEM2A & M bil & 1,8 e 0,3 & III & T1bN1bM0 & 170,0 & 8,9 & $\mathrm{~N}$ & $S$ & $\mathrm{~N}$ & $S$ & $U$ & 1 \\
\hline 30 & M & 28 & C620R & NEM2A/CMTF & M bil & 0,4 e 0,1 & I & T1NOMO & $<10,0$ & 7,1 & $S$ & $\mathrm{~N}$ & $\mathrm{~N}$ & $\mathrm{~N}$ & sem tumor & I \\
\hline 31 & M & 2 & C620R & NEM2A & M bil & 0,4 e 0,4 & I & T1aNOMO & 26,5 & 5,9 & $S$ & $\mathrm{~N}$ & $\mathrm{~N}$ & $N$ & sem tumor & 1 \\
\hline 33 & $\mathrm{~F}$ & 28 & C620R & NEM2A/CMTF & M bil & $1 \mathrm{e} ?$ & IV c & T4aN1M1 & $<2,0$ & sem info & $\mathrm{N}$ & St & $\mathrm{N}$ & $S$ & U & 0,5 \\
\hline 34 & $\mathrm{~F}$ & 24 & C620R & NEM2A/CMTF & M bil & 4 & IV c & T3N1M1 & 85,0 & 82353,0 & $\mathrm{~N}$ & $S$ & $\mathrm{~N}$ & $\mathrm{~N}$ & sem tumor & 1 \\
\hline 35 & $\mathrm{~F}$ & 21 & C620R & NEM2A/CMTF & M bil & 1 & III & T1N1bM0 & 344,0 & 15,7 & $\mathrm{~N}$ & $S$ & $\mathrm{~N}$ & $\mathrm{~N}$ & sem tumor & 1 \\
\hline 36 & $M$ & 8 & C620R & NEM2A/CMTF & U & 0,1 & I & T1NOMO & 10,9 & $<2,0$ & $S$ & $\mathrm{~N}$ & $\mathrm{~N}$ & $\mathrm{~N}$ & sem tumor & I \\
\hline
\end{tabular}

F, feminino; M, masculino; Id Diag, idade ao diagnóstico; M bil, tumor multicêntrico bilateral; U, tumor unicêntrico; HCC, Hiperplasia de células-C; sem info, sem informações; $\mathbf{t}$, óbito CMT; H, óbito pneumonia; CMT, Carcinoma Medular de Tireóide; FEO, Feocromocitoma; HPT, Hiperparatireoidismo primário.

${ }^{*}$ TNM, estadiamento do CMT (Sobin, 2010): ${ }^{* *}$ Calcitonina, referência: homens, $<8,4 \mathrm{pg} / \mathrm{mL} /$ mulheres, $<: 5,0$ pg/mL (Método: imunoquimioluminométrico, Immulite USA, CA) 


\subsection{Análise de polimorfismos do gene p27 em uma grande família com NEM2A/CMT-F}

Polimorfismos no gene p27 foram analisados em 28 membros em uma grande família com CMT familial associada à mutação germinativa c.1858T>C (p.C620R) localizada no éxon 10 do gene RET. Tivemos acesso ao tecido tumoral de 17 dos 28 pacientes, com a finalidade de realizarmos as análises moleculares descritas previamente em Métodos.

Alguns membros dessa família também apresentam megacólon congênito. Aproximadamente 35 membros afetados desta família eram portadores dessa mutação (p.C620R) e a boa parte deles já apresentava CMT na primeira consulta, com dimensões variando de $0,2 \mathrm{~cm}$ (microcarcinoma in situ, confirmado por dosagem de calcitonina e biópsia do nódulo) até $9,0 \mathrm{~cm}$. Durante os 10 últimos anos (2002-2012), todos os pacientes desta família os quais foram operados com até 12 anos de idade, por meio de tireoidectomia total associada à limpeza ganglionar cervical, apresentam-se atualmente bioquimicamente curados (níveis séricos de calcitonina basal $<2 \mathrm{pg} / \mathrm{mL}$ ). Dados clínicos adicionais desta família foram previamente publicados parcialmente (Frank-Raue et al., 2010).

Os indivíduos desta família são originários de zonas rurais e urbanas de diferentes municípios próximos à cidade de Arapiraca, Estado de Alagoas. Vários deles migraram para a cidade de São Paulo ou regiões da Grande São Paulo, e um destes pacientes foi o primeiro a procurar 0 Hospital das Clínicas, tendo-se tornado o caso-índice desta família. 
A média de idade dos indivíduos submetidos á tireoidectomia total foi de $22 \pm 17$ anos, variando entre 2 e 84 anos. Exceto o caso 11 que foi submetido à tireoidectomia total preventiva aos 2 anos de idade, todos os outros pacientes já apresentavam CMT, documentado por exames prévios à cirurgia (biópsia de tireoide, dosagem de calcitonina) ou pelo exame anatomopatológico. Os resultados patológicos mostraram que o caso 11 apresentava somente hiperplasia das células C (HCC); o CMT era unicêntrico em um paciente (caso 28) (Tabela 9). O tamanho do CMT à patologia e/ou ultrassonografia variou entre $0,1 \mathrm{~cm}$ (caso 28) e 9,0 cm (caso 19). O estadiamento do CMT variou de I ao IVc. A classificação TNM variou de T0N0M0 a T4N1M1 (caso 22), sendo que neste último caso a paciente apresentava metástases do CMT em fígado e baço (não analisados nesse estudo).

Os valores pré-cirúrgicos de calcitonina variaram de indetectável até mais de $144.497,0 \mathrm{pg} / \mathrm{mL}$ (caso 25). Valores de calcitonina pós-cirúrgicos abaixo de 2,0 pg/mL são muito majoritariamente (mas não obrigatoriamente) relacionados à "cura bioquímica" e esta condição estava presente em vários dos casos aqui analisados. Em geral, nesta família, os pacientes tireoidectomizados com até 12 anos de idade não apresentaram qualquer tipo de recidiva.

O óbito devido ao CMT ocorreu no caso 1, aos 34 anos; caso 19, aos 84 anos; e caso 22 aos 35 anos de idade. Recidiva tumoral ocorreu em 14 pacientes. Nenhum dos 28 casos estudados apresentava hiperparatireoidismo. O Feocromocitoma estava presente em somente um paciente desta família, e era unilateral (caso 22). 
Tabela 9 - Dados clínicos da família de Arapiraca com NEM2A/CMT-F e mutação germinativa C620R no gene RET

\begin{tabular}{|c|c|c|c|c|c|c|c|c|c|c|c|c|c|c|}
\hline \multicolumn{3}{|c|}{ Paciente } & \multicolumn{8}{|c|}{ CMT } & \multicolumn{2}{|r|}{ FEO } & \multirow[b]{2}{*}{ Megacólon*** } & \multirow{2}{*}{$\begin{array}{l}\text { Óbito/idade } \\
\text { (anos) }\end{array}$} \\
\hline Caso $n^{\circ}$ & Sexo & $\begin{array}{l}\text { Id diag } \\
\text { (anos) }\end{array}$ & Tumor & Pirúrgia & $\mathrm{HCC}^{*}$ & $\begin{array}{l}\text { Calcitonina pós- } \\
\text { cirurgia (última) }\end{array}$ & TNM $^{* *}$ & Estágio"\# & $\begin{array}{l}\text { Metástase após } \\
\text { cirúrgia }\end{array}$ & Curado & Tumor & $\begin{array}{l}\text { Id diag/exclusão } \\
\text { (anos) }\end{array}$ & & \\
\hline 1 & $\mathrm{~F}$ & 8 & $S$ & $S$ & $\mathrm{~S}$ & 10,2 & T1N0M0 & 2 & $\mathrm{~N}$ & $S$ & $\mathrm{~N}$ & 8 & $\mathrm{~N}$ & $\mathrm{~N}$ \\
\hline 2 & $\mathrm{~F}$ & 16 & $S$ & $S$ & $S$ & $<2,0$ & T1N0M0 & 2 & $\mathrm{~N}$ & $S$ & $\mathrm{~N}$ & 15 & $\mathrm{~N}$ & $\mathrm{~N}$ \\
\hline 3 & $\mathrm{~F}$ & 37 & $S$ & $S$ & $S$ & $<2,0$ & T1N1M0 & 3 & $S$ & $\mathrm{~N}$ & $\mathrm{~N}$ & 55 & $\mathrm{~N}$ & $\mathrm{~N}$ \\
\hline 4 & $\mathrm{~F}$ & 50 & $S$ & $\mathrm{~N}$ & $S$ & sem info & TONOMO & 1 & $\mathrm{~N}$ & $\mathrm{~N}$ & $\mathrm{~N}$ & 59 & $\mathrm{~N}$ & $\mathrm{~N}$ \\
\hline 5 & $\mathrm{M}$ & 23 & $S$ & $S$ & S & $<2,0$ & T1N1M0 & 3 & $\mathrm{~N}$ & $S$ & $\mathrm{~N}$ & 22 & $S$ & $\mathrm{~N}$ \\
\hline 6 & M & 13 & $S$ & $S$ & $S$ & $<2,0$ & T1N1M0 & 2 & $\mathrm{~N}$ & $S$ & $\mathrm{~N}$ & sem info & $\mathrm{N}$ & $\mathrm{N}$ \\
\hline 8 & M & 26 & $S$ & $S$ & $S$ & 458,0 & T3N1M1 & 4 & $S$ & $\mathrm{~N}$ & $\mathrm{~N}$ & 25 & $\mathrm{~N}$ & CMT/34 \\
\hline 9 & $\mathrm{~F}$ & 19 & $S$ & $S$ & $S$ & 291,0 & T1N1M0 & 3 & $S$ & $\mathrm{~N}$ & $\mathrm{~N}$ & 30 & $\mathrm{~N}$ & $\mathrm{~N}$ \\
\hline 10 & $\mathrm{~F}$ & 34 & $S$ & $S$ & $S$ & 1821,0 & T3N1M1 & 4 & $S$ & & $\mathrm{~N}$ & 50 & $\mathrm{~N}$ & $\mathrm{~N}$ \\
\hline 11 & $M$ & 2 & $\mathrm{~N}$ & $\mathrm{~N}$ & $S$ & 16,7 & TONOMO & 1 & $\mathrm{~N}$ & $\mathrm{~s}$ & $\mathrm{~N}$ & 4 & $S$ & $\mathrm{~N}$ \\
\hline 12 & $M$ & 8 & $S$ & $S$ & $S$ & $<2,0$ & T1N0M0 & 2 & $\mathrm{~N}$ & $S$ & $\mathrm{~N}$ & 8 & $\mathrm{~N}$ & $\mathrm{~N}$ \\
\hline 13 & $\mathrm{~F}$ & 11 & $S$ & $S$ & $S$ & $<2,0$ & T1N0M0 & 2 & $\mathrm{~N}$ & $S$ & $\mathrm{~N}$ & 12 & $\mathrm{~N}$ & $\mathrm{~N}$ \\
\hline 14 & $\mathrm{~F}$ & 14 & $S$ & $S$ & $S$ & $<2,0$ & T1N0M0 & 2 & $\mathrm{~N}$ & $S$ & $\mathrm{~N}$ & 14 & $S$ & $\mathrm{~N}$ \\
\hline 15 & $M$ & 5 & $\mathrm{~N}$ & $S$ & $\mathrm{~N}$ & $<2,0$ & TONOMO & 1 & $\mathrm{~N}$ & $S$ & $\mathrm{~N}$ & 7 & $\mathrm{~S}$ & $\mathrm{~N}$ \\
\hline 16 & $M$ & 8 & $\mathrm{~N}$ & $S$ & $S$ & $<2,0$ & TONOMO & 1 & $\mathrm{~N}$ & $S$ & $\mathrm{~N}$ & 8 & $\mathrm{~N}$ & $\mathrm{~N}$ \\
\hline 18 & $\mathrm{~F}$ & 18 & $\mathrm{~S}$ & $\mathrm{~S}$ & $\mathrm{~S}$ & sem info & T2N1M0 & 2 & $\mathrm{~N}$ & $\mathrm{~S}$ & $\mathrm{~N}$ & 17 & $\mathrm{~N}$ & $\mathrm{~N}$ \\
\hline 19 & $\mathrm{~F}$ & 84 & $S$ & $\mathrm{~N}$ & $S$ & 402,0 & T3N2M1 & 3 & $\mathrm{~N}$ & $\mathrm{~N}$ & $\mathrm{~N}$ & 84 & $\mathrm{~N}$ & Pneumonia/84 \\
\hline 20 & $\mathrm{~F}$ & 10 & $S$ & $S$ & $S$ & $<2,0$ & T1N0MO & 2 & $\mathrm{~N}$ & $\mathrm{~N}$ & $\mathrm{~N}$ & sem info & $\mathrm{N}$ & $\mathrm{N}$ \\
\hline 21 & $M$ & 28 & $S$ & $S$ & $S$ & 7,1 & T1N0M0 & 2 & $\mathrm{~N}$ & $S$ & $\mathrm{~N}$ & sem info & $\mathrm{N}$ & $\mathrm{N}$ \\
\hline 22 & $\mathrm{~F}$ & 27 & $S$ & $S$ & $S$ & sem info & T4aN1M1 & 4 & $S$ & $\mathrm{~N}$ & $S$ & 27 & $\mathrm{~N}$ & CMT/35 \\
\hline 23 & $\mathrm{~F}$ & 25 & $S$ & $S$ & $S$ & 27,6 & T1N0M0 & 2 & $\mathrm{~N}$ & $\mathrm{~N}$ & $\mathrm{~N}$ & 25 & $\mathrm{~N}$ & $\mathrm{~N}$ \\
\hline 24 & $\mathrm{~F}$ & 25 & $S$ & $S$ & $S$ & 144497,0 & T3N1M1 & 4 & $S$ & $\mathrm{~N}$ & $\mathrm{~N}$ & 38 & $\mathrm{~N}$ & $\mathrm{~N}$ \\
\hline 25 & $\mathrm{~F}$ & 22 & $S$ & $S$ & $S$ & 82353,0 & T3N1M1 & 4 & $S$ & $\mathrm{~N}$ & $\mathrm{~N}$ & 35 & $\mathrm{~N}$ & $\mathrm{~N}$ \\
\hline 26 & $\mathrm{~F}$ & 21 & $\mathrm{~S}$ & $S$ & $\mathrm{~S}$ & 15,7 & T1N1M0 & 3 & $S$ & $\mathrm{~N}$ & $\mathrm{~N}$ & 33 & $\mathrm{~N}$ & $\mathrm{~N}$ \\
\hline 27 & $\mathrm{~F}$ & 16 & $S$ & $S$ & $S$ & $<2,0$ & T1N0M0 & 2 & $\mathrm{~N}$ & $S$ & $\mathrm{~N}$ & 23 & $\mathrm{~N}$ & $\mathrm{~N}$ \\
\hline 28 & $M$ & 8 & $S$ & $S$ & $S$ & $<2,0$ & T1NOMO & 2 & $\mathrm{~N}$ & $S$ & $\mathrm{~N}$ & 8 & $S$ & $\mathrm{~N}$ \\
\hline
\end{tabular}

F, feminino; M, masculino; Id diag, idade ao diagnóstico; *HCC, Hiperplasia de células C; S, sim; N, não; **TNM, estadiamento do CMT (Sobin, 2010); ***Megacólon

${ }^{\text {\# }}$ Calcitonina, referência: homens, $<8,4 \mathrm{pg} / \mathrm{mL} /$ mulheres, $<5,0 \mathrm{pg} / \mathrm{mL}$ (Método: imunoquimioluminométrico, Immulite - USA, CA).

\#\# Estágio: 1, somente HCC; 2, CMT sem metástase em linfonodo; 3, CMT com metástase em linfonodo, sem metástases à distância; 4 , CMT com metástases à distância. 


\section{MÉTODOS}


Os processos de extração de DNA, PCR e sequenciamento foram realizados no laboratório de Endocrinologia Genética/LIM-25 do Hospital das Clínicas, Faculdade de Medicina da Universidade de São Paulo, HCFMUSP.

As análises de Western blot (WB) foram realizadas em colaboração com o Instituto de Biociências da USP (IB-USP).

Os ensaios de imunuhistoqúimica (IHQ) foram executados em colaboração com a Dra. Sheila A. Coelho Siqueira do Laboratório de Patologia do HC-FMUSP (LIM-14).

Os dados clínicos e exames bioquímicos dos pacientes foram obtidos dos prontuários médicos e de consultas, por meio do banco de dados do sistema Intranet do HC-FMUSP.

\subsection{Extração de DNA}

\subsubsection{Sangue Total}

A extração de DNA genômico de leucócitos do sangue periférico foi realizada pela técnica de Salting-out (Miller, 1988) e/ou pelo kit comercial QIAamp DNA Mini (QIAgen, Hilden, Alemanha), seguindo instruções descritas pelo protocolo do fabricante. 


\subsubsection{Tumor}

A seleção da região tumoral para extração de DNA foi realizada através da análise histológica prévia do fragmento cirúrgico. Foi realizado um corte de aproximadamente $3 \mu \mathrm{M}$ no fragmento tumoral com auxílio de um micrótomo. Em seguida o tecido foi corado com hematoxilina-eosina e analisado ao microscópio.

Cerca de $2 \mathrm{mg}$ do tecido tumoral foram seccionadas e fragmentadas com auxílio de nitrogênio líquido e maceração com pistilo. Após isto, o macerado foi submetido à extração de DNA utilizando o kit DNeasy® Tissue (QIAgen, Hilden, Alemanha) seguindo instruções descritas pelo protocolo do fabricante.

As verificações da concentração e qualidade do DNA extraído de sangue e tumor foram realizadas por espectrofotometria utilizando 0 equipamento NanoDrop (Thermo Scientific, USA). A análise da qualidade do DNA extraído foi baseada no resultado da relação das leituras de absorbância $A_{260} / A_{280}$, sendo considerados valores de DNA em torno de 1.8 como qualidade aceitável.

\subsection{Rastreamento de mutação e/ou variantes polimórficas nos genes p15, p18 e p27}

O rastreamento de mutações e/ou variantes polimórficas foi realizado pelas técnicas de Reação em Cadeia da Polimerase (PCR), seguido pelo sequenciamento direto de DNA. 
Os oligonucleotídeos iniciadores (primers) utilizados para PCR foram obtidos com auxílio do programa Primer3 v4.0 (http://frodo.wi.mit.edu/). As sequências dos iniciadores (primers) e os tamanhos dos produtos amplificados na reação de PCR estão descritos na tabela 10.

Tabela 10 - Sequências dos primers e tamanhos dos produtos amplificados para os genes $p 15, p 18$ e $p 27$

\begin{tabular}{|c|c|c|c|c|}
\hline \multirow{2}{*}{ Gene } & \multirow{2}{*}{ Éxon* } & \multicolumn{2}{|c|}{ Sentido $5^{\prime}\left(3^{\prime}\right)$} & \multirow{2}{*}{$\begin{array}{c}\text { Tamanho } \\
(\mathrm{pb})\end{array}$} \\
\hline & & Senso & Reverso & \\
\hline \multirow{2}{*}{ p15 } & 2 & TGGGAAAGAAGGGAAGAGTG & TTTGCTGGGTAAAAGCCTGT & 399 \\
\hline & 3 & CGGCATCTCCCATACCTG & GGGTGGGAAATTGGGTAAGA & 374 \\
\hline \multirow{2}{*}{ p18 } & 2 & GCAAAGGAAAGGGGAAAAAG & GGGTCACGTAGGCAACATTA & 248 \\
\hline & 3 & TGCACTTGAAGGATTCTACCAT & AGGGAAAAGCCAAGGAAAGA & 680 \\
\hline \multirow{2}{*}{ p27 } & 2 & GTCGGGGTCTGTGTCTTTTG & AGGGAAAAGCCAAGGAAAGA & 762 \\
\hline & 3 & CTGACTATGGGGCCAACTTC & GCCAGCAACCAGTAAGATCAG & 294 \\
\hline
\end{tabular}

*Éxon 1 não é codificante para os três genes. $\mathrm{pb}$, pares de bases

\subsection{Análise somática de RET nos tumores NEM2}

Foi realizada a verificação da possível ocorrência de um segundo evento somático no éxon específico do gene RET dos tumores NEM2 do estudo. Foi analisada somente a amplificação do éxon específico em que o paciente apresentava a mutação germinativa no gene RET. As sequências dos primers utilizados para amplificação dos éxons hotspots estão descritas na tabela 11. 
Tabela 11 - Sequências dos primers e tamanhos dos produtos amplificados para os exon $10,11,13,14$ e 16 do gene RET

\begin{tabular}{|c|c|c|c|}
\hline \multirow{2}{*}{ Éxon } & \multicolumn{2}{|c|}{ Sentido $5^{\prime} \rightarrow 3^{\prime}$} & \multirow{2}{*}{$\begin{array}{c}\text { Tamanho } \\
\text { (pb) }\end{array}$} \\
\hline & Senso & Reverso & \\
\hline 10 & AGGCTGAGTGGGCTACGTCTG & GTTGAGACCTCTGTGGGGCT & 204 \\
\hline 11 & ATGAGGCAGAGCATACGCAGCC & CTTGAAGGCATCCACGGAGACC & 336 \\
\hline 13 & ATGAGGCAGAGCATACGCAGCC & AGAACAGGGCTGTATGGAGC & 277 \\
\hline 14 & ATGAGGCAGAGCATACGCAGCC & CATATGCACGCACCTTCATC & 294 \\
\hline 16 & CTGAAAGCTCAGGGATAGGG & GGCATGGGACTAGCAAGGGTG & 458 \\
\hline
\end{tabular}

$\mathrm{pb}$, pares de bases

\subsection{Reação em Cadeia da Polimerase - PCR}

Foi padronizado um único protocolo para PCR para amplificação do produto de todos os genes analisados no presente estudo. Este protocolo apresentou as seguintes condições em um volume final de $25 \mu$ de reação: 1X PCR Buffer (200 mM Tris pH 8.4, $500 \mathrm{mM} \mathrm{KCl}$ ), 2,0 mM MgCl $2,0,2 \mathrm{mM}$ de cada dNTP's, 5 pmol de cada oligonucleotídeo iniciador (senso e reverso), $1 \cup$ da enzima Taq DNA Polymerase Recombinant (Invitrogen, São Paulo) e 20-50 ng de DNA (conforme tamanha do amplicon). A amplificação foi realizada no termociclador modelo PTC-200 (MJ Research), utilizando os seguintes parâmetros de termociclagem: $95{ }^{\circ} \mathrm{C} 5$ min (denaturação inicial), seguido de 35 ciclos apresentando às seguintes condições: $95{ }^{\circ} \mathrm{C} 20$ seg, $60{ }^{\circ} \mathrm{C} 20$ seg e $72{ }^{\circ} \mathrm{C} 30$ seg; e $72{ }^{\circ} \mathrm{C} 10$ min para uma extensão final da fita do DNA. 
A detecção do produto amplificado na PCR foi realizada por eletroforese em gel de agarose $2 \%$ utilizando como marcador de amplificação o reagente Blue Green Loading Dye 1 (LGC Biotecnologia, USA). Como padrão de peso molecular foi utilizado o reagente 100 bp DNA ladder (Invitrogen, USA). Os parâmetros de eletroforese foram 120 Volts por 40 min. A verificação foi realizada no transluminador sobre luz ultravioleta (UV).

\subsection{Purificação e quantificação do produto amplificado}

Para retirada de resíduos e/ou produtos não incorporados na reação de PCR (sais, proteínas, primers), foi realizado processo de purificação utilizando o kit PureLink ${ }^{\mathrm{TM}}$ PCR Purification kit (Invitrogen, USA) e/ou a enzima ExoSAP-IT ${ }^{\circledR}$ (USB, Ohio), seguindo instruções descritas nos protocolos dos fabricantes.

A verificação da concentração aproximada do DNA purificado foi realizada em gel de agarose $2 \%$ utilizando como padrão de quantificação o reagente Low DNA Mass ${ }^{\mathrm{TM}}$ Ladder (Invitrogen, USA). Foram aplicados $4 \mu \mathrm{l}$ do padrão e $4 \mu$ do produto de PCR purificado. Os parâmetros de eletroforese foram 120 Volts por $40 \mathrm{~min}$. A verificação foi realizada no transluminador sobre luz ultravioleta (UV).

A quantidade de produto amplificado foi estimada através da comparação da intensidade da banda da amostra com a de cada uma das bandas do padrão de quantificação. 


\subsection{Reação de Sequenciamento}

O sequenciamento direto dos produtos amplificados foi realizado pela tecnologia fluorescente utilizando o reagente BigDye ${ }^{\circledR}$ Terminator Cycle Sequencing v3.1 (Applied Biosystems, Foster City, CA), usando os mesmos primers da PCR descritos na tabela 10 e 11. O protocolo padronizado apresentou as seguintes concentrações finais em $10 \mu \mathrm{l}$ de volume final de reação: 1X Sequencing Buffer, 1:16 mix BigDye terminator, 5 pmol de primer e 15-20 ng DNA. A concentração de DNA foi adequada conforme o tamanho do produto de PCR a ser sequenciado. O programa de termociclagem apresentou às seguintes condições: 25 ciclos: $95{ }^{\circ} \mathrm{C} 10 \mathrm{seg}, 50{ }^{\circ} \mathrm{C} 10 \mathrm{seg} \mathrm{e}$ $60{ }^{\circ} \mathrm{C} 1 \mathrm{~min}$.

As fitas senso e reverso foram analisadas em todos os casos.

\subsection{Purificação do produto da reação de sequenciamento}

Para retirada de resíduos (sal, proteínas) e principalmente produtos não incorporados durante a reação (primers, ddNTP's), foi realizada purificação através do processo de precipitação alcoólica Para isto, utilizouse o protocolo Etanol Absoluto/Acetato de sódio (3M)/ EDTA (125 mM), conforme protocolo padronizado pelo nosso laboratório.

Após precipitação, o pellet seco, foi ressuspendido em $10 \mu \mathrm{l}$ do reagente Hi-Di Formamide (Applied Biosystems, USA), denaturado a $95^{\circ} \mathrm{C}$ por 3 min e gelo 5 min, e em seguida submetido à eletroforese capilar no 
equipamento ABI3130xI Genetic Analyzer (Applied Biosystems, USA), seguindo instruções descritas pelo fabricante.

\subsection{Análise das sequências}

A análise das sequências foi realizada com auxílio do software Mutation Surveyor $\circledast$ DNA Variant Software v3.30 (SoftGenetic, State College PA, USA). Foi realizada comparação do consenso formado entres as fitas senso e reverso de cada amostra com a sequência-referência especifica de cada gene em estudo, a qual foi obtida no banco de dados do NCBI (http://www.ncbi.nlm.nih.gov/gene). As sequências-referências utilizadas nas análises dos genes do presente estudo estão descritas na tabela 12.

As amostras que apresentaram variantes genéticas em relação à referência foram repetidas em duplicata, utilizando-se para isto uma nova extração de DNA.

Tabela 12 - Sequências referências utilizadas nas análises do sequenciamento direto dos genes p27, p18, p15 e RET

\begin{tabular}{cc}
\hline Gene & Referência \\
\hline$C D K N 1 B / p 27^{\text {Kip1 }}$ & NM004064 \\
$C D K N 2 C / p 18^{I N K 4 C}$ & NM078826 \\
$C D K N 2 B / p 15$ & NM078487 \\
$R E T$ & NM020975.4 \\
\hline
\end{tabular}




\subsection{Análise dos polimorfismos p.V109G no gene p27 por PCR-RFLP e c.-79C>T por sequenciamento - Grupo controle}

A genotipagem dos polimorfismos $p . V 109 \mathrm{G}$ no gene $p 27$ foi realizada por amplificação do éxon 1 , seguida de digestão por enzima de restrição (PCR-RFLP - Restriction Fragment Lengh Polymorphism). O protocolo de PCR utilizado foi o mesmo já previamente descrito. A digestão do produto amplificado foi realizada com a enzima Bgll (Fermentas Life Science, Canadá), que apresenta a propriedade de digerir regiões do DNA que apresentam as sequências descritas abaixo:

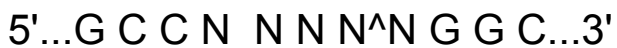 \\ $3^{\prime} \ldots$... G G N^N N N N C C G...5'}

O protocolo para reação de digestão do produto de PCR apresentou as seguintes condições, em um volume final de $20 \mu \mathrm{l}$ : 1X Buffer $\mathrm{O}(50 \mathrm{mM}$ Tris- $\mathrm{HCl}-\mathrm{pH}$ 7.5, $10 \mathrm{mM} \mathrm{MgCl} 2,100 \mathrm{mM} \mathrm{NaCl}, 0.1 \mathrm{mg} / \mathrm{mL} \mathrm{BSA}$ ), $1 \mathrm{U}$ enzima Bgll e 100 - 200 ng de DNA. O processo de clivagem ocorreu a uma temperatura $37^{\circ} \mathrm{C}$ por um período de 3 horas. Para inativação de resíduos de $B g l l$ foi realizada uma incubação a $65^{\circ} \mathrm{C}$ por 20 minutos.

A deteç̧ão do produto digerido foi realizada por eletroforese em gel de agarose na concentração de $3 \%$. Foram utilizados $10 \mu \mathrm{l}$ do produto de digestão, que foram ressuspendidos em $1 \mu \mathrm{l}$ do marcador e carreador BlueGreen I (LGC, Brasil). Foi utilizado como marcador de peso molecular o reagente 100 bp DNA ladder (Invitrogen, USA). Os parâmetros de eletroforese utilizados foram: 80 Volts por 3 horas. 
A validação do método de genotipagem por PCR-RFLP do SNP p.V109G foi realizada comparando-se os resultados de 100 amostras que foram executadas pelo método de sequenciamento direto.

A análise do polimorfismo c.-79C>T localizada na região intrônica foi realizada em 133 amostras de DNA de indivíduos-controles por sequenciamento direto, utilizando-se os primers descritos na tabela 10.

\subsection{Análise in silico}

Foi realizado estudo in silico, por meio de programas computacionais, de todas as variantes polimórficas encontradas nas regiões codificadoras.

Estes programas preditivos avaliam através de diferentes algoritmos as características físico-químicas, conservação dos aminoácidos entre as diferentes espécies animais e predizem o grau de impacto biológico (patogenicidade). A tabela 13 mostra os programas utilizados nesse estudo.

As alterações encontradas em regiões intrônicas de splicing do DNA foram avaliadas pelos programas computacionais GENSCAN (http://genes.mit.edu/GENSCAN.html) e Berkeley Drosophila Genome Project - BDGP (http://www.fruitfly.org/seq_tools/splice.html). 
Tabela 13 - Programas preditivos de computador utilizados para análise in silico das regiões codificadoras

\begin{tabular}{ll}
\hline Programa & \multicolumn{1}{c}{ Referência } \\
\hline PolyPhen-2 & http://genetics.bwh.harvard.edu/pph2/ \\
PANTHER & http://www.pantherdb.org/ \\
SIFT & http://sift.jcvi.org/ \\
Align GVGD & http://agvgd.iarc.fr/ \\
Pmut & http://mmb.pcb.ub.es/PMut/ \\
FastSNP & http://fastsnp.ibms.sinica.edu.tw/ \\
SNAP & http://www.rostlab.org/services/snap/ \\
MutPred & http://mutpred.mutdb.org/ \\
\hline
\end{tabular}

\subsection{Análise de microssatélites do gene p27}

A análise de outros possíveis eventos genéticos somáticos de p27 (perda de heterozigose - LOH e/ou instabilidade de microssatélites) foi realizada. Para isto, foram usados marcadores de microssatélites flanqueadores por amplificação via PCR, utilizando-se o primer senso com marcação fluorescente 6-FAM na posição $5^{\prime}$. A tabela 14 apresenta os marcadores, sequências dos primers e possíveis tamanhos dos produtos amplificados.

A LOH foi realizada somente em casos em que havia disponibilidade de amostras pareadas de sangue e do tumor de um mesmo paciente. Amostras com alelo em homozigose no sangue não foram analisadas por não serem informativas. Os marcadores que se mostraram informativos de 
cada um dos tumores foram posteriormente analisados quanto à perda de heterozigose.

O software GeneMarker a v2.2.0 (SoftGenetics, USA) foi utilizado para determinar os valores de altura e área dos picos representativos dos alelos.

Foi considerado como perda de heterozigose um valor $\leq 0,6$, indicando que a amostra tumoral apresentava significativa perda do alelo de maior tamanho, enquanto que um valor de $\mathrm{LOH} \geq 1,6$ indica a perda do alelo de menor tamanho no tumor. Foram consideradas como apresentando LOH apenas as amostras com valores que puderam ser incluídas em ambos os parâmetros citados acima. Todas as amostras que apresentavam provável LOH foram repetidas por meio de uma nova reação de amplificação.

A ausência e/ou diminuição do sinal fluorescente no tumor de algum alelo que foi encontrado no sangue, foi considerada compatível com perda somática do alelo normal (LOH) no gene em estudo.

Tabela 14 - Sequência dos marcadores de microssatélites utilizados para análise de LOH do gene p27 locus 12p13

\begin{tabular}{|c|c|c|c|c|}
\hline \multirow{2}{*}{ Marcador } & \multicolumn{2}{|c|}{ Sentido $5^{\prime} \rightarrow 3^{\prime}$} & \multirow{2}{*}{ Localização no cromossomo } & \multirow{2}{*}{ Tamanho (pb } \\
\hline & Senso* & Reverso & & \\
\hline D12S358 & CCACATGCCAATAATTTCAGC & G GCACAACAAAGTATGGCACAG & 12.639.351-12.639.498 & 148 \\
\hline D12S391 & AACAGGATCAATGGATGCAT & AGCTTGCAGATGGACTGTCA & $12.449 .931-12.450 .106$ & 176 \\
\hline D12S1580 & CTGTCTTTAGGATGTTGGCA & TCAGTTCTCAGGGACTTGTG & 13.348.001-13.348.172 & 172 \\
\hline
\end{tabular}




\subsection{Análise de expressão proteica de p27 e Skp2}

Foi realizada análise de expressão proteica por Western blot de p27 e também de Skp2, que é uma das proteínas que promove a proteólise de p27.

\subsubsection{Extração de proteína e análise de Western blot para p27}

Estavam disponíveis para o estudo 20 tecidos tumorais, sendo 10 CMT (casos 13, 16, 21, 23, 24, 29 e 35) e 10 FEO (casos 10, 14, 19, 28 e 33) e 2 tecidos tireoidianos com histologia normal, que foram utilizados como amostras calibradoras controle.

Nos CMTs, o número de tumores e a respectiva mutação RET foram: 4 tumores com mutação C620R, 4 com C634R, e 2 com C634Y/Y791F. Quanto aos FEOs, os achados foram: 5 com C620R, 3 com C634R e 2 com C634Y/Y791F.

Cada tumor e tecido-controle foram analisados em duplicata. $\mathrm{O}$ controle endógeno da reação foi o gene da $\beta$-actina e a amostra calibradora, utilizada para comparação dos resultados foram os tecidos normais.

Os anticorpos primários utilizados foram anti-p27 policlonal M-197 (Santa Cruz, CA, USA) diluído a 1:300, anticorpo monoclonal $\beta$-actina diluído

a 1:250 (Santa Cruz, CA, USA) e anticorpo monoclonal anti- Skp2 diluído a 1:10 (Zymed, USA). 


\subsubsection{Extração da proteína p27}

Cerca de $2 \mathrm{mg}$ do tecido tumoral foram utilizados para extração de proteína total. Cada fragmento tumoral, ainda mantido em gelo, foi triturado manualmente em almofariz e pistilo de vidro. Em seguida, adicionou-se solução NP40 para lise celular (Invitrogen, USA) e mantidas no gelo por 30 min, realizando homogeneização no vórtex a cada $10 \mathrm{~min}$. Em seguida, o lisado proteico foi centrifugado a $13000 \mathrm{rpm}$ por $10 \mathrm{~min}$ e o sobrenadante foi transferido para um novo tubo.

A concentração proteica foi determinada usando o ensaio BCA Protein Assay (Thermo Scientific, USA).

\subsubsection{Western blot (WB)}

Aproximadamente $20 \mu \mathrm{g}$ de produto extraído foram separados em gel $15 \%$ SDS-PAGE por $2 \mathrm{~h}$ e transferidos para uma membrana de nitrocelulose (Hybond, GE Healthcare).

A membrana foi lavada em solução de tampão Tris-Salino contendo 0,1\% de Tween 20 (TTBS), em seguida foi incubada a temperatura ambiente e sobre agitação (3000 rpm) em solução de leite em pó $5 \%$ com tampão TTBS para bloqueio dos sítios inespecíficos de ligação ao anticorpo.

A membrana foi então incubada overnight, sob agitação (3000 rpm) e refrigeração com solução de leite em pó $5 \%$ e o anticorpo primário. Após lavagens (duas com tampão Tris-salino e duas com TTBS por $5 \mathrm{~min}$ ), a 
membrana foi incubada por 60 min em solução de leite em pó $5 \%$ com anticorpo secundário policlonal diluído a 1:1000. Após incubação, as lavagens foram repetidas e as bandas das proteínas foram detectadas por reação quimioluminescente, pelo sistema ECL Western blotting Detection Reagents (GE healthcare, UK), seguida pela exposição em filme de raio-X.

Os dados numéricos foram obtidos por densitometria, utilizando o software gratuito ImageJ $1.42 q$ (http://rsbweb.nih.gov/ij/) (NIH, Bethesda, Maryland).

A quantificação de p27 e Skp2 foi realizada através da análise de quantificação relativa. Realizou-se o cálculo da média e dos desvios padrões dos valores das densidades óticas (DO) das triplicatas das amostras tumorais e dos tecidos controles para p27, Skp2 e $\beta$-actina. O valor médio da DO de p27 e Skp2 foram divididos pela média da DO do controle endógeno $\beta$-actina. Em seguida, esse valor foi divido pelo valor da expressão relativa da amostra calibradora (média das DO dos tecidos normais).

\subsection{Imunohistoquímica (IHQ)}

No presente estudo, foram analisados 19 tumores em blocos parafinados, sendo que 15 eram de pacientes com CMT (casos 3, 4, 8, 15, $17,20,22,23,26,27,29,30,31,33$ e 35$)$ e quatro eram de pacientes com FEO (casos 4, 9, 16, e 29). Nos casos 4 e 29 foi possível a análise de ambos 
os tumores, CMT e FEO. Foram incluídas, como controles, duas biópsias de tecido tireoidiano normal e uma biópsia de tecido de pele.

Lâminas não coradas foram submetidas ao processo de desparafinização conforme o procedimento a seguir: colocar em estufa a $60{ }^{\circ} \mathrm{C}$ por $20 \mathrm{~min}$, secar em temperatura ambiente por $5 \mathrm{~min}$; desparafinizadas e reidratadas por três processos de incubação com soluções de xilol e etanol $100 \%$, o que foi seguido por duas lavagens com solução de etanol $80 \%$. Após esse processo, as lâminas foram lavadas por três vezes com água deionizada e transferidas para uma solução de tampão Tris-salino. Para bloqueio da reação, as lâminas foram transferidas para uma solução de $3 \%$ de peróxido de hidrogênio e incubadas por $5 \mathrm{~min}$, e em seguida tratadas com solução aquecida de solução de citrato $10 \mathrm{mM} \mathrm{pH} \mathrm{6,0}$ por 45 min e resfriadas por 20 min.

As lâminas foram incubadas por 60 min em solução contendo anticorpo monoclonal anti-p27 (Santa Cruz, CA, USA) diluído 1:300. Em seguida, foram realizados três processos de lavagens com água deionizada e as laminas foram transferidas para uma solução de tampão TBS. O anticorpo secundário foi adicionado e incubado por $30 \mathrm{~min}$, seguindo-se três lavagens com água deionizada e mantidas em solução de TBS.

Para coloração, foi aplicada solução de diaminobenzina (DAB) (Ventana, USA) e a seguir incubou-se por 8 min a temperatura ambiente. Esse reagente é um cromógeno que produz uma cor marrom quando precipitado e pode ser visualizado com a luz do microscópio. E por fim, as 
lâminas foram coradas com solução de hematoxilina-eosina para visualização do núcleo e citoplasma.

A análise das lâminas foi realizada por meio de duplo-cego e os resultados discordantes foram reavaliados por um terceiro médico patologista, especialista na área. As amostras foram inicialmente analisadas a baixa resolução $(5 x)$ para localização da área tumoral, e depois por alta resolução (20x) usando-se microscópio Olympus BX61. Os critérios para análise foram os seguintes: número de células no campo de análise, descritas em porcentagem aproximada, que está com marcação de p27 nuclear; localização celular de p27 (citoplasma, núcleo ou a combinação de ambos) e intensidade da marcação (ausente, baixo, médio e alto). Todas as amostras foram realizadas em duplicata.

Para amostras tumorais com HCC ou microcarcinoma, foi utilizada como guia, para localização da área tumoral, outra lâmina contendo marcação imunohistoquímica para calcitonina.

\subsection{Análise Estatística}

As análises estatísticas foram realizadas com auxílio do programa SPSS v20.0 para Windows (SPSS, Inc., Chicago, USA). Os diferentes testes estatísticos foram aqui aplicados considerando-se vários fatores, como tamanho da amostra e tipo de distribuição dos dados obtidos.

A cura e recidiva da doença CMT foram descritas utilizando-se de parâmetros clínico-patológicos e bioquímicos estabelecidos. Os genótipos 
para os SNPs encontrados no gene p27 e mutações no RET foram expressos por meio de uso de frequências absolutas e relativas. As idades dos pacientes ao exame médico inicial e as idades em que estes pacientes foram submetidos à tireoidectomia total, foram analisadas e descritas segundo prognósticos com uso de médias e desvios padrões (Kirkwood e Sterne, 2006).

A verificação da existência de possíveis associações entre as características qualitativas nominais e os prognósticos foi realizada por intermédio do uso de teste do $\chi 2$ ou teste exato de Fisher ou ainda por meio de testes da razão de verossimilhanças. Esses dois últimos testes foram aplicados devido ao número limitado de pacientes pertencentes a presente amostra (Kirkwood e Sterne, 2006).

As variáveis qualitativas ordinais foram comparadas segundo prognóstico por meio do teste de Mann-Whitney (Kirkwood e Sterne, 2006). As variáveis quantitativas foram testadas por meio de regressão logística simples.

Os valores calculados dos odds ratios (OR) foram apresentados com os respectivos intervalos com $95 \%$ de confiança (Hosmer e Lemeshow, 2000), para estimar as possíveis associações das características analisadas com os prognósticos.

Os mesmos testes citados acima foram também aplicados para verificar possíveis associações comparativas entre as características tumorais e clínicas dos pacientes e também entre os diferentes tipos de mutações genéticas. Estas últimas avaliações foram realizadas tanto para 
todos os pacientes em seu conjunto, como para os pacientes pertencentes a uma mesma família.

O Test t de Student foi aplicado para comparar as diferenças entre os grupos de estudo na análise de expressão relativa para p27 e Skp2.

Os resultados foram considerados estatisticamente significantes para os valores de $p \leq 0,05$ 
5 RESULTADOS 


\subsection{Análise geral dos dados}

A análise geral dos dados clínico-patológicos e bioquímicos identificou os seguintes fatores como potenciais moduladores de cura e/ou recidiva dos pacientes com NEM2: a) idade da cirurgia: pacientes que tiveram forte tendência a apresentarem maior índice de cura foram os que operam com menor idade $(p=0,05)$; b) localização do CMT: pacientes com localização do CMT multicêntrico bilateral apresentam estatisticamente menor frequência de cura que em outras localizações $(p=0,002) ; c)$ estadiamentos mais avançados apresentaram menor frequência de cura $(p<0,05)$; $d)$ e pacientes com maiores níveis séricos pós-cirúrgicos de calcitonina apresentaram menor frequência de cura $(p<0,001)$ (Dados em Anexos - Tabelas suplementares 1 e 2 ).

\subsection{Rastreamento de mutações nos tumores nos genes $p 15, p 18$ e p27}

Não foi encontrada nenhuma alteração gênica que fosse considerada patogênica nas 66 amostras tumorais analisadas no estudo. Foram identificadas variantes polimórficas que serão descritas a seguir. 


\subsubsection{Gene p15}

Neste gene foi encontrada uma variante em homozigose na região intrônica c.43-27C>A (rs2069426) em dois tumores do caso 32 (2/66; 3\%). Esta variante apresenta uma frequência alélica, segundo o banco de dados 1000 Genomes, de 7,2\% (MAF: A=0,072/158) (Figura 7). As análises de predição in silico mostraram que essa variante não altera a região de splicing, sendo assim considerada provavelmente não patogênica. Essa variante também foi encontrada na amostra de sangue do caso 32 , mostrando ser uma alteração germinativa.

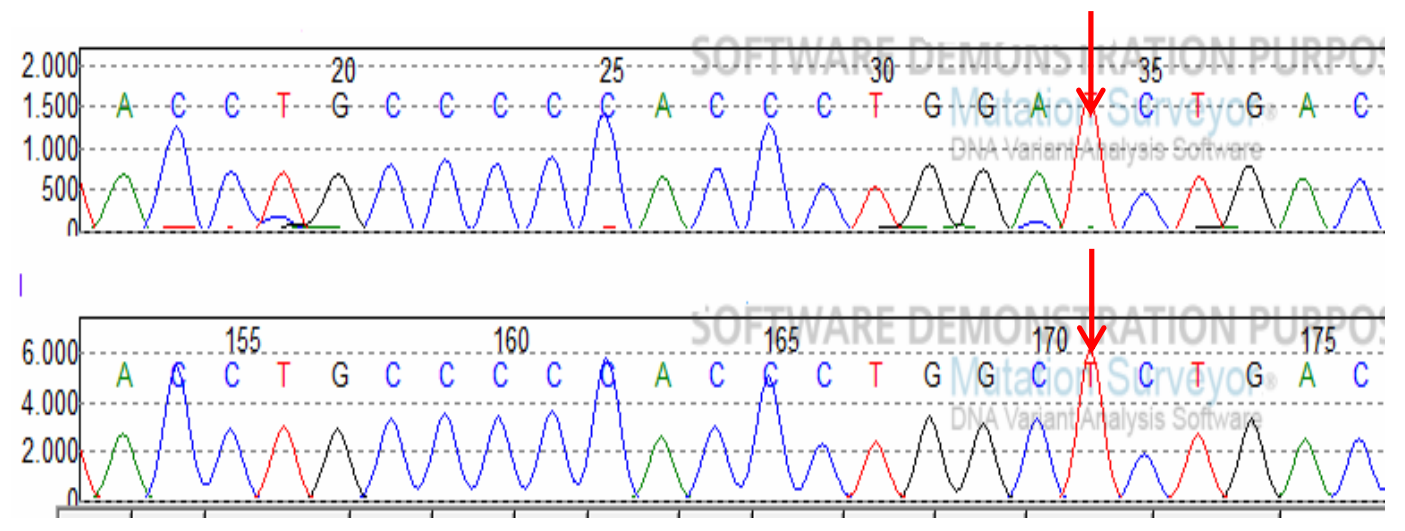

Figura 7 - Eletroferograma mostrando variante polimórfica em homozigose c. 43-27C>A (rs2069426) na região intrônica do gene $p 15$. A figura acima mostra a sequência com a alteração e a sequência abaixo contém a referência selvagem (setas vermelhas indicam a posição de interesse) 


\subsubsection{Gene p18}

Neste gene foram encontradas duas variantes polimórficas em heterozigose, sendo a primeira uma alteração não sinônima no éxon 2 e a outra na região $3^{\prime} U T R$. As duas variantes foram encontradas em sete tumores $(7 / 66 ; 10,6 \%)$ provenientes de 3 casos advindos de uma mesma família com dupla mutação RET C634Y/Y791F (casos 3, 9 e 15). A primeira variante foi a G114G c.342C>T (rs1043141) que tem frequência alélica, descrita no banco de dados 1000 Genomes, de 5.5\% (MAF: T= 0,055/120).

A segunda variante foi localizada na região 3'UTR $c^{*} .151 C>T$ (rs12855) com frequência alélica de 1,4\% (MAF: T= 0,140/306) (Figuras 8 e 9). As análises in silico mostraram que essas duas alterações não são patogênicas. Essas variantes também foram nas análises do sangue desses três casos, mostrando ser uma alteração germinativa. 

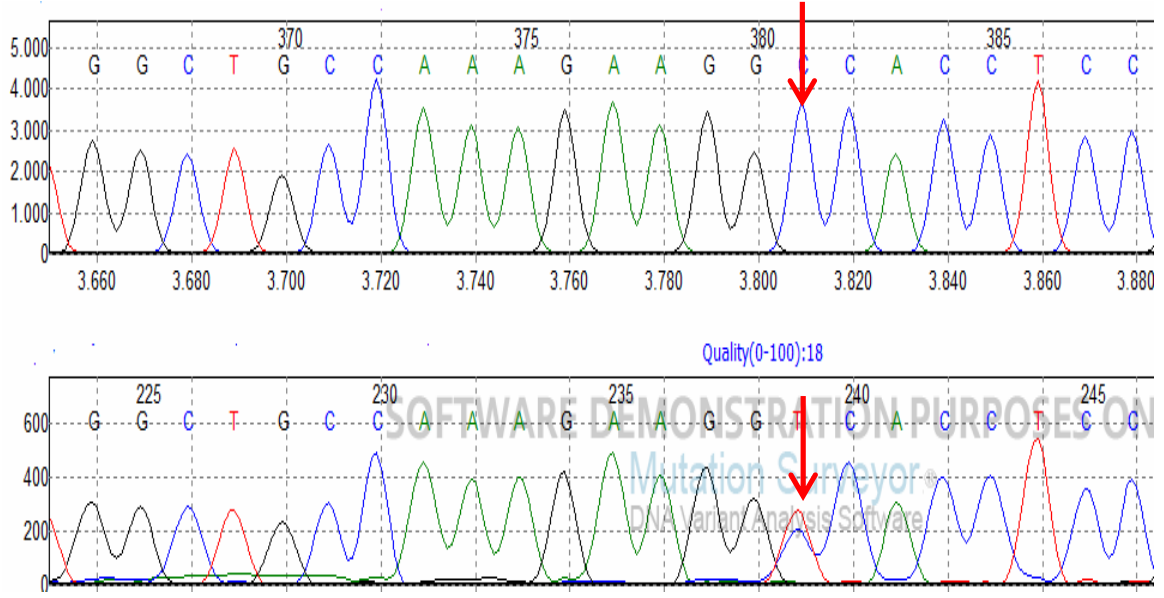

Figura 8 - Eletroferograma mostrando a variante sinônima G114G (rs1043141) em heterozigose no éxon 2 do gene $p 18$. A figura acima mostra a sequência referência normal (selvagem) e abaixo a sequência com a alteração (setas vermelhas indicam a posição de interesse)
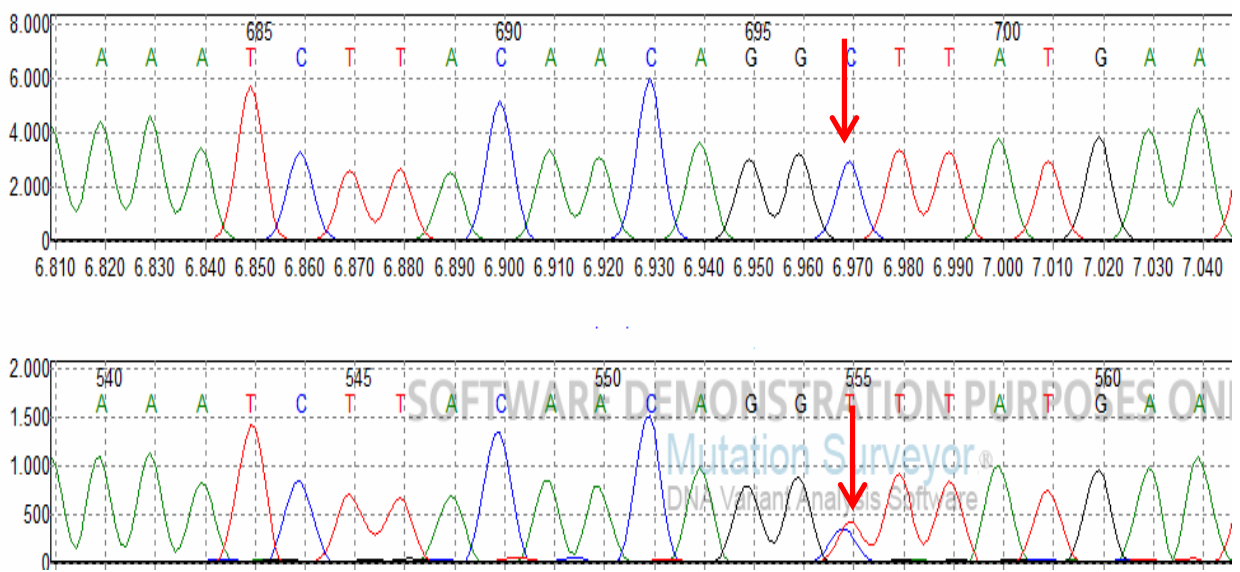

Figura 9 - Eletroferograma mostrando a variante intrônica 3'UTR $c^{*} .151 C>T$ (rs12855) em heterozigose no gene p18. A figura acima mostra a sequência referência normal e de abaixo mostra a sequência com a alteração (setas vermelhas indicam a posição) 


\subsubsection{Gene p27}

Neste gene foram identificados os dois polimorfismos já descritos na literatura e que são associados à susceptibilidade e modulação fenotípica em diversos tipos de tumores: a) c.-79C>T (rs34330) localizado na região 5'UTR e apresenta uma frequência alélica de 34\% (MAF: T=0,342/746); e b) a variante c.326T>G p.V109G (rs2066827) localizada no éxon 1 do gene, com uma frequência alélica de 29\% (MAF: G=0,296/646) (Figuras 10 e 11). As frequências alélicas desses SNPs foram obtidas de acordo com o banco de dados 1000 Genomes.

Os genótipos obtidos para a variante c.-79C>T do gene p27 nos 66 tumores foram: 39 CC (59\%), 24 CT (36\%) e 3 TT (5\%). Os genótipos do polimorfismo p.V109G foram: 32 TT (48\%), 27 TG (41\%) e 7 GG (11\%).

Com a finalidade de análise estatística, os genótipos das duas variantes no p27 foram divididos em dois grupos para comparação: homozigoto selvagem e heterozigoto mutado/ homozigoto mutado. 

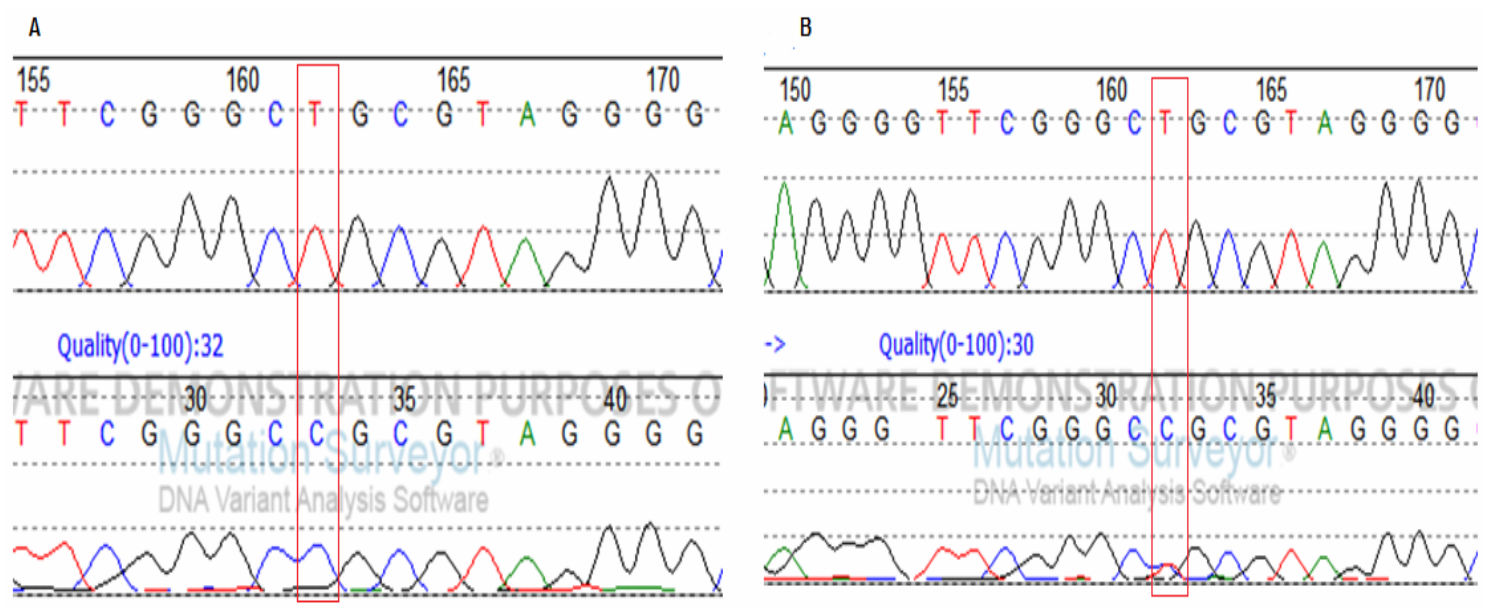

Figura 10 - Eletroferogramas mostrando a variante, c.-79C>T (rs34330) localizado na região $5^{\prime}-U T R$ do gene $p 27$. (A) em homozigose e (B) heterozigose. A caixa vermelha indica a posição da variante
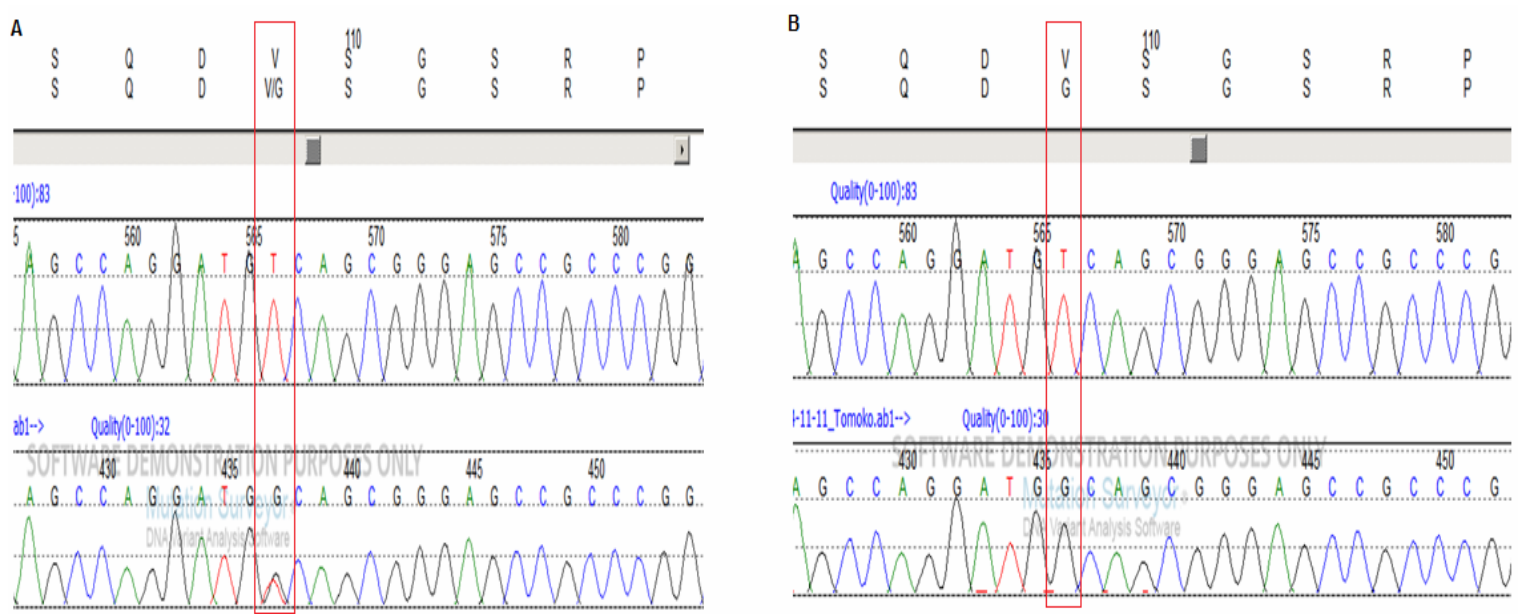

Figura 11 - Eletroferogramas mostrando a variante c.326T>G p.V109G, rs2066827) localizada no éxon 1 do gene p27. (A) em heterozigose e $(B)$ em homozigose. A caixa vermelha indica a posição da variante 
Não houve associação estatisticamente significante da variante c.79C>T (rs34330) com as características clinico-patológicas e bioquímicas dos pacientes $(p>0,05)$ (Tabela 15).

Ambos os genótipos, heterozigoto mutado (TG) e homozigoto mutado (GG) para o polimorfismo p.V109G (rs2066827) do gene p27, apresentaram associação estatisticamente significante com: a) os fenótipos NEM2A e NEM2A/CMT-F $(p=0,019)$, b) com a presença de hiperparatireoidismo primário $(p=0,006)$ e, c) com a menor expressão nuclear de $p 27$, documentada por Western blot $(p=0,048)$ (vide também dados dos resultados de Western blot a seguir) (Tabela 16). 
Tabela 15 - Correlação entre as características clínico-patológicas e bioquímicas dos pacientes apresentando NEM2 e os genótipos do polimorfismo c.-79C>T do gene p27

\begin{tabular}{|c|c|c|c|c|c|c|c|}
\hline \multirow{3}{*}{$\begin{array}{l}\text { Variável } \\
\text { Sexo }\end{array}$} & \multicolumn{4}{|c|}{ SNP1 p27-79T } & \multirow{2}{*}{\multicolumn{2}{|c|}{ Total }} & \multirow{3}{*}{$\begin{array}{c}\boldsymbol{p} \\
0,567^{*}\end{array}$} \\
\hline & \multicolumn{2}{|c|}{$\mathrm{CC}$} & \multicolumn{2}{|c|}{$\mathrm{TC} / \mathrm{TT}$} & & & \\
\hline & & & & & & & \\
\hline Feminino & 2 & 33,3 & 3 & 60,0 & 5 & 45,5 & \\
\hline Masculino & 4 & 66,7 & 2 & 40,0 & 6 & 54,5 & \\
\hline Idade da cirurgia (anos) & \multirow{2}{*}{\multicolumn{2}{|c|}{$47,7(13,8)$}} & & & & & $0,329^{* *}$ \\
\hline média (DP) & & & \multicolumn{2}{|c|}{$37,4(13,9)$} & \multicolumn{2}{|c|}{$43,0(14,2)$} & \\
\hline Idade (anos) & \multirow{2}{*}{\multicolumn{2}{|c|}{$50,7(14,0)$}} & & & & & $0,052^{\star \star}$ \\
\hline média (DP) & & & & $9,4)$ & & 4,5) & \\
\hline Fenótipo NEM2 & & & & & & & \\
\hline NEM2A & 6 & 100,0 & 5 & 100,0 & 11 & 100,0 & \\
\hline Níveis de risco mutação RET ATA 2009 & & & & & & & \\
\hline Muito alto & 6 & 100,0 & 5 & 100,0 & 11 & 100,0 & \\
\hline Familial & & & & & & & \\
\hline Hereditário & 6 & 100,0 & 5 & 100,0 & 11 & 100,0 & \\
\hline SNP2 p27_V109G & & & & & & & $0,411 \#$ \\
\hline$\pi$ & 2 & 33,3 & 1 & 20,0 & 3 & 27,3 & \\
\hline GG & 1 & 16,7 & 0 & 0,0 & 1 & 9,1 & \\
\hline TG & 3 & 50,0 & 4 & 80,0 & 7 & 63,6 & \\
\hline Tumor_CMT & & & & & & & $0,545^{*}$ \\
\hline Ausente- & 3 & 50,0 & 1 & 20,0 & 4 & 36,4 & \\
\hline Presente & 3 & 50,0 & 4 & 80,0 & 7 & 63,6 & \\
\hline CMT-Localização & & & & & & & $0,247 \#$ \\
\hline $\mathrm{HCC}$ & 0 & 0,0 & 1 & 20,0 & 1 & 9,1 & \\
\hline Multicêntrico unilateral & 1 & 16,7 & 0 & 0,0 & 1 & 9,1 & \\
\hline Multicêntrico bilateral & 5 & 83,3 & 4 & 80,0 & 9 & 81,8 & \\
\hline $\mathbf{T}$ & & & & & & & $0,792^{* *}$ \\
\hline T1 & 2 & 33,3 & 3 & 60,0 & 5 & 45,5 & \\
\hline T2 & 4 & 66,7 & 1 & 20,0 & 5 & 45,5 & \\
\hline T3 & 0 & 0,0 & 1 & 20,0 & 1 & 9,1 & \\
\hline $\mathbf{N}$ & & & & & & & $0,545^{*}$ \\
\hline NO & 5 & 83,3 & 3 & 60,0 & 8 & 72,7 & \\
\hline N1/N2 & 1 & 16,7 & 2 & 40,0 & 3 & 27,3 & \\
\hline M & & & & & & & \\
\hline MO & 6 & 100,0 & 5 & 100,0 & 11 & 100,0 & \\
\hline Calcitonina - pós-cirúrgia (pg/mL) & & & & & & & $0,792^{\star *}$ \\
\hline$<=10$ & 4 & 66,7 & 4 & 80,0 & 8 & 72,7 & \\
\hline 10 a 150 & 1 & 16,7 & 0 & 0,0 & 1 & 9,1 & \\
\hline$>150$ & 1 & 16,7 & 1 & 20,0 & 2 & 18,2 & \\
\hline Tumor NEM2- Hiperparatireoidismo & & & & & & & $0,567^{*}$ \\
\hline Não & 4 & 66,7 & 2 & 40,0 & 6 & 54,5 & \\
\hline Sim & 2 & 33,3 & 3 & 60,0 & 5 & 45,5 & \\
\hline Tumor NEM2- FEO & & & & & & & $0,545^{*}$ \\
\hline Não & 1 & 16,7 & 2 & 40,0 & 3 & 27,3 & \\
\hline Sim & 5 & 83,3 & 3 & 60,0 & 8 & 72,7 & \\
\hline FEO- Localização & & & & & & & $0,412 \#$ \\
\hline Sem tumor & 1 & 16,7 & 1 & 25,0 & 2 & 20,0 & \\
\hline Unilateral & 3 & 50,0 & 2 & 50,0 & 5 & 50,0 & \\
\hline Bilateral & 1 & 16,7 & 0 & 0,0 & 1 & 10,0 & \\
\hline Bilateral assincrônico & 1 & 16,7 & 0 & 0,0 & 1 & 10,0 & \\
\hline Hiperplasia & 0 & 0,0 & 1 & 25,0 & 1 & 10,0 & \\
\hline FEO_Pass Score & & & & & & & $0,250^{* *}$ \\
\hline Benigno & 2 & 40,0 & 3 & 100,0 & 5 & 62,5 & \\
\hline Favorável & 1 & 20,0 & 0 & 0,0 & 1 & 12,5 & \\
\hline Agressivo & 2 & 40,0 & 0 & 0,0 & 2 & 25,0 & \\
\hline IHQ-p27 Nucleo (Expressao) & & & & & & & $0,400^{* *}$ \\
\hline Baixa & 1 & 25,0 & 1 & 100,0 & 2 & 40,0 & \\
\hline Alta & 3 & 75,0 & 0 & 0,0 & 3 & 60,0 & \\
\hline IHQ Citoplasma (Expressao) & & & & & & & $0,400^{* *}$ \\
\hline Ausente & 1 & 25,0 & 0 & 0,0 & 1 & 20,0 & \\
\hline Baixa & 2 & 50,0 & 0 & 0,0 & 2 & 40,0 & \\
\hline Moderada & 1 & 25,0 & 0 & 0,0 & 1 & 20,0 & \\
\hline Muito alta & 0 & 0,0 & 1 & 100,0 & 1 & 20,0 & \\
\hline Western Blot - Expressão nuclear p27 & & & & & & & $0,400^{\star *}$ \\
\hline Moderada & 0 & 0,0 & 2 & 66,7 & 2 & 40,0 & \\
\hline Alta & 1 & 50,0 & 0 & 0,0 & 1 & 20,0 & \\
\hline Muito alta & 1 & 50,0 & 1 & 33,3 & 2 & 40,0 & \\
\hline Western Blot Skp2 expressão nuclear & & & & & & & $0,800^{* *}$ \\
\hline Moderada & 0 & 0,0 & 1 & 33,3 & 1 & 20,0 & \\
\hline Alta & 1 & 50,0 & 1 & 33,3 & 2 & 40,0 & \\
\hline Muito alta & 1 & 50,0 & 1 & 33,3 & 2 & 40,0 & \\
\hline
\end{tabular}


Tabela 16 - Correlação das características clínico-patológicas e bioquímicas de pacientes apresentando NEM2 com os genótipos do polimorfismo p.V109G no gene p27

\begin{tabular}{|c|c|c|c|c|c|c|c|}
\hline \multirow{3}{*}{ Variável } & \multicolumn{4}{|c|}{ SNP2 P27 V109G } & \multirow{2}{*}{\multicolumn{2}{|c|}{ Total }} & \\
\hline & & & & & & & p \\
\hline & $\mathrm{n}$ & $\%$ & $\mathrm{n}$ & $\%$ & $\mathbf{n}$ & $\%$ & \\
\hline $\begin{array}{l}\text { Sexo } \\
\text { Feminino }\end{array}$ & & & & & & & 0,317 \\
\hline $\begin{array}{l}\text { Feminino } \\
\text { Masculino }\end{array}$ & 11 & 57,9 & 7 & 41,2 & 18 & 50,0 & \\
\hline $\begin{array}{l}\text { Masculino } \\
\text { Idade da cirurgia (anos) }\end{array}$ & 8 & 42,1 & 10 & 58,8 & 18 & 50,0 & \\
\hline $\begin{array}{l}\text { ldade da cirurgia (anos) } \\
\text { média (DP) }\end{array}$ & & $20,8)$ & & $5,7)$ & & 8,7) & $0,125^{* \star}$ \\
\hline Idade (anos) & & & & & & & $0,433^{* *}$ \\
\hline média (DP) & & $(9,1)$ & & $7,5)$ & & $8,3)$ & \\
\hline Fenótipo NEM2 & & & & & & & 0,019\# \\
\hline NEM2A & 5 & 26,3 & 12 & 70,6 & 17 & 47,2 & \\
\hline NEM2A/CMT-F & 13 & 68,4 & 4 & 23,5 & 17 & 47,2 & \\
\hline NEM2B & 1 & 5,3 & 1 & 5,9 & 2 & 5,6 & \\
\hline Níveis de risco mutação RET ATA 2009 & & & & & & & $0,196^{* *}$ \\
\hline Moderado & 0 & 0,0 & 1 & 5,9 & 1 & 2,8 & \\
\hline Alto & 15 & 78,9 & 7 & 41,2 & 22 & 61,1 & \\
\hline Muito alto & 3 & 15,8 & 8 & 47,1 & 11 & 30,6 & \\
\hline Altíssimo & 1 & 5,3 & 1 & 5,9 & 2 & 5,6 & \\
\hline Familial & & & & & & & $>0,999^{*}$ \\
\hline Mutação de novo & 1 & 5,3 & 1 & 5,9 & 2 & 5,6 & \\
\hline Hereditário & 18 & 94,7 & 16 & 94,1 & 34 & 94,4 & \\
\hline SNP1 p27_79T & & & & & & & $0,728 \#$ \\
\hline TाT & 1 & 5,3 & 1 & 5,9 & 2 & 5,6 & \\
\hline $\mathrm{CC}$ & 10 & 52,6 & 11 & 64,7 & 21 & 58,3 & \\
\hline TC & 8 & 42,1 & 5 & 29,4 & 13 & 36,1 & \\
\hline Tumor_CMT & & & & & & & $0,684^{*}$ \\
\hline Ausente- & 3 & 15,8 & 4 & 23,5 & 7 & 19,4 & \\
\hline Presente & 16 & 84,2 & 13 & 76,5 & 29 & 80,6 & \\
\hline CMT-Localização & & & & & & & $0,904^{*}$ \\
\hline $\mathrm{HCC}$ & 2 & 10,5 & 1 & 5,9 & 3 & 8,3 & \\
\hline Multicêntrico unilateral & 2 & 10,5 & 1 & 5,9 & 3 & 8,3 & \\
\hline Multicêntrico bilateral & 13 & 68,4 & 13 & 76,5 & 26 & 72,2 & \\
\hline Unicêntrico & 2 & 10,5 & 2 & 11,8 & 4 & 11,1 & \\
\hline $\mathbf{T}$ & & & & & & & $0,415^{\star *}$ \\
\hline Tо & 1 & 5,3 & 1 & 5,9 & 2 & 5,6 & \\
\hline T1 & 9 & 47,4 & 10 & 58,8 & 19 & 52,8 & \\
\hline T2 & 4 & 21,1 & 4 & 23,5 & 8 & 22,2 & \\
\hline T3 & 4 & 21,1 & 2 & 11,8 & 6 & 16,7 & \\
\hline T4 & 1 & 5,3 & $\mathrm{o}$ & $\mathrm{o}$ & 1 & 2,8 & \\
\hline $\mathbf{N}$ & & & & & & & 0,158 \\
\hline No & 9 & 47,4 & 12 & 70,6 & 21 & 58,3 & \\
\hline $\mathrm{N} 1 / \mathrm{N} 2$ & 10 & 52,6 & 5 & 29,4 & 15 & 41,7 & \\
\hline M & & & & & & & $0,342^{*}$ \\
\hline MO & 15 & 78,9 & 16 & 94,1 & 31 & 86,1 & \\
\hline M1 & 4 & 21,1 & 1 & 5,9 & 5 & 13,9 & \\
\hline Calcitonina - pós-cirúrgia (pg/mL) & & & & & & & $0,127^{\star *}$ \\
\hline$<=10$ & 7 & 41,2 & 11 & 68,8 & 18 & 54,5 & \\
\hline 10 a 150 & 4 & 23,5 & 3 & 18,8 & 7 & 21,2 & \\
\hline$>150$ & 6 & 35,3 & 2 & 12,5 & 8 & 24,2 & \\
\hline Tumor NEM2- Hiperparatireoidismo & & & & & & & $0,006^{\star}$ \\
\hline Não & 19 & 100,0 & 11 & 64,7 & 30 & 83,3 & \\
\hline $\operatorname{Sim}$ & 0 & 0,0 & 6 & 35,3 & 6 & 16,7 & \\
\hline Tumor NEM2- FEO & & & & & & & 0,098 \\
\hline Não & 15 & 78,9 & 9 & 52,9 & 24 & 66,7 & \\
\hline Sim & 4 & 21,1 & 8 & 47,1 & 12 & 33,3 & \\
\hline FEO- Localização & & & & & & & $0,172 \#$ \\
\hline Sem tumor & 14 & 73,7 & 9 & 56,2 & 23 & 65,7 & \\
\hline Unilateral & 4 & 21,1 & 4 & 25,0 & 8 & 22,9 & \\
\hline Bilateral & $\mathrm{o}$ & 0,0 & 2 & 12,5 & 2 & 5,7 & \\
\hline Bilateral assincrônico & 0 & 0,0 & 1 & 6,2 & 1 & 2,9 & \\
\hline Hiperplasia & 1 & 5,3 & $\mathrm{o}$ & 0,0 & 1 & 2,9 & \\
\hline FEO_Pass Score & & & & & & & $0,788^{* *}$ \\
\hline Beniḡno & 2 & 50,0 & 5 & 71,4 & 7 & 63,6 & \\
\hline Favorável & 1 & 25,0 & $\mathrm{o}$ & 0,0 & 1 & 9,1 & \\
\hline Agressivo & 1 & 25,0 & 2 & 28,6 & 3 & 27,3 & \\
\hline IHQ-p27 Nucleo (Expressao) & & & & & & & $0,481^{* *}$ \\
\hline Ausente & 2 & 25,0 & $\mathrm{o}$ & 0,0 & 2 & 11,8 & \\
\hline Baixa & 1 & 12,5 & 2 & 22,2 & 3 & 17,6 & \\
\hline Moderada & 1 & 12,5 & $\mathrm{o}$ & 0,0 & 1 & 5,9 & \\
\hline Alta & 3 & 37,5 & 7 & 77,8 & 10 & 58,8 & \\
\hline Muito alta & 1 & 12,5 & $\mathrm{o}$ & 0,0 & 1 & 5,9 & \\
\hline IHQ Citoplasma (Expressao) & & & & & & & $0,815^{\star *}$ \\
\hline Ausente & 3 & 37,5 & 1 & 11,1 & 4 & 23,5 & \\
\hline Baixa & $\mathrm{o}$ & 0,0 & 3 & 33,3 & 3 & 17,6 & \\
\hline Moderada & 3 & 37,5 & 3 & 33,3 & 6 & 35,3 & \\
\hline Alta & 2 & 25,0 & 1 & 11,1 & 3 & 17,6 & \\
\hline Muito alta & $\mathrm{o}$ & 0,0 & 1 & 11,1 & 1 & 5,9 & \\
\hline Western Blot - Expressão nuclear p27 & & & & & & & $0,048^{\star *}$ \\
\hline Moderada & $\mathrm{o}$ & 0,0 & 2 & 28,6 & 2 & 16,7 & \\
\hline Alta & $\mathrm{o}$ & 0,0 & 3 & 42,9 & 3 & 25,0 & \\
\hline Muito alta & 5 & 100,0 & 2 & 28,6 & 7 & 58,3 & \\
\hline Western Blot Skp2 expressão nuclear & & & & & & & $0,530^{* *}$ \\
\hline Moderada & 1 & 20,0 & 1 & 14,3 & 2 & 16,7 & \\
\hline Alta & 3 & 60,0 & 3 & 42,9 & 6 & 50,0 & \\
\hline Muito alta & 1 & 20,0 & 3 & 42,9 & 4 & 33,3 & \\
\hline
\end{tabular}




\subsubsection{Frequência dos genótipos de p27 no grupo controle}

As frequências dos genótipos do SNP rs2066827 (p.V109G) no grupo controle de 885 indivíduos foram: 116 GG (13,1\%), 406 GT (45,9 \%) e 363 TT (41 \%). As frequências alélicas do SNP rs34330 (c.-79C>T) em 133 amostras do grupo controle foram: 27 TT $(20,3 \%), 75$ CC $(56,4 \%)$ e 31 CT (23,3\%). Nenhum desvio significativo do equilíbrio de Hardy-Weinberg foi observado para estes dois polimorfismos.

\subsubsection{Análise da associação de polimorfismos no gene p27 sobre 0 fenótipo NEM2A/CMT-F de uma grande família}

Para avaliar se os polimorfismos no gene p27 estariam influenciando o fenótipo da grande família aqui estudada com NEM2A/CMT-F e mutação germinativa C620R no gene RET, foi realizada a análise de correlação entre os dados clínico-patológicos e bioquímicos de 28 membros dessa família com os genótipos dos SNPs de p27: -838C>T, c.-79C>T e p.V109G.

A correlação dos dados clínico-patológicos e bioquímicos com os três polimorfismos no p27 mostra que eles não estão modulando o fenótipo NEM2A/CMT-F nessa grande família $(p>0,05)$ (Dados em Anexo - Tabelas suplementares 3 e 4$)$. 


\subsubsection{Análise somática de RET nos tumores}

Além da análise das análises somáticas dos genes p15, p18 e p27, foi também analisado o status somático do gene RET, e foi evidenciada a perda somática do alelo normal do gene RET em 3 tumores $(3 / 66 ; 4,5 \%)$, sendo um tumor proveniente do caso 26 e dois do caso 10 . No caso 26 houve perda somática total do alelo selvagem no códon 620 do RET (Figura 12, A e B). No caso 10 foi verificada perda parcial do alelo normal do códon 611 nos dois tumores analisados, sendo que em um deles a perda foi quase total. Provavelmente, a perda total não pode ser descartada, pois a presença do alelo normal pode ter ocorrido por contaminação com tecido adjacente não tumoral (normal) (Figura 13, A e B). 

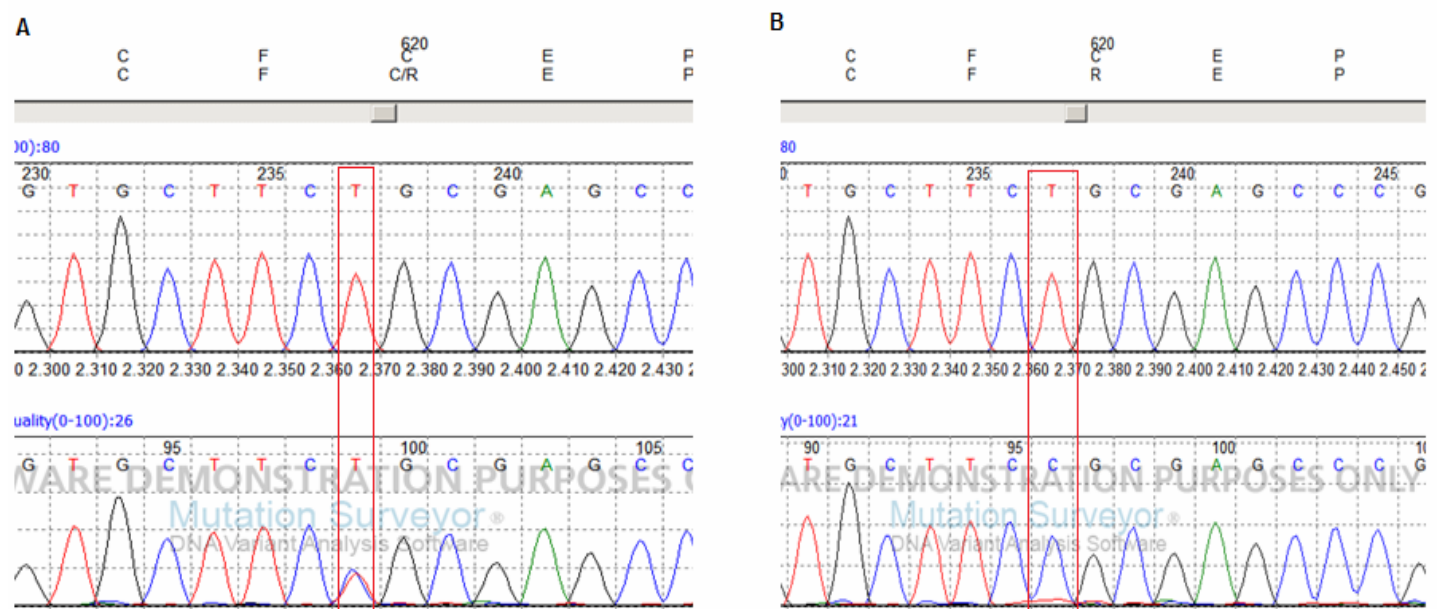

Figura 12 - Eletroferogram de região do éxon 10 gene RET. Evidência de perda somática do alelo normal do códon 620 em um caso de CMT (caso 26). Caixa vermelha indica alteração. A, genotipagem realizado no sangue; $B$, genotipagem do tumor. Eletroferogramas indicados acima correspondem a sequência referência selvagem
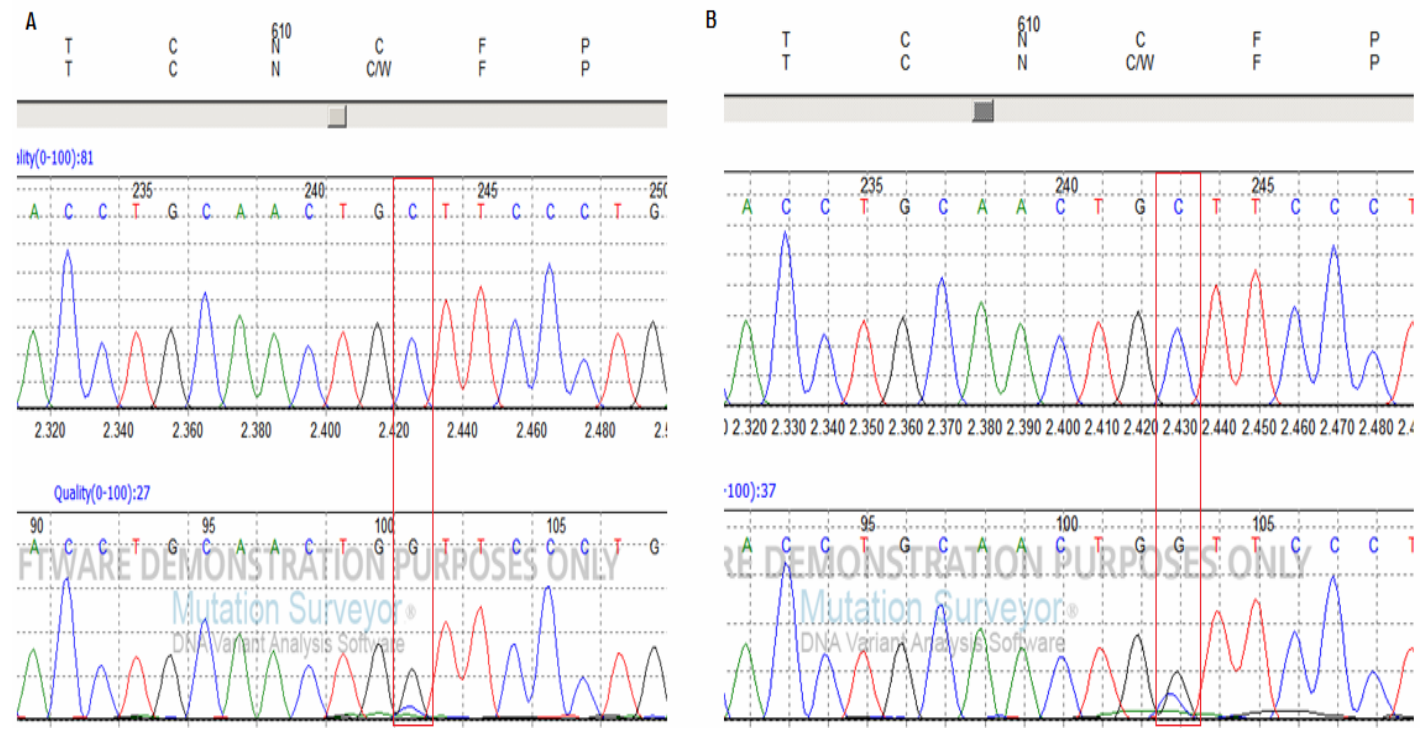

Figura 13 - Eletroferograma de região éxon 11 gene RET. Evidência de perda somática do alelo normal do códon 611 em dois tumores do caso 10. A, tumor 1 indicando presença da alteração somática e resquícios do alelo normal; $\mathrm{B}$, tumor 2 indicando uma perda parcial do alelo normal. Caixa em vermelho indica a posição da alteração e os eletroferogramas indicados acima para as figuras $A$ e $B$ correspondem à sequência referência selvagem 
Esses dados evidenciam a perda de heterozigose pode ocorrer em um proto-oncogene e que este evento somático faz parte do processo de tumorigênese da NEM2. Entretanto, devido ao número pequeno de casos analisados, não pode ser estimado se este segundo evento no RET poderia estar contribuindo para a variabilidade fenotípica ou agressividade da doença. Interessante, que no caso 26 a paciente apresentava um estadiamento de T3N1aM e foi tireoidectomizada aos 84 anos de idade sem realização de limpeza dos gânglios cervicais, mas que teve óbito por pneumonia.

\subsection{Análise de microssatélites para p27}

Foi realizada análise de microssatélites em 15 amostras tumorais que se mostraram em heterozigose para a variante p.V109G nas amostras de sangue (15/36; 41,6\%). A análise dos tumores desses 15 pacientes evidenciou manutenção da heterozigose. Esse é outro dado, além do rastreamento de mutações, que evidencia que alterações moleculares somáticas no gene p27 em amostras de tumores NEM2 não são frequentes.

\subsection{Expressão e localização celular de p27}

As análises de expressão da proteína p27 pelas técnicas de Western blot e imunohistoquímica evidenciaram uma redução na expressão de p27 nas amostras de CMT. Quanto ao FEO, notou-se que em adrenal normal a 
expressão de p27 já é mais baixa, por isso um dado interessante encontrado foi quando houve comparação dos níveis de expressão em relação à mutação RET.

Foi possível também a análise por Western blot da proteína Skp2, que faz parte do complexo que degrada p27 nuclear.

A seguir seguem os achados de expressão e localização de p27.

\subsubsection{Western blot de p27 e Skp2}

Foi analisada a expressão das proteínas p27 e Skp2 por meio da técnica de Western blot em 20 amostras tumorais, sendo 10 advindas de CMT (casos 13, 16, 21, 23, 24, 29, 35) e 10 advindas de FEO (casos, 10, 14, 19, 28 e 33), as quais apresentavam as seguintes mutações no protooncogene RET: C620R, C634R, C634Y/Y791F (Figuras 14 e 15). Não estavam disponíveis para esse estudo amostras de tecidos tumorais dos pacientes com mutações nos códons V804M e M918T. Como foi utilizado um anticorpo não-fosforilado, os níveis de expressão de p27 e Skp2 correspondem às proteínas com localização nuclear. 


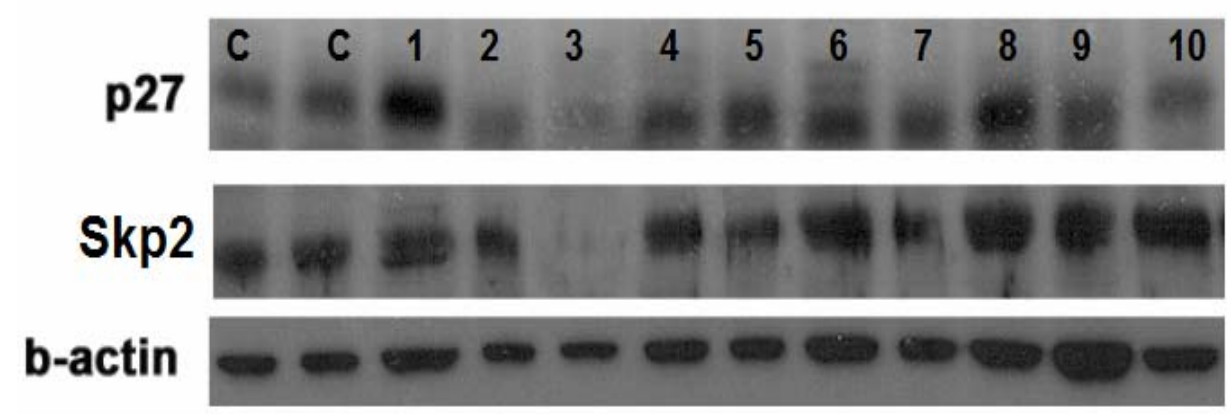

Figura 14 - Expressão de p27 e Skp2 por Western blot (WB) em CMT. Gel de WB para p27, Skp2 e $\beta$-actina. C, controles; 1-4, tumores com mutação C620R; 5-8, tumores C634; e 9-10, tumores com dupla mutação C634Y/Y791F

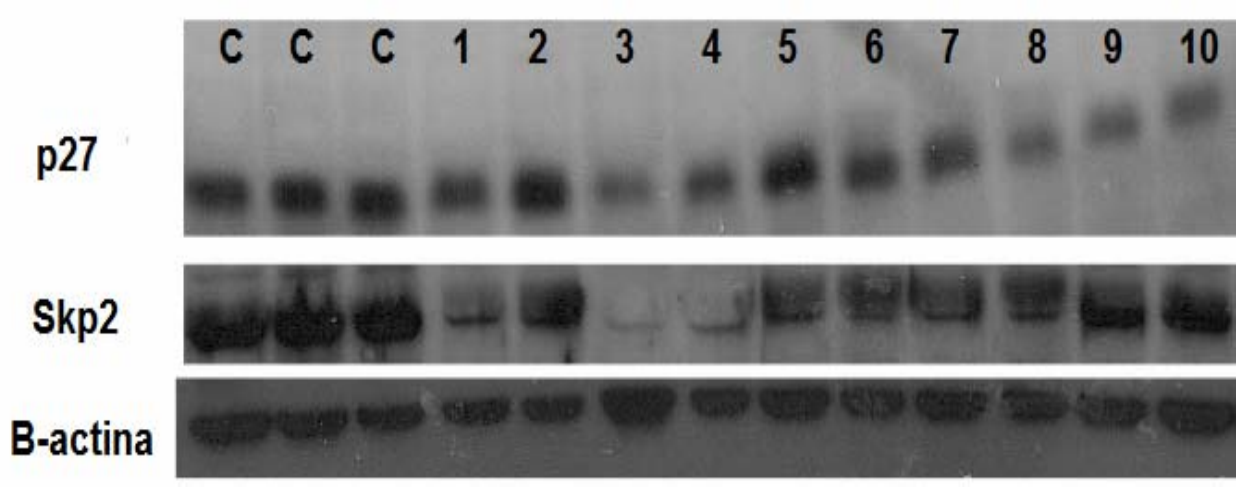

Figura 15 - Expressão de p27 e Skp2 por Western blot (WB) em FEO. Gel de WB para p27, Skp2 e $\beta$-actina. C, controles; 1-5, tumores com mutação C620R; 6-8, tumores C634R; e 9-10, tumores com dupla mutação C634Y/Y791F 


\subsubsection{CMT}

O resultado da média da expressão relativa de p27 e Skp2 (proteína alvo/ proteína endógena) foi normalizado com o resultado da amostra calibradora (média da expressão relativa das amostras provenientes dos tecidos tireoidianos normais).

As amostras teciduais de CMT evidenciaram uma expressão reduzida de p27 quando comparadas com as amostras do grupo controle. Assim sendo, nos dois grupos que apresentam a mutação RET no códon 634 (grupos com mutações nos códons 634 e 634/791), houve redução de expressão proteica de mais da metade ou três vezes menos quando comparados com a média de expressão do tecido normal, respectivamente (Tabela 17; Figura 16).

Quanto à proteína Skp2, também houve redução na expressão semelhante em todos os grupos estudados quando comparados com o controle (calibrador), tendo havido redução mais acentuada no grupo 634/791 (Tabela 17; Figura 17).

A relação entre os níveis de expressão das proteínas p27 e Skp2 mostrou-se menor nos grupos com a mutação RET no códon 634 (grupos 634 e 634/791) (Tabela 17; Figura 18).

Na tabela 13 constam os resultados finais de expressão relativa de p27 e Skp2 obtidos através da média das densidades óticas cada grupo de estudo. Nesta tabela também está apresentada a média da relação entre as expressões das duas proteínas no tecido tumoral (p27/Skp2). 
Tabela 17 - Resultado da expressão relativa de p27, Skp2 e relação p27/Skp2 nuclear dos três grupos de estudo em amostras de CMT

\begin{tabular}{lccc}
\hline \multirow{2}{*}{ Grupos } & \multicolumn{3}{c}{ Expressão Relativa* } \\
\cline { 2 - 4 } & p27/ $\beta$-actina & Skp2/ $\beta$-actina & p27/Skp2 \\
\hline Calibrador & $1,7(\mathrm{DP} \pm 0,2)$ & $1,4(\mathrm{DP} \pm 0,1)$ & $1,3(\mathrm{DP} \pm 0,1)$ \\
620 & $0,9(\mathrm{DP} \pm 0,1)$ & $0,8(\mathrm{DP} \pm 0,4)$ & $1,4(\mathrm{DP} \pm 0,9)$ \\
634 & $0,8(\mathrm{DP} \pm 0,1)$ & $0,8(\mathrm{DP} \pm 0,1)$ & $1,0(\mathrm{DP} \pm 0,1)$ \\
$634 / 791$ & $0,5(\mathrm{DP} \pm 0,1)$ & $0,7(\mathrm{DP} \pm 0,4)$ & $0,7(\mathrm{DP} \pm 0,2)$ \\
\hline
\end{tabular}

*Expressão relativa calculada com a média dos resultados da leitura de DO dos alvos para cada grupo de estudo.

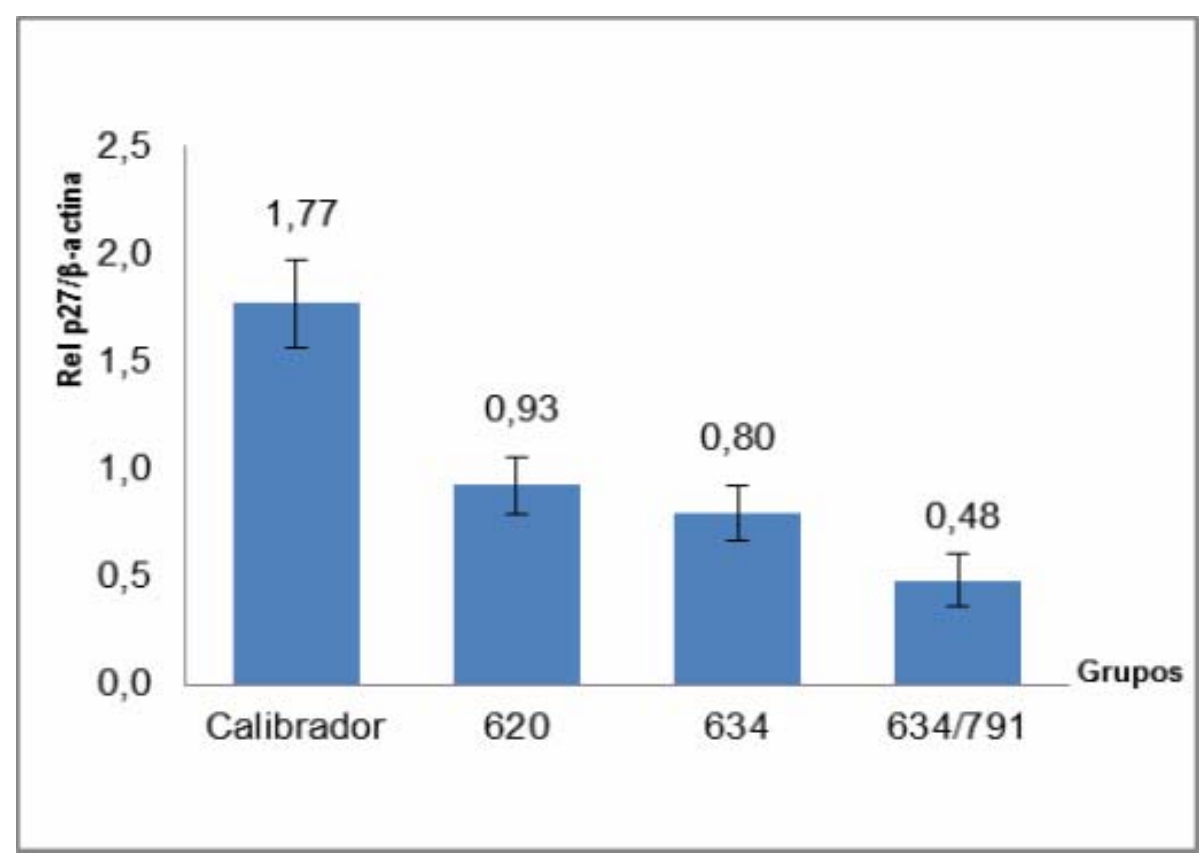

Figura 16 - Expressão relativa de p27 nuclear em cada um dos grupos de estudo, em amostras de CMT. Os desvios padrões foram calculados considerando o erro específico de cada grupo. $\mathrm{O}$ grupo "Calibrador" corresponde à média das densidades óticas (DO) dos tecidos normais e o gene da $\beta$-actina foi 0 normalizador da reação 


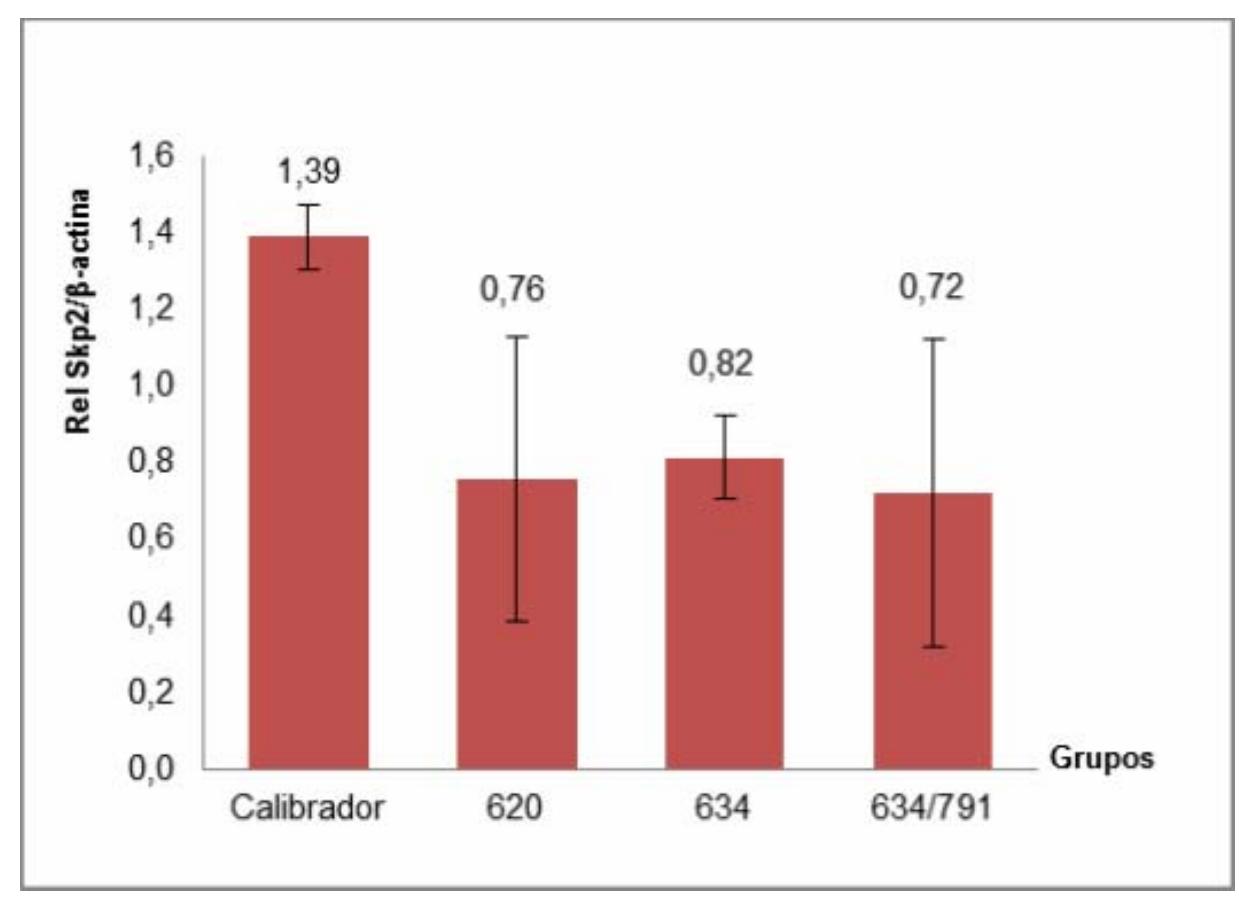

Figura 17 - Expressão relativa Skp2 nuclear em cada um dos grupos e estudo em amostras de CMT. Os desvios padrões foram calculados considerando o erro específico de cada grupo. $O$ grupo "Calibrador" corresponde à média das densidades óticas (DO) dos tecidos normais e o gene da $\beta$-actina foi 0 normalizador da reação

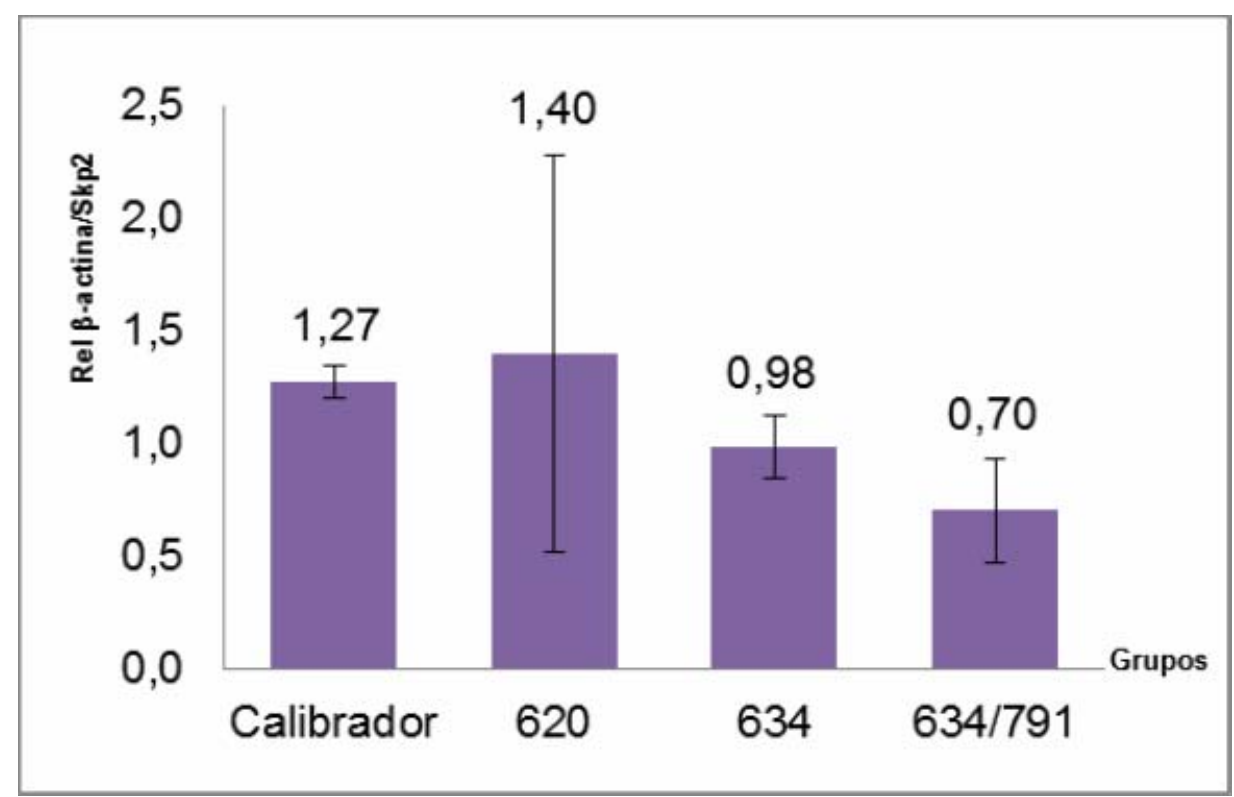

Figura 18 - Relação p27 e Skp2 nuclear em cada um dos grupos de estudo em amostras de CMT. Os desvios padrões foram calculados considerando o erro específico de cada grupo. O grupo "Calibrador" corresponde à média das densidades óticas (DO) dos tecidos normais 
Devido às diferenças dos níveis de expressão de p27 e Skp2 em relação a cada um dos grupos estudados, foi realizada uma análise comparativa utilizando o Teste-T (Student's T-test). Foi verificado se havia uma correlação entre o códon mutado RET e os níveis de expressão de p27 e Skp2.

As análises realizadas mostraram tendência para redução da expressão de p27 em relação ao códon mutado do $R E T$, ou seja, os dois grupos de pacientes que apresentavam mutação no códon 634 (grupos 634 e 634/791) revelaram menor expressão de p27 quando comparados individualmente com três diferentes grupos: a) o grupo controle (calibrador) $(p=0,05$ e $p=0,03) ;$ b) com o grupo com mutação no códon 620 do RET (grupo 620) $(p=0,04, p=0,002, p=0,03)$; e c) também quando comparados os dois grupos com a mutação no códon 634 entre si (grupos 634 e 634/791) $(p=0,007)($ Tabela 18).

Já para a Skp2, foi verificada associação da redução da expressão dessa proteína somente no grupo 634, quando comparada com o grupo controle $(p=0,04)$. Na análise da relação entre as proteínas $p 27 / S k p 2$, não foi verificada redução dos níveis de expressão de ambas as proteínas (Tabela 18). 
Tabela 18 - Análise comparativa dos grupos de estudo em relação à expressão relativa de p27 e Skp2 nuclear utilizando o Teste-T em amostras de CMT

\begin{tabular}{|c|c|c|c|}
\hline \multirow{2}{*}{ Grupos mutação RET } & \multicolumn{3}{|c|}{ Test-T $\left(p \leq 5^{*}\right)$} \\
\hline & p27/ $/$-actina & Skp2/ $\beta$-actina & p27/Skp2 \\
\hline $\mathrm{N} \times 620$ & 0,378 & 0,296 & 0,645 \\
\hline NX 634 & $0,05^{*}$ & $0,045^{*}$ & 0,856 \\
\hline $\mathrm{N} \times 634 / 791$ & $0,032^{*}$ & 0,314 & 0,157 \\
\hline $620 \times 634$ & $0,045^{*}$ & 0,697 & 0,471 \\
\hline $620 \times 634 / 791$ & $0,002^{*}$ & 0,889 & 0,099 \\
\hline $620 \times 634+634 / 791$ & $0,036^{*}$ & 0,845 & 0,216 \\
\hline $634 \times 634 / 791$ & $0,0071^{*}$ & 0,54 & 0,071 \\
\hline $634 \times 634 / 791+620$ & 0,888 & 0,697 & 0,641 \\
\hline
\end{tabular}

*valor estatisticamente significante.

\subsubsection{FEO}

Nos grupos de FEO, verificou-se que o grupo controle, (calibrador) apresentou expressão reduzida de p27 e maior expressão de Skp2 em relação aos grupos estudados. Esse dado evidencia diferenças nos níveis de expressão de p27 e Skp2 inter-tecidual de p27 e Skp2. Como os níveis de expressão do grupo controle foram baixos para p27, eles não foram utilizados para comparação dos níveis de expressão. A comparação foi realizada entre os diferentes grupos analisados (grupos com mutações no RET nos éxons 620, 634 e 634/791).

A análise de expressão relativa mostrou que o grupo que apresenta a dupla mutação no RET (634/791) tendeu a uma expressão menor de p27 em relação aos demais grupos (Figura 19). Esse mesmo grupo tendeu a apresentar uma expressão maior de Skp2 em relação aos demais grupos. O 
grupo que apresentou uma menor expressão de Skp2 foi o com mutação RET 620 (Tabela 19; Figura 20).

A análise da relação entre as proteínas p27 e Skp2 dentro do tecido tumoral evidenciou que o tecido da adrenal normal apresentava baixos níveis de p27 e Skp2 em relação ao tecido tumoral. Novamente, os grupos que apresentaram menor relação das duas proteínas foram os que apresentavam mutação no códon 634, sendo que o grupo com dupla mutação nos códons 634/791 demonstraram maior redução (Tabela 19; Figura 21).

Tabela 19 - Resultado da expressão relativa de p27, Skp2 e relação p27/Skp2 nuclear dos grupos de estudo em amostras de FEO

\begin{tabular}{|c|c|c|c|}
\hline \multirow{2}{*}{ Grupos } & \multicolumn{3}{|c|}{ Expressão Relativa* } \\
\hline & p27/ß-actina & Skp2/ß-actina & p27/Skp2 \\
\hline Calibrador & $0,43(\mathrm{DP} \pm 0,07)$ & $1,07(\mathrm{DP} \pm 0,03)$ & $0,4(\mathrm{DP} \pm 0,06)$ \\
\hline 620 & $0,79(\mathrm{DP} \pm 0,21)$ & $0,43(\mathrm{DP} \pm 0,23)$ & $2,29(\mathrm{DP} \pm 0,80)$ \\
\hline 634 & $1,15(\mathrm{DP} \pm 0,26)$ & $0,76(\mathrm{DP} \pm 0,07)$ & $1,49(\mathrm{DP} \pm 0,21)$ \\
\hline 634/791 & $0,70(\mathrm{DP} \pm 0,10)$ & $0,94(\mathrm{DP} \pm 0,18)$ & $0,81(\mathrm{DP} \pm 0,17)$ \\
\hline
\end{tabular}

*Expressão relativa calculada com a média dos resultados da leitura de DO dos alvos para cada grupo de estudo. 


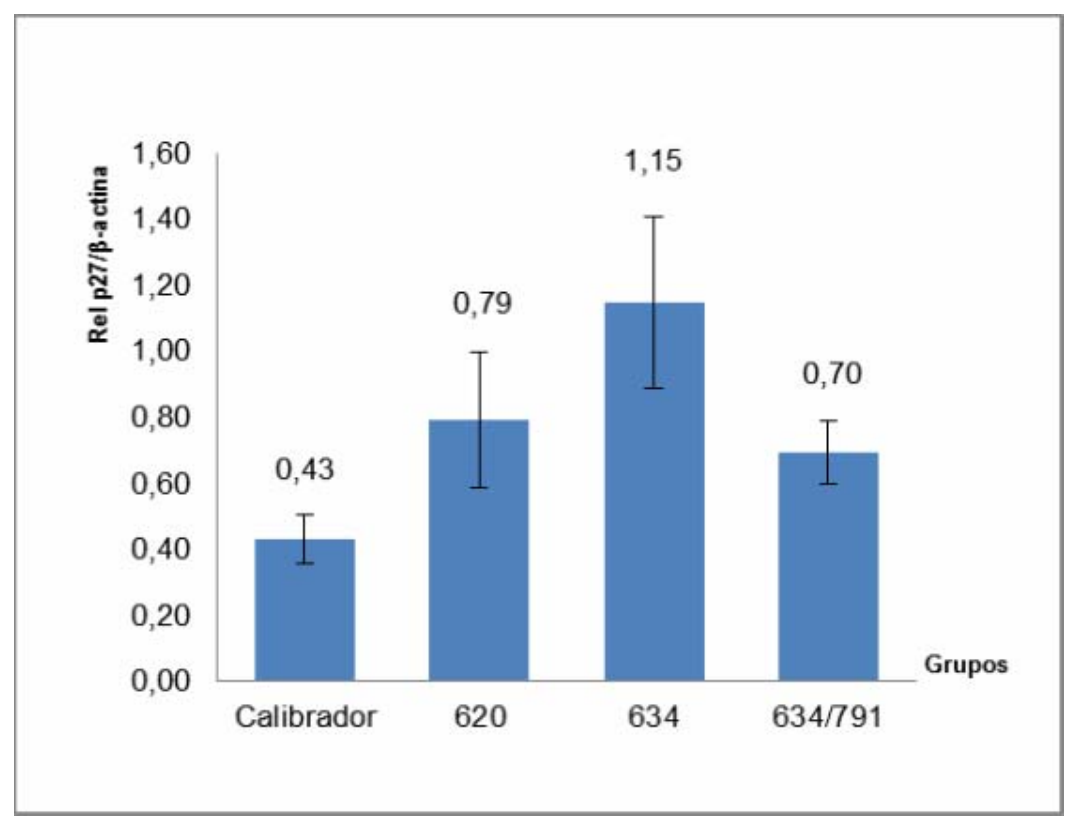

Figura 19 - Expressão relativa de p27 nuclear em cada um dos grupos analisados em amostras de FEO. Os desvios padrões foram calculados com o erro específico de cada grupo. O grupo "Calibrador" corresponde à média das densidades óticas (DO) dos tecidos normais e o gene da $\beta$-actina foi o normalizador da reação

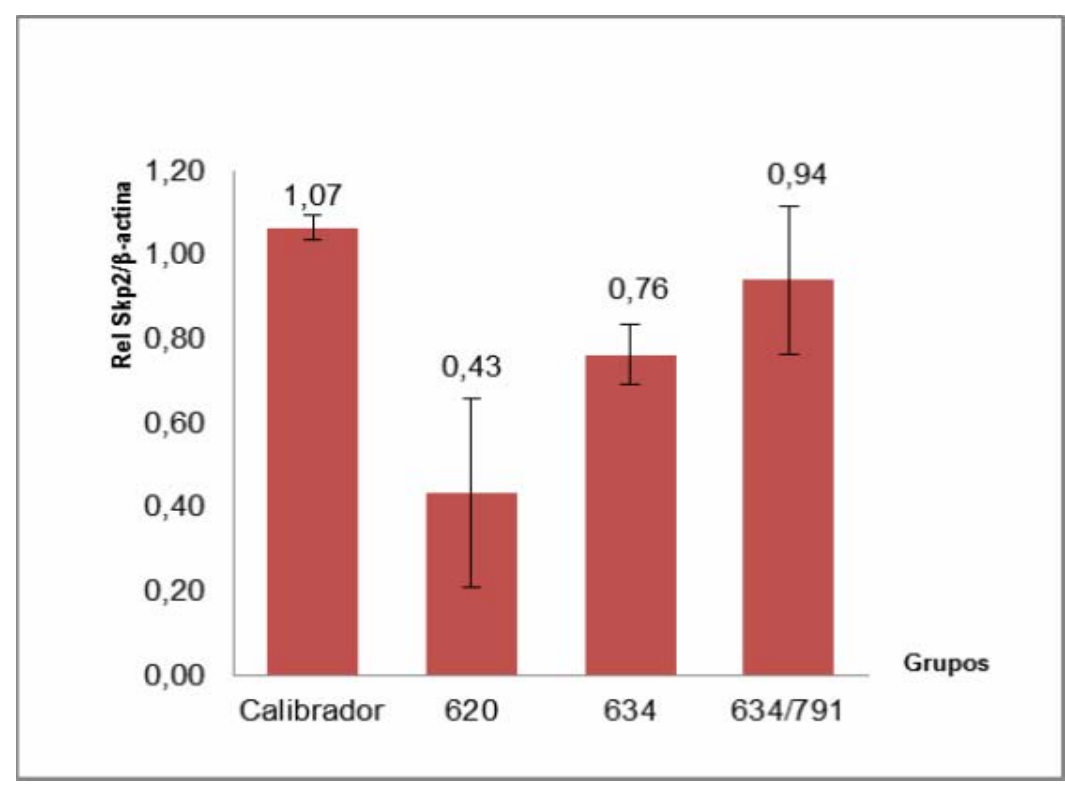

Figura 20 - Expressão relativa Skp2 nuclear em cada dos grupos analisados em amostras de FEO. Os desvios padrões foram calculados com o erro específico de cada grupo. O grupo "Calibrador" corresponde à média das densidades óticas (DO) dos tecidos normais e o gene da $\beta$-actina foi o normalizador da reação 


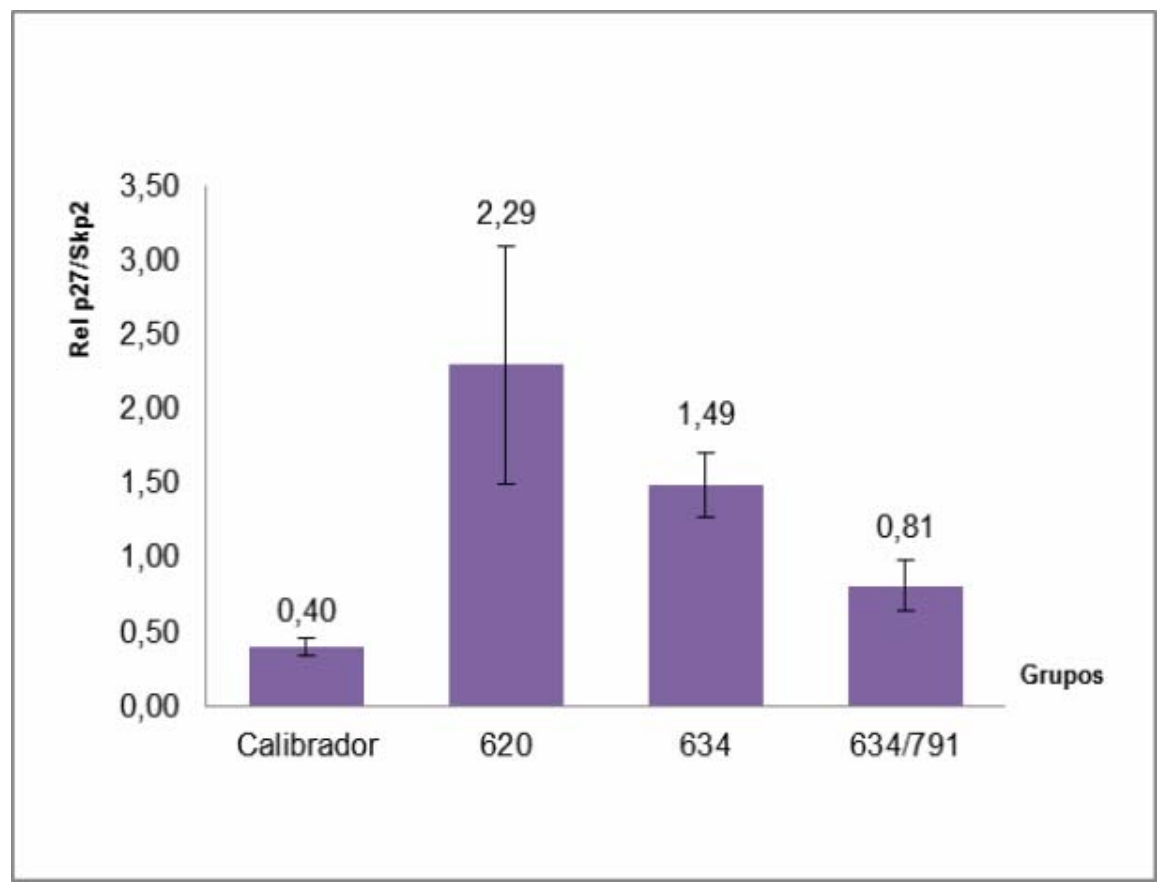

Figura 21 - Relação das proteínas p27 e Skp2 nuclear em cada um dos grupos analisados em amostras de FEO. Os desvios padrões foram calculados levando em conta o erro específico de cada grupo. O grupo "Calibrador" corresponde à média das densidades óticas (DO) dos tecidos normais

Como procedido em relação às amostras de $\mathrm{CMT}$, foi realizada a análise do test-T para comparação entre os resultados de expressão proteica de cada grupo. A baixa expressão de p27, na comparação do grupo controle com os demais grupos, provavelmente se deveu à baixa expressão de p27 nessas amostras, como relatado anteriormente $(p=0,02, p=0,009$, $p=0,03)$. Quando se comparou a expressão proteica de p27 entre os grupos com diferentes mutações no RET, foi verificada tendência para baixa expressão no grupo com mutação no códon 634. Assim, quando este grupo foi comparado com o grupo 620 e pareado $634 / 791+620$, os resultados foram $p=0,074, p=0,07$, respectivamente (Tabela 20 ). 
Foi verificada clara redução de expressão de Skp2 em todos os grupos analisados quando comparados com o grupo controle $(p=0,003$ e $p=0,002)$, exceto para o grupo 634/791 $(p>0,05)$. Quando comparados entre os grupos, também foi verificada tendência à redução de Skp2 $(p=0,05$, $p=0,03, p=0,09$ e $p=0,05)($ Tabela 20).

A redução dos níveis de expressão de p27 no grupo controle pôde ser observada por meio da análise da relação p27/Skp2 $(p=0,02, p=0,001$ e $p=0,02$ ). Foi verificada também a redução dos níveis de expressão em ambas as proteínas quando realizada comparação 634/791 versus grupo $634(p=0,034)$ (Tabela 20).

Tabela 20 - Análise comparativa dos grupos de estudo em relação à expressão relativa de p27 e Skp2 nuclear utilizando o teste-T

\begin{tabular}{lccc}
\hline \multirow{2}{*}{ Grupos mutação RET } & \multicolumn{3}{c}{ Test-T $\left(p \leq 5^{*}\right)$} \\
\cline { 2 - 4 } & p27/ $\beta$-actina & Skp2/ $\beta$-actina & p27/Skp2 \\
\hline N X 620 & $0,028^{*}$ & $0,003^{*}$ & $0,024^{*}$ \\
N X 634 & $0,0098^{*}$ & $0,002^{*}$ & $0,001^{*}$ \\
N X 634/791 & $0,037^{*}$ & 0,288 & $0,027^{*}$ \\
620 X 634 & 0,074 & $0,05^{*}$ & 0,528 \\
620 X 634/791 & 0,566 & $0,037^{*}$ & 0,153 \\
620 X 634 + 634/791 & 0,328 & $0,009^{*}$ & 0,107 \\
634 X 634/791 & 0,126 & 0,192 & $0,034^{*}$ \\
634 X 634/791+620 & 0,07 & $0,05^{*}$ & 0,96 \\
\hline \hline
\end{tabular}

*valor estatisticamente significante. 


\subsection{Imunohistoquímica p27}

A expressão e localização sub-celular de p27 foram avaliadas por imunohistoquímica (IHQ) de 19 tecidos tumorais parafinados, incluindo 17 CMT e 2 FEO. Em dois casos estavam disponíveis os dois tecidos tumorais (casos 4 e 29), entretanto os resultados não estão descritos na tabela 21. No campo da lâmina analisada, a média aproximada de células expressando p27 nuclear foi de $59 \pm 26,5 \%$.

Os tecidos normais (não neoplásico) provenientes da tireoide, pele e adrenal mostraram marcação nuclear uniforme e forte, e marcação citoplasmática fraca. Já nos tecidos neoplásicos 4/17 (23,5\%) apresentaram marcação nuclear moderada/baixa e a marcação citoplasmática moderada/alta foi evidenciadas em 10/17 (59\%). A figura 22 mostra os casos representativos verificados por $\mathrm{IHQ}$.

Foram verificadas diferenças na marcação nuclear e citoplasmática entre os tumores. A localização de p27 celular (marcação positiva) estava presente no núcleo de 15/17 casos (88\%) e no citoplasma em 12/17 (70,6\%) casos. Em dois casos 2/17 (casos 8 e 33) houve ausência de marcação de p27 nuclear $(11,7 \%)$, sendo que no caso 33 verificado somente a marcação no citoplasma (Tabela 21).

A análise das lâminas permitiu a separação das 17 amostras em três grupos com padrões distintos de localização da proteína p27 intracelular: positivo para núcleo, positivo para citoplasma, ou positivo para ambos. Quanto aos níveis de expressão proteica, os padrões identificados foram: negativo, baixo, moderado e alto (Tabela 21). 
Os resultados obtidos para localização de p27 intracelular foram: núcleo positivo $(15 / 17,88 \%)$, núcleo negativo $(2 / 17,12 \%)$, citoplasma positivo $(13 / 17,76 \%)$ e citoplasma negativo $(4 / 17,23,5 \%)$ (Tabela 21$)$.

Os resultados dos níveis de expressão obtidos para os tumores com marcação nuclear e citoplasmática positivos foram: ausente $(2 / 17,12 \%)$, baixa $(3 / 17,23,5 \%)$, moderada $(1 / 17,6 \%)$ e alta $(10 / 17,59 \%)$. E os níveis de expressão citoplasmática foram: ausente $(4 / 17,23,5 \%)$, baixa $(3 / 17,17 \%)$, moderada $(6 / 17,36 \%)$ e alta $(4 / 17,23,5 \%)$ (Tabela 21 ; Figura 22$)$.

Os resultados estatísticos iniciais não mostraram correlação entre a localização e intensidade de expressão de p27 com aspectos clínicos dos pacientes estudados, como estadiamento do tumor e recidiva da doença. Uma segunda análise foi realizada para pesquisa de possível associação de aspectos genéticos dos pacientes com a expressão de p27 nos tumores. Nenhuma correlação foi identificada em relação à localização da proteína (núcleo vs. citoplasma), ou da intensidade de expressão de p27 no citoplasma. Entretanto, as análises de p27 no núcleo dos CMTs mostraram uma correlação estatisticamente positiva entre o genótipo do SNP V109G e a intensidade de expressão ( $p=0.03$, Fisher exact test, 2-tailed). Treze casos $(3,8,9,15,16,20,22,23,26,29,30,33$ e 35$)(13 / 17 ; 76,5 \%)$ participantes da fase inicial do rastreamento clínico (operados com mais de 20 anos de idade) foram incluídos (Tabela 21). Os quatro casos jovens $(4,17,27$ e 31) (4/17; $23,5 \%)$, portadores de mutação no RET e operados preventivamente à tireoidectomia total, não foram incluídos nessas análises para evitar resultados decorrentes de hiperplasias de células-C ou tumores em estágio 
muito inicial. Dos cinco pacientes com o genótipo V109G-TT, dois tinham ausência e dois tinham baixos níveis de expressão de p27 nuclear (4/5; 80\%). Quanto aos oitos casos com os genótipos V109G-GG ou GT, somente um deles $(1 / 8 ; 12,25 \%)$ apresentava baixa expressão de p27 nuclear, enquanto os sete casos restantes com esse genótipo apresentavam alta expressão $(87,75 \%)$.

Para a verificação de potencial associação entre a localização subcelular e os níveis de expressão de p27 e o grau de agressividade da doença, as 17 amostras foram divididas em dois grupos de acordo com o estadiamento: I/II (casos 3, 9, 16, 17, 20, 22, 27, 30 e 31) e III/IV (4, 8, 15, 23, 26, 29, 33, 35). Essa divisão em grupos permitiu a documentação da tendência do alelo T do polimorfismo p.V109G estar relacionado aos casos mais agressivos.

Nos dois casos onde houve a perda total de p27 nuclear correspondiam aos casos 8 (Figura 22-D) e 33 que apresentavam (um) estágio tumoral nível IV e foram a óbito devido ao CMT. Os dois casos apresentavam o genótipo TT para a variante p.V109G.

Três casos onde os níveis de expressão citoplasmáticos eram altos pertenciam a pacientes com estágio III (casos 23, 26 e 29). Além disto, nos casos 23 e 26 os níveis de calcitonina no pós-cirúrgico ainda estavam elevados (80,7 pg/ mL e $402 \mathrm{pg} / \mathrm{mL}$, respectivamente). Nesses três casos o genótipo p.V109G foram: TG (caso 23), TT (caso 26) e TG (caso 29), ou seja, nestes três o alelo T estava presente. 


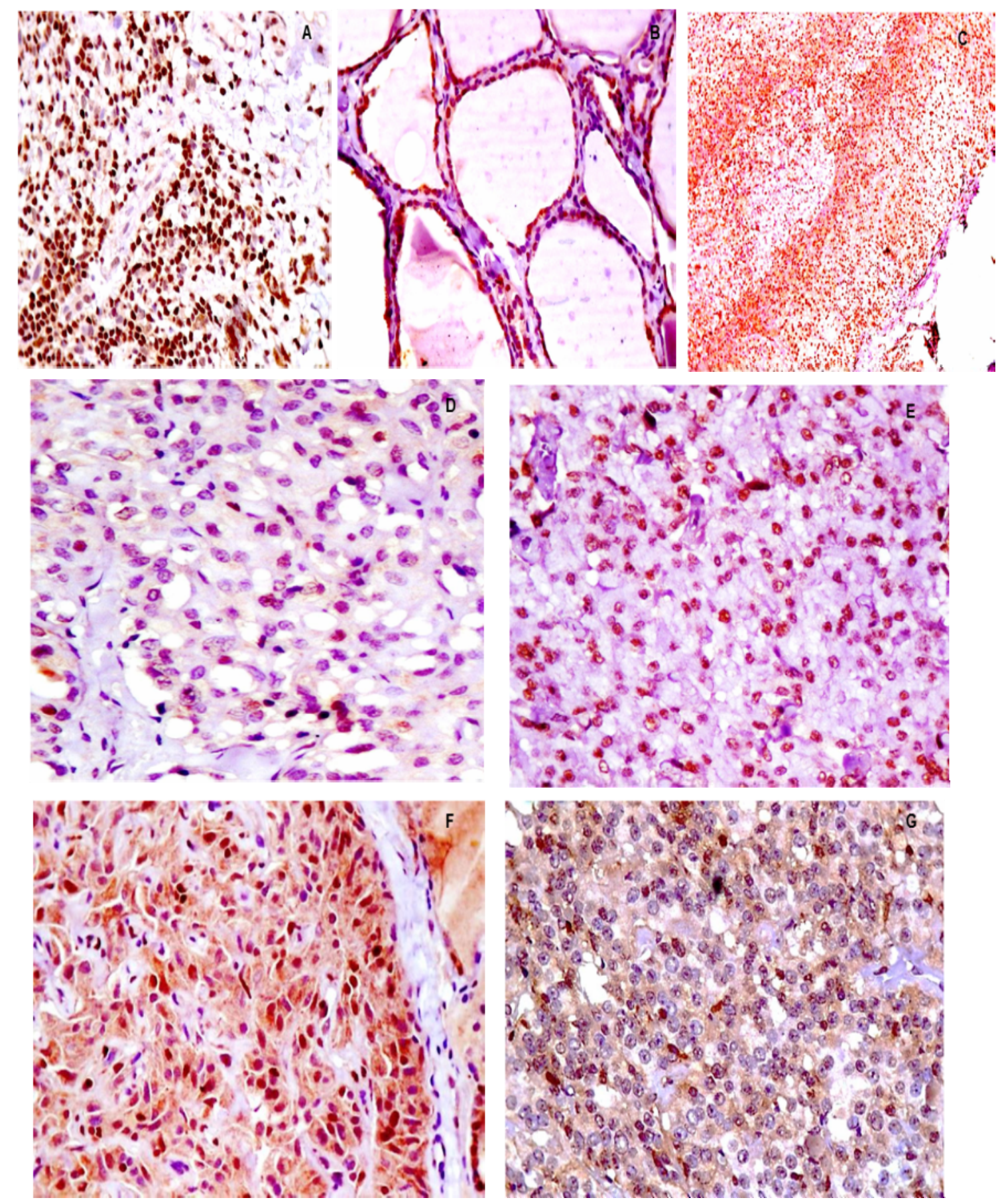

Figura 22 - Expressão e localização de p27 em CMT. Fotomicrografia dos casos representativos. A, tecido controle de pele; $\mathrm{B}$, tecido não-neoplásico da tireóide; $C$, tecido não-neoplásico da adrenal; D, sem expressão nuclear e citoplasmática; $E$, com expressão nuclear e ausência de expressão citoplasmática; $F$, com expressão nuclear e citoplasmática; $G$, negativo núcleo e expressão citoplasmática. X400. 
Tabela 21 - Genótipos polimorfismos c.-79C>T e p.V109G no gene p27, características clinico-patológicas e bioquímicas e resultados da análise da expressão proteica de p27 por imunohistoquímica em amostras de CMT

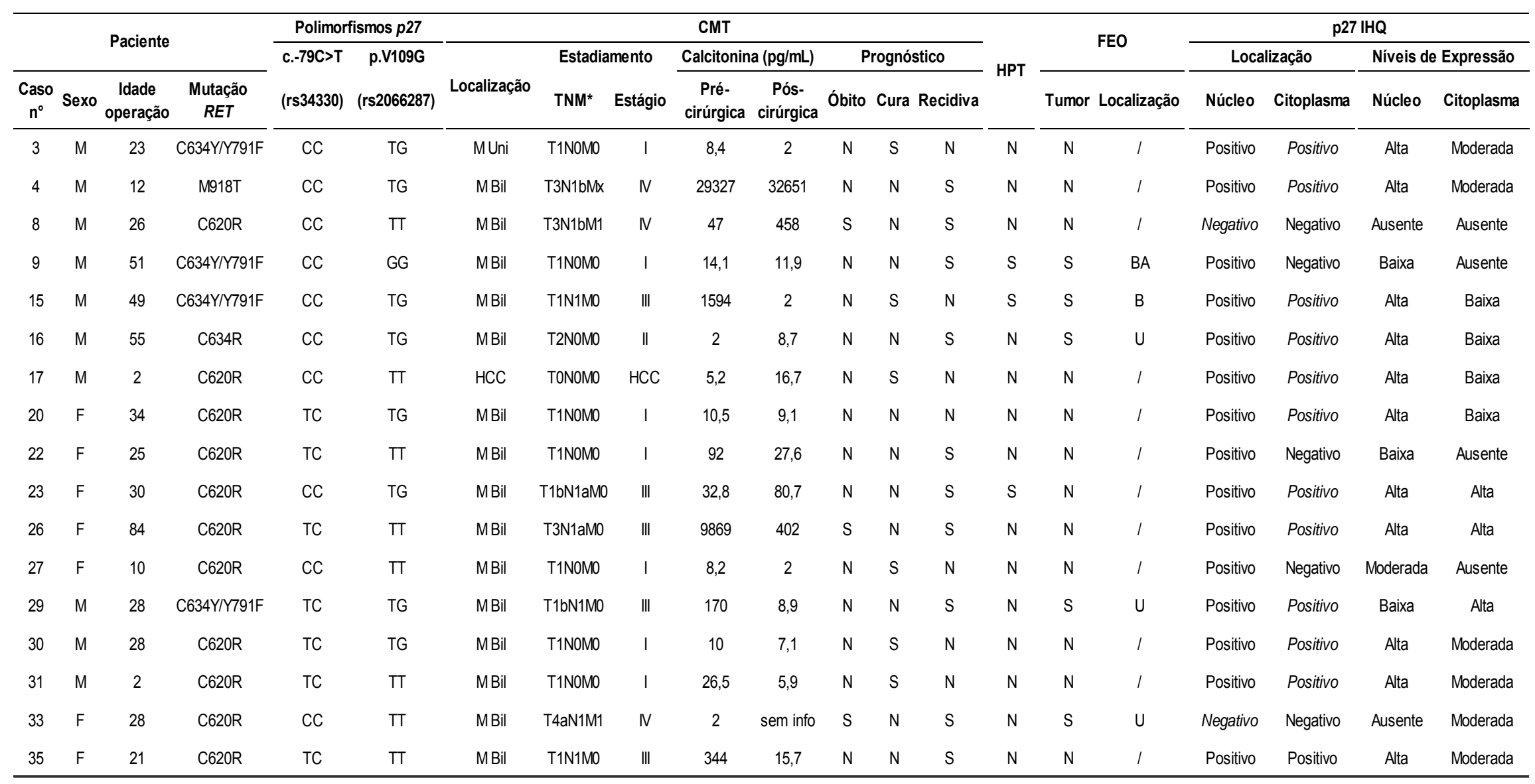

M, masculino; F, feminino; M Uni, multicêntrico unilateral; M Bil, multicêntrico bilateral; HCC, hiperplasia de células-C; N, ausente; S, presente; HPT, Hiperparatireoidismo primário; FEO, Feocromocitoma; BA, tumor bilateral assincrônico; B, tumor bilateral; U, tumor unilateral; /, sem tumor; Positivo e Negativo, correspondem a marcação do anticorpo anti-p27 nas células.

Níveis de calcitonina: homens: $<8,4 \mathrm{pg} / \mathrm{mL}$; mulheres: $<5,0 \mathrm{pg} / \mathrm{mL}$

*TNM, estadiamento tumor, metástase em linfonodos e metástase à distância 
6 DISCUSSÃO 


\subsection{Tumorigênese}

A tumorigênese é um processo que envolve a participação de vários genes, principalmente a ativação de diversos proto-oncogenes e inativação de genes supressores de tumor. Esses processos acarretam instabilidade genômica na célula, a qual promove a aquisição dos sinalizadores do câncer transformando assim a célula normal em neoplásica (Hanahan e Weinberg, 2011).

\subsubsection{Tumorigênese da NEM2}

Aproximadamente $95 \%$ dos casos de NEM2 são ocasionados pela presença de mutação germinativa no RET. Mutações no RET também são responsáveis por, no mínimo, cerca de $70 \%$ dos casos com CMT Familiar (Mulligan, 1993). Além disto, casos com CMT esporádico frequentemente apresentam vários tipos de mutação somática no RET, sendo no códon 918 o mais prevalente, além de mutações somáticas no gene RAS (Elisei et al., 2008; Raue. 2009 e 2010).

Sendo o RET um proto-oncogene, a presença de um alelo alterado pode desencadear a formação do tumor. Entretanto, observa-se dentre os afetados pertencentes a uma mesma família com NEM2, uma grande variabilidade fenotípica em relação à precocidade do tumor, idade ao 
diagnóstico, progressão e agressividade dos tumores. Essas características sugerem o envolvimento de outros eventos genéticos e/ou epigenéticos na tumorigênese da NEM2 (Mulligan, 1995).

A ativação do receptor RET e fosforilação dos sítios de tirosina ativam importantes vias de transmissão de sinais de transdução intracelular, incluindo Ras/Raf/MEK/ERK e Ras/PI3K/PTEN/Akt/mTOR, na qual ocorre a fosforilação do sítio Y1062. Essas vias são vitais para o processo de divisão e transformação celular e são rigorosamente controladas por diversos eventos que se iniciam da superfície celular e vão até a expressão gênica no núcleo (Kodama et al., 2005).

A regulação dessas vias é mediada por uma série de quinases, fosfatases e outras proteínas. Eventos genéticos e epigenéticos podem ocorrer em muitos elementos dessas vias levando à sinalização celular descontrolada, causando crescimento celular e proliferação descontrolada, e promovendo a formação do tumor ou crescimento celular anormal. Essas vias têm sido extensamente estudadas por diversos grupos com o propósito de desenvolver alvos terapêuticos para supressão da progressão tumoral e também aperfeiçoar o manejo dos pacientes (Steelman et al., 2008). Dentre as proteínas reguladas por essas vias ativadas por RET destacam-se a p18 e p27.

\subsubsection{1 p18 e p27}

Estudos em modelo animal mostraram que as interações de algumas proteínas reguladoras do ciclo celular promovem a formação de tumores 
endócrinos. Em particular, animais com duplo knockout para p27 ou p21 com perda de p18 resultam em tumores relacionados às síndromes NEM1 e NEM2 (Franklin et al., 2000).

No presente estudo, nos 66 tumores analisados não foram encontradas alterações somáticas no gene p18. Entretanto, van Veelen et al. (2009) identificaram seis mutações somáticas inativadoras de p18 em amostras de CMT e FEO humanos. Cada uma dessas alterações inibe parcialmente a função e reduzem a estabilidade da proteína p18. Esses dados mostraram, pela primeira vez, o envolvimento desse gene na tumorigênese NEM2. Este grupo também analisou previamente (2008) o envolvimento do p18 na progressão do CMT em modelos animais transgênicos. Nas linhagens RET2B;p18 +/- e RET2B;p18 -/- houve (uma) maior incidência de (no) desenvolvimento do CMT, em comparação às linhagens RET2B, p18+/- e p18-/-. Em adição ao estudo citado, verificou-se também que RET ativado promove o desenvolvimento precoce do CMT e a presença de tumores de maiores dimensões nos animais p18-/-;p27+/-Estes dados evidenciam, que quando a via RET está ativada de maneira anormal (presença de mutação ativadora) ela inibe as vias de p18 e p27 do controle do ciclo celular, promovendo o descontrole na divisão celular e formação do tumor (Figura 23).

Nenhuma variante patogênica foi encontrada no gene p27 nas amostras de tumores analisadas no presente projeto. Nossos dados estão de acordo com a literatura, pois ao contrário de outros genes supressores de tumor, deleções e/ou mutações no gene p27 são eventos raros em cânceres 
humanos e a desregulação de receptores tirosina-quinase (por exemplo, RET) ativam as vias de sinalização Src/BCR-ABL e Ras/MEK/MAPK, ou PI3K/AKT, que contribuem para o processo oncogênico, pois induzem, através da fosforilação em sítios específicos, a degradação e/ou translocação para o citoplasma da p27 (Larrea, 2009).

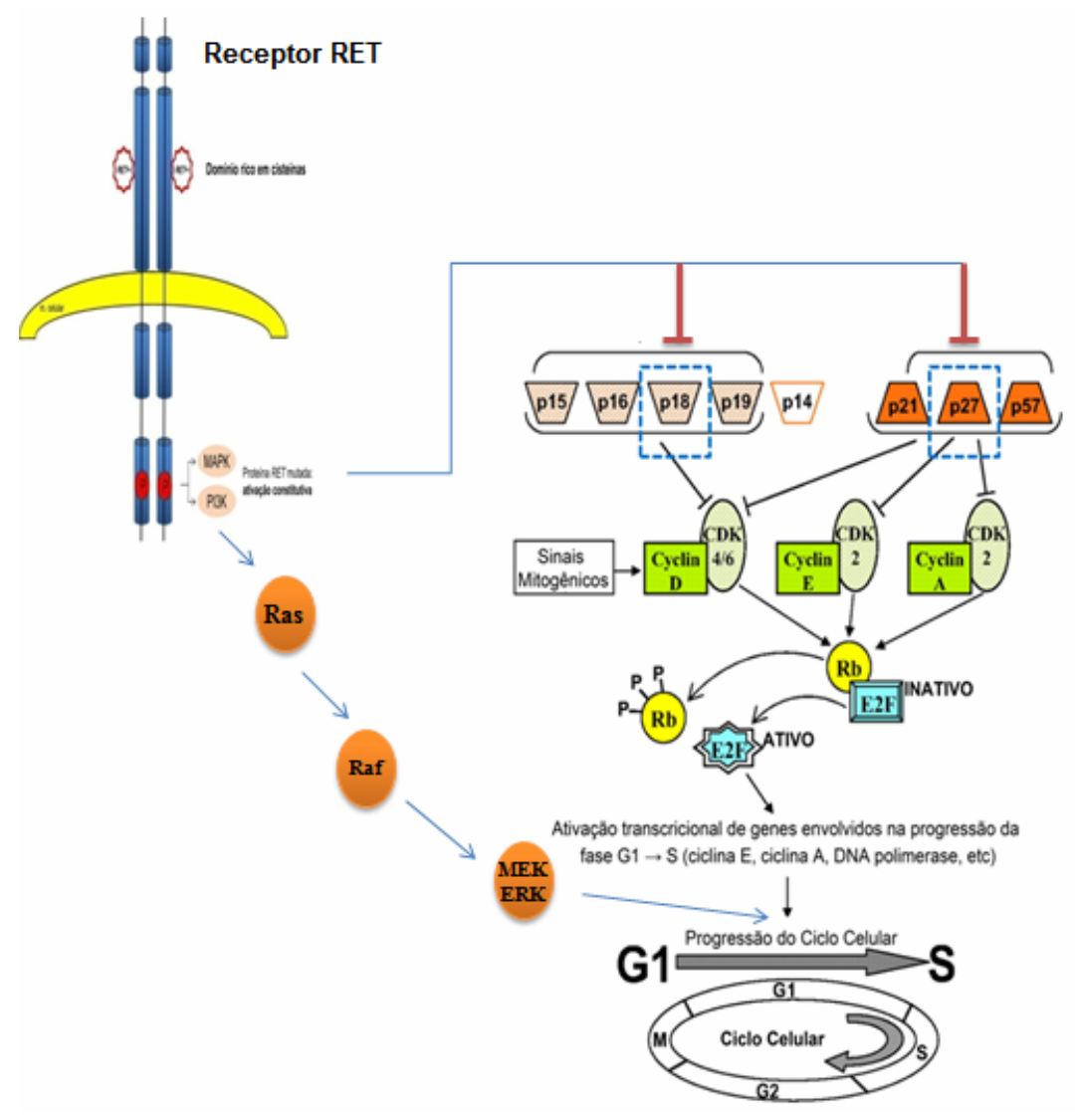

Figura 23 - Sinergismo molecular da proteina RET ativada com as proteínas p18 e p27 na tumorigênsese da NEM2 (Josh et al., 2007)

O gene p27 mostrou-se de grande interesse no estudo de susceptibilidade a tumores endócrinos após identificação de mutação 
germinativa no gene cakn1b em ratos, o que predispunha ao desenvolvimento espontâneo de tumores relacionados à NEM1 e NEM2; esta condição em animais foi denominada MENX (Fritz et al., 2002).

Diversos estudos mostraram perda ou redução da expressão de p27 em diversos tipos de câncer, incluindo de mama, cólon, pulmão, próstata, linfomas e gliomas (Chu et al., 2008). Em tumores primários, baixos níveis de p27 têm sido associados à redução no tempo de sobrevida do paciente.

A expressão de p27 é regulada por processos transcripcionais, traducionais e pós-traducionais (Hengst et al., 1996). As análises de expressão proteica por Western blot nos tumores NEM2 mostraram uma redução na expressão de p27 nas amostras CMT e FEO. Essa baixa expressão provavelmente ocorre devido à desregulação do receptor tirosinaquinase (no nosso caso, a proteína RET)_que pode estar ativando as vias de sinalização Src/BCR-ABL e Ras/MAP/ERK quinase, ou PI3K/AKT as quais fosforilam p27 em sítios específicos. Estes eventos contribuem para o processo oncogênico por intermédio da indução da perda de p27 nuclear (degradação proteolítica) e/ou sua translocação para o citoplasma (Chappel et al., 2011; Wander et al., 2011).

A inibição do ciclo celular é uma das funções fisiológicas de p27. Entretanto, em muitos tipos de câncer, não somente a redução nuclear de p27, mas também a sua sub-localização citoplasmática promove a ação de p27 como fator oncogênico, pois esta se liga a proteínas do RhoA e inibe a formação do complexo Rhoa-ROCK, aumentando a motilidade celular ligada ao processo de metástase (Larrea et al., 2009; Wander et al., 2011). Por 
isso, os estudos de expressão por imunohistoquímica podem funcionar como fator prognóstico de agressividade, de acordo com a localização subcelular de $\mathrm{p} 27$.

Um dado interessante observado no presente estudo de expressão por Western blot nas amostras de CMT foi a existência de correlação estatisticamente significante entre a expressão de p27 e o códon mutado no RET. Observou-se que quanto mais agressiva a mutação, menor foi a expressão de p27. Provavelmente esse controle deve ocorrer devido à correlação genótipo-fenótipo muito evidente nos casos de NEM2. Cada uma das mutações RET tem um poder específico e particular de fosforilação dos sítios de tirosina da proteina RET. De acordo com o consenso e classificação da American Thyroid Association, ATA (Kloos et al., 2009), mutações RET no códon 620 são classificadas no nível de risco B e estão relacionadas a CMT menos agressivos e ao desenvolvimento mais tardio; mutações no códon 634 estão classificadas no nível de risco C, com alto risco de desenvolver precocemente CMT e FEO; a mutação Y791F é classificada como nível A, com baixo risco transformação celular. Em estudo recente mostrou-se que o genótipo C634Y/Y791F (uma mutação mais agressiva associada a uma mais "branda") está associado ao fenótipo de FEO mais agressivo (Toledo et al., 2010)

Foi observada também uma redução na expressão de Skp2 nas amostras de CMT analisadas no presente estudo. Possivelmente, nesses tumores a via de degradação de p27 por Skp2 poderiam não estar com a expressão aumentada, como usualmente é observado em muitos tipos de 
tumores. Entretanto, outras vias que degradam p27 podem estar alteradas, tais como Jab1 (responsável por se ligar à p27 e exportá-la para o citoplasma, onde é degradada pelo complexo formado com Skp2) (Tomoda et al., 1999 e 2002).

Mais recentemente foram identificados novos mecanismos reguladores da expressão de p27, independentes da proteólise, os micros RNAs (miRNA). Dois poliastrônicos miRNAs, miR-221 e miR-222, foram reconhecidos como potenciais reguladores da tradução de p27. Glioblastomas com níveis elevados de miR-221 e 222 apresentaram baixos níveis de p27 proteico, sugerindo que ação desses miRNAs promovem a progressão do câncer pela inibição da expressão de p27. Interessante notar que o aumento da expressão de miR-221 e miR-222 é correlacionado com pior prognóstico em carcinomas papilíferos de tireóide, glioblastomas e adenocarcinoma pancreático (Wander et al., 2010).

A expressão de Skp2, uma ubiquitina ligase que faz parte de um dos complexos de degradação de p27, normalmente está aumentada em cânceres humanos. O aumento da degradação de p27 resulta em uma proliferação descontrolada e consequente progressão do tumor (Hershko, 2008).

\subsubsection{Polimorfismos no gene p27 como modulares de fenótipo em uma grande família com NEM2}

No presente estudo foi investigado a possibilidade do gene supressor de tumor p27, recentemente associada à síndrome NEM4 (Pellegata et al., 
2006), exercer um papel de modulador de fenótipo em uma extensa família com NEM2 associada à mutação C620R no gene RET. Nenhuma variante patogênica foi identificada nesses pacientes, excluindo a possibilidade de uma segunda mutação estar influenciando o fenótipo nessa família.

Nesta genealogia, o gene p27 apresentava duas variantes polimórficas em heterozigose c.-79C>T (rs34330) e p.V109G (rs2066827). Todos os pacientes dessa família foram analisados para esses polimorfismos e foram realizadas análises estatísticas para verificar se poderia haver uma associação entre essas variantes polimórficas em p27 e as manifestações clínicas dos pacientes. Esses SNPs apresentam baixa penetrância alélica $(<5 \%)$ e foram descritos como potencialmente funcionais. Estudos in vitro relataram que a variante c.-79C>T apresenta diminuição na transcrição gênica em tumores de tireoide (Landa et al., 2010). A variante p.V109G está associada fator de risco e progressão de diferentes tumores incluindo os de próstata (Kibel et al., 2003), carcinoma oral de células escamosas (Li et al., 2004), câncer invasivo do ovário (Gayther et al., 2007), câncer de mama (Tighli et al., 2005) e carcinoma pancreático (Chen et al., 2010). Em contraposição, um estudo recente mostrou que a variante alélica G na posição 326 confere um efeito protetor em relação ao carcinoma medular de tireoide (Pasquali et al., 2010).

O polimorfismo p.V109G está localizado na região codificadora (éxon 1) do gene $p 27$, mais especificamente em um domínio de ligação de p27 com Jab1, uma proteína envolvida na degradação de p27 (Tomoda, 1999; Shiraso, 2009). Estudos mostraram uma expressão aumentada de Jab1 e 
redução da expressão de p27 estão associados com o avanço do estágio tumoral e pior prognóstico em diversos tipos de câncer (Tomoda et al., 2002). A baixa expressão de p27 é um fator associado a um pior prognóstico em diversos tumores (revisado por Chu, 2008). Uma vez que o polimorfismo p.V109G se localiza no domínio de degradação de p27, levando à menor expressão de p27, este pode ser o motivo de estudos de câncer de mama indicarem essa variante como um possível fator molecular para risco, prognóstico e invasão tumoral.

O polimorfismo c.-79C>T está localizado na região não transcrita do gene p27 (5'UTR) e foi relatado estar associado a maior risco de câncer de próstata (Chang et al., 2004).

A localização citoplasmática de p27 tem sido associada à vários tipos de tumores com pior prognóstico (Liang et al., 2002; Li et al., 2006, Naidu et al., 2007; Huang et al., 2008).

A associação do genótipo p27 V109G-TT com menor expressão nuclear identificada em nossos casos sugere que este genótipo, e consequentemente a maior chance de perda de sua expressão nuclear, pode estar envolvido na regulação da agressividade do CMT. Interessante notar que esse mesmo genótipo ( $p 27$ V109G-TT) foi recentemente relatado estar associado com maior agressividade e chance de recidiva em CMTs esporádicos, em uma casuística européia (Pasquali et al., 2011). Os dois únicos casos com estadiamento 4 (metástases à distância) de nossa casuística apresentavam o genótipo p27 V109G-TT associado à perda completa de expressão de p27 no núcleo. Entretanto, quando se analisou 
em conjunto toda nossa casuística, não foi mostrada associação deste genótipo com a recidiva tumoral em nossos pacientes com CMT familial. 


\section{CONCLUSÕES}


No presente projeto, estudamos, de forma original, o papel do gene p27 na variabilidade fenotípica de pacientes com NEM2 e mutação germinativa no RET. A identificação de mutações em p27 associadas à susceptibilidade a tumores neuroendócrinos (NEM4) e a associação do polimorfismo V109G com maior agressividade em CMTs esporádicos relatados em uma casuística européia, levantaram a hipótese que variantes genéticas nesse gene poderiam estar envolvidas na tumorigenese de tumores NEM2-relacionados. Entretanto, nossos dados mostram que variantes em p27 e outros genes codificadores de CDKIs não estão diretamente implicados na tumorigenese da NEM2 e que as mutações germinativas no RET teriam um papel central, e talvez exclusivo, no desenvolvimento e progressão dos tumores analisados. Nossos resultados, apesar de negativos, estão de acordo com recente artigo que analisou exomas de CMTs de pacientes com NEM2 e mutação RET e demonstrou a ausência de segundos eventos genéticos frequentes nesses tumores.

Além disto, nossas análises usando Western blot e imunohistoquímica mostraram que a expressão de p27 em tumores NEM2 apresentou correlação com o tipo de mutação germinativa RET e que o SNP p27 V109G pode influenciar na localização subcelular da proteina p27 em CMTs. Entretanto, os efeitos dessas possíveis mudanças na expressão de p27 não se mostraram clinicamente significativos quando nossa casuística foi analisada como um todo. 


\section{ANEXOS}


Tabela Suplementar 1. Análise geral dos dados clínico-patológicos e bioquímicos em relação aos fatores para cura do CMT.

\begin{tabular}{|c|c|c|c|c|c|c|c|c|c|}
\hline & & Cura d & NEN & & & & & & \\
\hline Variável & & & & & OR & IC ( & $5 \%$ & Total & $\mathbf{p}$ \\
\hline & $\mathrm{n}$ & $\%$ & $\mathrm{n}$ & $\%$ & & Inferior & Superior & & \\
\hline Sexo & & & & & & & & & 0,180 \\
\hline Feminino & 12 & 66,7 & 6 & 33,3 & 1,00 & & & 18 & \\
\hline Masculino & 8 & 44,4 & 10 & 55,6 & 2,50 & 0,65 & 9,65 & 18 & \\
\hline Idade operação (anos) & & & & & & & & & $0,051 \&$ \\
\hline média (DP) & 35 , & 19,4) & 22 & 15,1) & 0,953 & 0,908 & 1,000 & $29,6(18,7)$ & \\
\hline $\begin{array}{l}\text { Idade (anos) } \\
\text { média (DP) }\end{array}$ & 43 & 18,3) & 31 & 16,5) & 0,958 & 0,916 & 1,002 & $377(18,3)$ & $0,061 \&$ \\
\hline Fenótipo NEM2 & & & & & & & & & $0,295 \#$ \\
\hline NEM2A & 9 & 52,9 & 8 & 47,1 & 1,00 & & & 17 & \\
\hline NEM2A/CMT-F & 9 & 52,9 & 8 & 47,1 & 1,00 & 0,26 & 3,85 & 17 & \\
\hline NEM2B & 2 & 100,0 & 0 & 0,0 & & & & 2 & \\
\hline Níveis de risco mutação RET ATA 2009 & & & & & & & & & $0,440^{* *}$ \\
\hline Moderado & 0 & 0,0 & 1 & 100,0 & 1,00 & & & 1 & \\
\hline Alto & 12 & 54,5 & 10 & 45,5 & & & & 22 & \\
\hline Muito alto & 6 & 54,5 & 5 & 45,5 & & & & 11 & \\
\hline Altíssimo & 2 & 100,0 & o & 0,0 & & & & 2 & \\
\hline Familial & & & & & & & & & $0,492^{*}$ \\
\hline Mutação de novo & 2 & 100,0 & 0 & 0,0 & 1,00 & & & 2 & \\
\hline Hereditário & 18 & 52,9 & 16 & 47,1 & & & & 34 & \\
\hline SNP1 p27_79T & & & & & & & & & $0,860 \#$ \\
\hline TT & 1 & 50,0 & 1 & 50,0 & 1,00 & & & 2 & \\
\hline $\mathrm{CC}$ & 11 & 52,4 & 10 & 47,6 & 0,91 & 0,05 & 16,54 & 21 & \\
\hline TC & 8 & 61,5 & 5 & 38,5 & 0,63 & 0,03 & 12,41 & 13 & \\
\hline SNP2 p27_V109G & & & & & & & & & $0,900 \#$ \\
\hline TT & 10 & 52,6 & 9 & 47,4 & 1,00 & & & 19 & \\
\hline GG & 1 & 50,0 & 1 & 50,0 & 1,11 & 0,06 & 20,49 & 2 & \\
\hline TG & 9 & 60,0 & 6 & 40,0 & 0,74 & 0,19 & 2,92 & 15 & \\
\hline Tumor_CMT & & & & & & & & & $0,204^{*}$ \\
\hline Ausente- & 2 & 28,6 & 5 & 71,4 & 1,00 & & & 7 & \\
\hline Presente & 18 & 62,1 & 11 & 37,9 & 0,24 & 0,04 & 1,48 & 29 & \\
\hline CMT-Localização & & & & & & & & & $0,002 \#$ \\
\hline $\mathrm{HCC}$ & 0 & 0,0 & 3 & 100,0 & 1,00 & & & 3 & \\
\hline Multicêntrico unilateral & 1 & 33,3 & 2 & 66,7 & & & & 3 & \\
\hline Multicêntrico bilateral & 19 & 73,1 & 7 & 26,9 & & & & 26 & \\
\hline Unicêntrico & 0 & 0,0 & 4 & 100,0 & & & & 4 & \\
\hline T & & & & & & & & & $0,001^{* *}$ \\
\hline To & 0 & 0,0 & 2 & 100,0 & & & & 2 & \\
\hline T1 & 7 & 36,8 & 12 & 63,2 & & & & 19 & \\
\hline T2 & 6 & 75,0 & 2 & 25,0 & & & & 8 & \\
\hline T3 & 6 & 100,0 & 0 & 0,0 & & & & 6 & \\
\hline T4 & 1 & 100,0 & 0 & 0,0 & & & & 1 & \\
\hline $\mathbf{N}$ & & & & & & & & & 0,001 \\
\hline No & 7 & 33,3 & 14 & 66,7 & 1,00 & & & 21 & \\
\hline N1/N2 & 13 & 86,7 & 2 & 13,3 & 0,08 & 0,01 & 0,44 & 15 & \\
\hline $\mathbf{M}$ & & & & & & & & & $0,053^{*}$ \\
\hline MO & 15 & 48,4 & 16 & 51,6 & 1,00 & & & 31 & \\
\hline M1 & 5 & 100,0 & 0 & 0,0 & & & & 5 & \\
\hline Calcitonina - pós-cirúrgia (pg/mL) & & & & & & & & & $<0,001^{\text {** }}$ \\
\hline$<=10$ & 4 & 22,2 & 14 & 77,8 & 1,00 & & & 18 & \\
\hline 10 a 150 & 5 & 71,4 & 2 & 28,6 & 0,11 & 0,02 & 0,83 & 7 & \\
\hline$>150$ & 8 & 100,0 & 0 & 0,0 & & & & 8 & \\
\hline Tumor NEM2- Hiperparatireoidismo & & & & & & & & & $0,672^{*}$ \\
\hline Não & 16 & 53,3 & 14 & 46,7 & 1,00 & & & 30 & \\
\hline Sim & 4 & 66,7 & 2 & 33,3 & 0,57 & 0,09 & 3,61 & 6 & \\
\hline Tumor NEM2- FEO & & & & & & & & & 0,813 \\
\hline Não & 13 & 54,2 & 11 & 45,8 & 1,00 & & & 24 & \\
\hline Sim & 7 & 58,3 & 5 & 41,7 & 0,84 & 0,21 & 3,43 & 12 & \\
\hline FEO- Localização & & & & & & & & & $0,573 \#$ \\
\hline Sem tumor & 13 & 56,5 & 10 & 43,5 & 1,00 & & & 23 & \\
\hline Unilateral & 4 & 50,0 & 4 & 50,0 & 1,30 & 0,26 & 6,52 & 8 & \\
\hline Bilateral & 1 & 50,0 & 1 & 50,0 & 1,30 & 0,07 & 23,43 & 2 & \\
\hline Bilateral assincrônico & 1 & 100,0 & 0 & 0,0 & & & & 1 & \\
\hline Hiperplasia & o & 0,0 & 1 & 100,0 & & & & 1 & \\
\hline FEO_Pass Score & & & & & & & & & $0,792^{* *}$ \\
\hline Benigno & 3 & 42,9 & 4 & 57,1 & 1,00 & & & 7 & \\
\hline Favorável & o & 0,0 & 1 & 100,0 & & & & 1 & \\
\hline Agressivo & 2 & 66,7 & 1 & 33,3 & 0,38 & 0,02 & 6,35 & 3 & \\
\hline IHQ-p27 Nucleo (Expressao) & & & & & & & & & $0,149^{* *}$ \\
\hline Ausente & 2 & 100,0 & 0 & 0,0 & 1,00 & & & 2 & \\
\hline Baixa & 3 & 100,0 & o & 0,0 & & & & 3 & \\
\hline Moderada & o & 0,0 & 1 & 100,0 & & & & 1 & \\
\hline Alta & 6 & 60,0 & 4 & 40,0 & & & & 10 & \\
\hline Muito alta & 0 & 0,0 & 1 & 100,0 & & & & 1 & \\
\hline IHQ Citoplasma (Expressao) & & & & & & & & & $0,961^{* *}$ \\
\hline Ausente & 3 & 75,0 & 1 & 25,0 & 1,00 & & & 4 & \\
\hline Baixa & 2 & 66,7 & 1 & 33,3 & 1,50 & 0,06 & 40,64 & 3 & \\
\hline Moderada & 3 & 50,0 & 3 & 50,0 & 3,00 & 0,19 & 47,96 & 6 & \\
\hline Alta & 2 & 66,7 & 1 & 33,3 & 1,50 & 0,08 & 40,64 & 3 & \\
\hline Muito alta & 1 & 100,0 & o & 0,0 & & & & 1 & \\
\hline Western Blot - Expressão nuclear p27 & & & & & & & & & $0,727^{* *}$ \\
\hline Moderada & 2 & 100,0 & 0 & 0,0 & 1,00 & & & 2 & \\
\hline Alta & 2 & 66,7 & 1 & 33,3 & & & & 3 & \\
\hline Muito alta & 5 & 71,4 & 2 & 28,6 & & & & 7 & \\
\hline Western Blot Skp2 expressão nuclear & & & & & & & & & $0,600^{* *}$ \\
\hline Moderada & 2 & 100,0 & 0 & 0,0 & 1,00 & & & 2 & \\
\hline Alta & 3 & 50,0 & 3 & 50,0 & & & & 6 & \\
\hline Muito alta & 4 & 100,0 & 0 & 0,0 & & & & 4 & \\
\hline
\end{tabular}


Tabela Suplementar 2. Análise geral dos dados clínico-patológicos e bioquímicos em relação aos fatores para recidiva do CMT.

\begin{tabular}{|c|c|c|c|c|c|c|c|c|}
\hline & & ecidiva & $\mathrm{ONE}$ & & & & & \\
\hline Variável & & & & & OR & IC & $95 \%)$ & Total \\
\hline & $\mathrm{n}$ & $\%$ & $\mathrm{n}$ & $\%$ & & Inferior & Superior & $\mathrm{n}$ \\
\hline Sexo & & & & & & & & \\
\hline Feminino & 7 & 38,9 & 11 & 61,1 & 1,00 & & & 18 \\
\hline Masculino & 11 & 61,1 & 7 & 38,9 & 0,40 & 0,11 & 1,55 & 18 \\
\hline Idade operação (anos) & & & & & & & & \\
\hline média (DP) & 23,3 & 14,5) & 35 & $(20,5)$ & 1,043 & 0,997 & 1,091 & $29,6(18,7)$ \\
\hline Idade (anos) & & & & & & & & \\
\hline média (DP) & $31, \mathrm{~s}$ & $15,8)$ & 43 & $(19,3)$ & 1,041 & 0,997 & 1,086 & $37,7(18,3)$ \\
\hline Fenótipo NEM2 & & & & & & & & \\
\hline NEM $2 A$ & 8 & 47,1 & 9 & 52,9 & 1,00 & & & 17 \\
\hline NEM2A/CMT-F & 10 & 58,8 & 7 & 41,2 & 0,62 & 0,16 & 2,42 & 17 \\
\hline NEM2B & 0 & 0,0 & 2 & 100,0 & & & & 2 \\
\hline Níveis de risco mutação RET ATA 2009 & & & & & & & & \\
\hline Moderado & 1 & 100,0 & 0 & 0,0 & 1,00 & & & 1 \\
\hline Alto & 11 & 50,0 & 11 & 50,0 & & & & 22 \\
\hline Muito alto & 6 & 54,5 & 5 & 45,5 & & & & 11 \\
\hline Altíssimo & 0 & 0,0 & 2 & 100,0 & & & & 2 \\
\hline Familial & & & & & & & & \\
\hline Mutação de novo & 0 & 0,0 & 2 & 100,0 & 1,00 & & & 2 \\
\hline Hereditário & 18 & 52,9 & 16 & 47,1 & & & & 34 \\
\hline SNP1 p27_79T & & & & & & & & \\
\hline 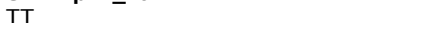 & 2 & 100,0 & 0 & 0,0 & 1,00 & & & 2 \\
\hline $\mathrm{CC}$ & 9 & 42,9 & 12 & 57,1 & & & & 21 \\
\hline $\mathrm{TC}$ & 7 & 53,8 & 6 & 46,2 & & & & 13 \\
\hline SNP2 p27_V109G & & & & & & & & \\
\hline TT $-1-c_{0}$ & 9 & 47,4 & 10 & 52,6 & 1,00 & & & 19 \\
\hline GG & 1 & 50,0 & 1 & 50,0 & 0,90 & 0,05 & 16,60 & 2 \\
\hline TG & 8 & 53,3 & 7 & 46,7 & 0,79 & 0,20 & 3,06 & 15 \\
\hline Tumor_CMT & & & & & & & & \\
\hline Ausente & 4 & 57,1 & 3 & 42,9 & 1,00 & & & 7 \\
\hline Presente & 14 & 48,3 & 15 & 51,7 & 1,43 & 0,27 & 7,55 & 29 \\
\hline CMT-Localização & & & & & & & & \\
\hline $\mathrm{HCC}$ & 3 & 100,0 & 0 & 0,0 & 1,00 & & & 3 \\
\hline Multicêntrico unilateral & 3 & 100,0 & 0 & 0,0 & & & & 3 \\
\hline Multicêntrico bilateral & 8 & 30,8 & 18 & 69,2 & & & & 26 \\
\hline Unicêntrico & 4 & 100,0 & 0 & 0,0 & & & & 4 \\
\hline $\mathbf{T}$ & & & & & & & & \\
\hline TO & 2 & 100,0 & 0 & 0,0 & 1,00 & & & 2 \\
\hline T1 & 13 & 68,4 & 6 & 31,6 & & & & 19 \\
\hline T2 & 2 & 25,0 & 6 & 75,0 & & & & 8 \\
\hline T3 & 1 & 16,7 & 5 & 83,3 & & & & 6 \\
\hline T4 & 0 & 0,0 & 1 & 100,0 & & & & 1 \\
\hline $\mathbf{N}$ & & & & & & & & \\
\hline NO & 16 & 76,2 & 5 & 23,8 & 1,00 & & & 21 \\
\hline $\mathrm{N} 1 / \mathrm{N} 2$ & 2 & 13,3 & 13 & 86,7 & 20,80 & 3,45 & 125,30 & 15 \\
\hline M & & & & & & & & \\
\hline MO & 18 & 58,1 & 13 & 41,9 & & & & 31 \\
\hline M1 & 0 & 0,0 & 5 & 100,0 & & & & 5 \\
\hline Calcitonina - pós-cirúrgia (pg/mL) & & & & & & & & \\
\hline$<=10$ & 16 & 88,9 & 2 & 11,1 & 1,00 & & & 18 \\
\hline 10 a 150 & 1 & 14,3 & 6 & 85,7 & 48,00 & 3,65 & 631,79 & 7 \\
\hline$>150$ & 0 & 0,0 & 8 & 100,0 & & & & 8 \\
\hline Tumor NEM2- Hiperparatireoidismo & & & & & & & & \\
\hline Não & 15 & 50,0 & 15 & 50,0 & 1,00 & & & 30 \\
\hline Sim & 3 & 50,0 & 3 & 50,0 & 1,00 & 0,17 & 5,77 & 6 \\
\hline Tumor NEM2- FEO & & & & & & & & \\
\hline Não & 14 & 58,3 & 10 & 41,7 & 1,00 & & & 24 \\
\hline Sim & 4 & 33,3 & 8 & 66,7 & 2,80 & 0,66 & 11,92 & 12 \\
\hline FEO- Localização & & & & & & & & \\
\hline Sem tumor & 13 & 56,5 & 10 & 43,5 & 1,00 & & & 23 \\
\hline Unilateral & 3 & 37,5 & 5 & 62,5 & 2,17 & 0,42 & 11,30 & 8 \\
\hline Bilateral & 1 & 50,0 & 1 & 50,0 & 1,30 & 0,07 & 23,43 & 2 \\
\hline Bilateral assincrônico & 0 & 0,0 & 1 & 100,0 & & & & 1 \\
\hline Hiperplasia & 1 & 100,0 & 0 & 0,0 & & & & 1 \\
\hline FEO_Pass Score & & & & & & & & \\
\hline Beniḡno & 4 & 57,1 & 3 & 42,9 & 1,00 & & & 7 \\
\hline Favorável & 1 & 100,0 & 0 & 0,0 & & & & 1 \\
\hline Agressivo & 0 & 0,0 & 3 & 100,0 & & & & 3 \\
\hline IHQ-p27 Nucleo (Expressao) & & & & & & & & \\
\hline Ausente & 0 & 0,0 & 2 & 100,0 & 1,00 & & & 2 \\
\hline Baixa & 0 & 0,0 & 3 & 100,0 & & & & 3 \\
\hline Moderada & 1 & 100,0 & 0 & 0,0 & & & & 1 \\
\hline Alta & 5 & 50,0 & 5 & 50,0 & & & & 10 \\
\hline Muito alta & 1 & 100,0 & 0 & 0,0 & & & & 1 \\
\hline IHQ Citoplasma (Expressao) & & & & & & & & \\
\hline Ausente & 1 & 25,0 & 3 & 75,0 & 1,00 & & & 4 \\
\hline Baixa & 2 & 66,7 & 1 & 33,3 & 0,17 & 0,01 & 4,52 & 3 \\
\hline Moderada & 3 & 50,0 & 3 & 50,0 & 0,33 & 0,02 & 5,33 & 6 \\
\hline Alta & 1 & 33,3 & 2 & 66,7 & 0,67 & 0,04 & 18,06 & 3 \\
\hline Muito alta & 0 & 0,0 & 1 & 100,0 & & & & 1 \\
\hline Western Blot - Expressão nuclear p27 & & & & & & & & \\
\hline Moderada & 0 & 0,0 & 2 & 100,0 & 1,00 & & & 2 \\
\hline Alta & 1 & 33,3 & 2 & 66,7 & & & & 3 \\
\hline Muito alta & 1 & 14,3 & 6 & 85,7 & & & & 7 \\
\hline Western Blot Skp2 expressão nuclear & & & & & & & & \\
\hline Moderada & 0 & 0,0 & 2 & 100,0 & 1,00 & & & 2 \\
\hline Alta & 2 & 33,3 & 4 & 66,7 & & & & 6 \\
\hline Muito alta & 0 & 0,0 & 4 & 100,0 & & & & 4 \\
\hline
\end{tabular}


Tabela Suplementar 3. Descrição dos fatores clínico-patológicos e bioquímicos de cura do CMT em indivíduos de uma grande família com NEM2A e mutação C620R no gene RET.

\begin{tabular}{|c|c|c|c|c|c|c|c|c|c|}
\hline \multirow{3}{*}{ Variável } & \multicolumn{4}{|c|}{ Cura do CMT } & \multirow{3}{*}{ OR } & \multirow{2}{*}{\multicolumn{2}{|c|}{ IC (95\%) }} & \multirow{3}{*}{$\begin{array}{c}\text { Total } \\
\mathrm{n}\end{array}$} & \multirow{3}{*}{$\mathbf{p}$} \\
\hline & \multicolumn{2}{|c|}{ Não } & \multicolumn{2}{|c|}{$\operatorname{Sim}$} & & & & & \\
\hline & $\mathrm{n}$ & $\%$ & $\mathrm{n}$ & $\%$ & & Inferior & Superior & & \\
\hline$\overline{\text { Sexo }}$ & & & & & & & & & $\overline{0,011}$ \\
\hline Feminino & 12 & 66,7 & 6 & 33,3 & 1,00 & & & 18 & \\
\hline Masculino & 2 & 18,2 & 9 & 81,8 & 9,00 & 1,46 & 55,48 & 11 & \\
\hline Idade diagnóstico CMT (anos) & & & & & & & & & $0,007 \&$ \\
\hline média (DP) & 32,2 & $(18,4)$ & 12,1 & $(7,3)$ & 0,79 & 0,67 & 0,94 & $21,8(17,0)$ & \\
\hline Diagnostico & & & & & & & & & 0,002 \\
\hline Screening & 3 & 20,0 & 12 & 80,0 & 1,00 & & & 15 & \\
\hline Sintomático & 11 & 78,6 & 3 & 21,4 & 0,07 & 0,01 & 0,41 & 14 & \\
\hline CMT & & & & & & & & & $0,100^{*}$ \\
\hline Não & 0 & 0,0 & 4 & 100,0 & 1,00 & & & 4 & \\
\hline Sim & 14 & 56,0 & 11 & 44,0 & & & & 25 & \\
\hline Cirugia & & & & & & & & & $>0,999^{*}$ \\
\hline Não & 2 & 50,0 & 2 & 50,0 & 1,00 & & & 4 & \\
\hline Sim & 12 & 48,0 & 13 & 52,0 & 1,08 & 0,13 & 8,95 & 25 & \\
\hline HCC pre operatorio & & & & & & & & & $>0,999^{*}$ \\
\hline Não & 0 & 0,0 & 1 & 100,0 & 1,00 & & & 1 & \\
\hline Sim & 14 & 50,0 & 14 & 50,0 & & & & 28 & \\
\hline Calcitonina pós & & & & & & & & & $0,001^{* *}$ \\
\hline$<=10$ & 3 & 18,8 & 13 & 81,2 & 1,00 & & & 16 & \\
\hline$>10$ e $<=150$ & 2 & 50,0 & 2 & 50,0 & 0,23 & 0,02 & 2,37 & 4 & \\
\hline$>150$ & 7 & 100,0 & 0 & 0,0 & & & & 7 & \\
\hline Estágio T & & & & & & & & & $0,023^{\star *}$ \\
\hline TO & 1 & 25,0 & 3 & 75,0 & 1,00 & & & 4 & \\
\hline T1 & 6 & 35,3 & 11 & 64,7 & 0,61 & 0,05 & 7,24 & 17 & \\
\hline $\mathrm{T} 2$ & 1 & 50,0 & 1 & 50,0 & 0,09 & 0,00 & 3,26 & 2 & \\
\hline T3 & 5 & 100,0 & 0 & 0,0 & & & & 5 & \\
\hline T4 & 1 & 100,0 & 0 & 0,0 & & & & 1 & \\
\hline Estágio $\mathbf{N}$ & & & & & & & & & 0,002 \\
\hline NO & 3 & 20,0 & 12 & 80,0 & 1,00 & & & 15 & \\
\hline N1/N2 & 11 & 78,6 & 3 & 21,4 & 0,07 & 0,01 & 0,41 & 14 & \\
\hline Estágio M & & & & & & & & & $0,006^{*}$ \\
\hline Mo & 8 & 34,8 & 15 & 65,2 & 1,00 & & & 23 & \\
\hline M1 & 6 & 100,0 & 0 & 0,0 & & & & 6 & \\
\hline FEO & & & & & & & & & $0,483^{*}$ \\
\hline Não & 13 & 46,4 & 15 & 53,6 & 1,00 & & & 28 & \\
\hline Sim & 1 & 100,0 & 0 & 0,0 & & & & 1 & \\
\hline Megacólon & & & & & & & & & $0,017^{*}$ \\
\hline Não & 14 & 60,9 & 9 & 39,1 & 1,00 & & & 23 & \\
\hline Sim & 0 & 0,0 & 6 & 100,0 & & & & 6 & \\
\hline SNP 802T & & & & & & & & & $0,585^{*}$ \\
\hline GG & 6 & 50,0 & 6 & 50,0 & 1,00 & & & 12 & \\
\hline TG/TT & 3 & 75,0 & 1 & 25,0 & 0,33 & 0,03 & 4,19 & 4 & \\
\hline SNP 838C & & & & & & & & & $0,181^{*}$ \\
\hline $\mathrm{CC}$ & 8 & 72,7 & 3 & 27,3 & 1,00 & & & 11 & \\
\hline CA/AA & 3 & 37,5 & 5 & 62,5 & 4,44 & 0,63 & 31,30 & 8 & \\
\hline SNP1 79T & & & & & & & & & 0,340 \\
\hline CT & 5 & 38,5 & 8 & 61,5 & 1,00 & & & 13 & \\
\hline TT & 9 & 56,2 & 7 & 43,8 & 0,49 & 0,11 & 2,16 & 16 & \\
\hline SNP2 V109G & & & & & & & & & $0,080^{*}$ \\
\hline TT & 13 & 59,1 & 9 & 40,9 & 1,00 & & & 22 & \\
\hline GT/GG & 1 & 14,3 & 6 & 85,7 & 8,67 & 0,89 & 84,84 & 7 & \\
\hline Total & 14 & 48,3 & 15 & 51,7 & & & & 29 & \\
\hline
\end{tabular}


Tabela Suplementar 4. Descrição dos fatores clínico-patológicos e bioquímicos de recidiva do CMT em indivíduos de uma grande família com NEM2A e mutação C620R no gene RET.

\begin{tabular}{|c|c|c|c|c|c|c|c|c|c|}
\hline \multirow{3}{*}{ Variável } & \multicolumn{4}{|c|}{ Metástase do CMT } & \multirow{3}{*}{ OR } & & & \multirow{3}{*}{$\begin{array}{c}\text { Total } \\
\mathrm{n}\end{array}$} & \multirow{3}{*}{$\mathbf{p}$} \\
\hline & \multicolumn{2}{|c|}{ Não } & \multicolumn{2}{|c|}{ Sim } & & \multicolumn{2}{|c|}{ IC $(95 \%)$} & & \\
\hline & $\mathrm{n}$ & $\%$ & $\mathrm{n}$ & $\%$ & & Inferior & Superior & & \\
\hline Sexo & & & & & & & & & $0,234^{*}$ \\
\hline Feminino & 10 & 55,6 & 8 & 44,4 & 1,00 & & & 18 & \\
\hline Masculino & 9 & 81,8 & 2 & 18,2 & 0,28 & 0,05 & 1,67 & 11 & \\
\hline Idade diagnóstico CMT (anos) & & & & & & & & & $0,172 \&$ \\
\hline média (DP) & 18,4 & $(19,4)$ & 28 & $(8,7)$ & 1,04 & 0,98 & 1,09 & $21,8(17,0)$ & \\
\hline Diagnostico & & & & & & & & & $0,021^{*}$ \\
\hline Screening & 13 & 86,7 & 2 & 13,3 & 1,00 & & & 15 & \\
\hline Sintomático & 6 & 42,9 & 8 & 57,1 & 8,67 & 1,39 & 53,85 & 14 & \\
\hline CMT & & & & & & & & & $0,268^{*}$ \\
\hline Não & 4 & 100,0 & 0 & 0,0 & 1,00 & & & 4 & \\
\hline Sim & 15 & 60,0 & 10 & 40,0 & & & & 25 & \\
\hline Cirugia & & & & & & & & & $0,268^{*}$ \\
\hline Não & 4 & 100,0 & 0 & 0,0 & 1,00 & & & 4 & \\
\hline Sim & 15 & 60,0 & 10 & 40,0 & & & & 25 & \\
\hline HCC pre operatorio & & & & & & & & & $>0,999^{*}$ \\
\hline Não & 1 & 100,0 & 0 & 0,0 & 1,00 & & & 1 & \\
\hline Sim & 18 & 64,3 & 10 & 35,7 & & & & 28 & \\
\hline Calcitonina pós & & & & & & & & & $0,019 * *$ \\
\hline$<=10$ & 14 & 87,5 & 2 & 12,5 & 1,00 & & & 16 & \\
\hline$>10$ e $<=150$ & 3 & 75,0 & 1 & 25,0 & 2,33 & 0,16 & 34,90 & 4 & \\
\hline$>150$ & 2 & 28,6 & 5 & 71,4 & 35,00 & 3,84 & 319,07 & 7 & \\
\hline Estágio T & & & & & & & & & $0,007^{* *}$ \\
\hline T0 & 4 & 100,0 & 0 & 0,0 & 1,00 & & & 4 & \\
\hline T1 & 13 & 76,5 & 4 & 23,5 & & & & 17 & \\
\hline T2 & 1 & 50,0 & 1 & 50,0 & & & & 2 & \\
\hline T3 & 1 & 20,0 & 4 & 80,0 & & & & 5 & \\
\hline T4 & 0 & 0,0 & 1 & 100,0 & & & & 1 & \\
\hline Estágio $\mathbf{N}$ & & & & & & & & & $<0,001^{*}$ \\
\hline NO & 15 & 100,0 & 0 & 0,0 & 1,00 & & & 15 & \\
\hline N1/N2 & 4 & 28,6 & 10 & 71,4 & & & & 14 & \\
\hline Estágio M & & & & & & & & & $0,011^{*}$ \\
\hline $\mathrm{MO}$ & 18 & 78,3 & 5 & 21,7 & 1,00 & & & 23 & \\
\hline M1 & 1 & 16,7 & 5 & 83,3 & 18,00 & 1,69 & 191,53 & 6 & \\
\hline FEO & & & & & & & & & $0,345^{*}$ \\
\hline Não & 19 & 67,9 & 9 & 32,1 & 1,00 & & & 28 & \\
\hline Sim & 0 & 0,0 & 1 & 100,0 & & & & 1 & \\
\hline Megacólon & & & & & & & & & $0,068^{*}$ \\
\hline Não & 13 & 56,5 & 10 & 43,5 & 1,00 & & & 23 & \\
\hline Sim & 6 & 100,0 & 0 & 0,0 & & & & 6 & \\
\hline SNP 802T & & & & & & & & & $0,569^{*}$ \\
\hline GG & 7 & 58,3 & 5 & 41,7 & 1,00 & & & 12 & \\
\hline TG/TT & 1 & 25,0 & 3 & 75,0 & 4,20 & 0,33 & 53,13 & 4 & \\
\hline SNP 838C & & & & & & & & & $0,352^{*}$ \\
\hline $\mathrm{CC}$ & 5 & 45,5 & 6 & 54,5 & 1,00 & & & 11 & \\
\hline CA/AA & 6 & 75,0 & 2 & 25,0 & 0,28 & 0,04 & 2,04 & 8 & \\
\hline SNP1 79T & & & & & & & & & $0,714^{*}$ \\
\hline CT & 8 & 61,5 & 5 & 38,5 & 1,00 & & & 13 & \\
\hline TT & 11 & 68,8 & 5 & 31,2 & 0,73 & 0,16 & 3,39 & 16 & \\
\hline SNP2 V109G & & & & & & & & & $0,367^{*}$ \\
\hline TT & 13 & 59,1 & 9 & 40,9 & 1,00 & & & 22 & \\
\hline GT/GG & 6 & 85,7 & 1 & 14,3 & 0,24 & 0,02 & 2,36 & 7 & \\
\hline Total & 19 & 65,5 & 10 & 34,5 & & & & 29 & \\
\hline
\end{tabular}


9 REFERÊNCIAS 
Agarwal SK, Mateo CM, Marx SJ. Rare germline mutations in cyclindependent kinase inhibitor genes in multiple endocrine neoplasia type 1 and related states. J Clin Endocrinol Metab. 2009 May;94(5):1826-34.

Amiel J, Lyonnet S. Hirschsprung disease, associated syndromes, and genetics: a review. J Med Genet. 2001 Nov;38(11):729-39.

Amiel J, Sproat-Emison E, Garcia-Barcelo M, Lantieri F, Burzynski G, Borrego S, Pelet A, Arnold S, Miao X, Griseri P, Brooks AS, Antinolo G, de Pontual L, Clement-Ziza M, Munnich A, Kashuk C, West K, Wong KK, Lyonnet S, Chakravarti A, Tam PK, Ceccherini I, Hofstra RM, Fernandez R, Hirschsprung Disease Consortium. Hirschsprung disease, associated syndromes and genetics: a review. J Med Genet. 2008 Jan;45(1):1-14. Epub 2007 Oct 26.

Arighi E, Borello MG, Sariola H. RET tyrosine kinase signaling in development and cancer. Cytokine \& Growth Factor Reviews. 2005; 16: 441467.

Arum SM, Dahia PL, Schneider K, Braverman LE. A RET mutation with decreased penetrance in the family of a patient with a "sporadic" pheochromocytoma. Endocrine. 2005 Nov;28(2):193-8.

Baldassarre G, Barone MV, Belletti B, Sandomenico C, Bruni P, Spiezia S, Boccia A, Vento MT, Romano A, Pepe S, Fusco A, Viglietto G. Key role of the cyclin-dependent kinase inhibitor p27kip1 for embryonal carcinoma cell survival and differentiation. Oncogene. 1999 Nov 4;18(46):6241-51. 
Bartsch DK, Hasse C, Schug C, Barth P, Rothmund M, Höppner W. A RET double mutation in the germline of a kindred with FMTC. Exp Clin Endocrinol Diabetes. 2000;108(2):128-32.

Baumgartner-Parzer SM, Lang R, Wagner L, Heinze G, Niederle B, Kaserer K, Waldhäusl W, Vierhapper H. Polymorphisms in exon 13 and intron 14 of the RET protooncogene: genetic modifiers of medullary thyroid carcinoma? $\mathrm{J}$ Clin Endocrinol Metab. 2005 Nov;90(11):6232-6. Epub 2005 Aug 23.

Brandi ML, Gagel RF, Angeli A, Bilezikian JP, Beck-Peccoz P, Bordi C, Conte-Devolx B, Falchetti A, Gheri RG, Libroia A, Lips CJ, Lombardi G, Mannelli M, Pacini F, Ponder BA, Raue F, Skogseid B, Tamburrano G, Thakker RV, Thompson NW, Tomassetti P, Tonelli F, Wells SA Jr, Marx SJ. Guidelines for diagnosis and therapy of MEN type 1 and type 2. J Clin Endocrinol Metab. 2001;86:5658-71.

Borriello A, Cucciolla V, Oliva A, Zappia V, Della Ragione F. p27Kip1 metabolism: a fascinating labyrinth. Cell Cycle. 2007 May 2;6(9):1053-61.

Burnichon N, Lepoutre-Lussey C, Laffaire J, Gadessaud N, Molinié V, Hernigou A, Plouin PF, Jeunemaitre X, Favier J, Gimenez-Roqueplo AP. A novel TMEM127 mutation in a patient with familial bilateral pheochromocytoma. Eur J Endocrinol. 2011 Jan;164(1):141-5. doi: 10.1530/EJE-10-0758. Epub 2010 Oct 5

Ceccherini I, Hofstra RM, Luo Y, Stulp RP, Barone V, Stelwagen T, Bocciardi $\mathrm{R}$, Nijveen $\mathrm{H}$, Bolino $A$, Seri $M$ et al. DNA polymorphisms and conditions for SSCP analysis of the 20 exons of the ret proto-oncogene. Oncogene. 1994 Oct;9(10):3025-9. 
Ceolin L, Siqueira DR, Ferreira CV, Romitti M, Maia SC, Leiria L, Crispim D, Ashton-Prolla P, Maia AL. Additive effect of RET polymorphisms on sporadic medullary thyroid carcinoma susceptibility and tumor aggressiveness. Eur $\mathrm{J}$ Endocrinol. 2012 May;166(5):847-54.

Chang BL, Zheng SL, Isaacs SD, Wiley KE, Turner A, Li G, Walsh PC, Meyers DA, Isaacs WB, Xu J. A polymorphism in the CDKN1B gene is associated with increased risk of hereditary prostate cancer. Cancer Res. 2004 Mar 15; 64(6): 1997-9.

Chappell WH, Steelman LS, Long JM, Kempf RC, Abrams SL, Franklin RA, Bäsecke J, Stivala F, Donia M, Fagone P, Malaponte G, Mazzarino MC, Nicoletti F, Libra M, Maksimovic-Ivanic D, Mijatovic S, Montalto G, Cervello M, Laidler P, Milella M, Tafuri A, Bonati A, Evangelisti C, Cocco L, Martelli AM, McCubrey JA. Ras/Raf/MEK/ERK and PI3K/PTEN/Akt/mTOR inhibitors: rationale and importance to inhibiting these pathways in human health. Oncotarget. 2011 Mar;2(3):135-64.

Chen J, Amos Cl, Merriman KW, Wei Q, Sen S, Killary AM, Frazier ML. Genetic variants of p21 and p27 and pancreatic cancer risk in non-Hispanic Whites: a case-control study. Pancreas. 2010;39(1):1-4.

Chen J, Saha P, Kornbluth S, Dynlacht BD, Dutta A. Cyclin-binding motifs are essential for the function of p21CIP1. Mol Cell Biol. 1996 Sep; 16(9):4673-82.

Chiappetta G, De Marco C, Quintiero A, Califano D, Gherardi S, Malanga D, Scrima M, Montero-Conde C, Cito L, Monaco M, Motti ML, Pasquinelli R, Agosti V, Robledo M, Fusco A, Viglietto G. Overexpression of the S-phase kinase-associated protein 2 in thyroid cancer. Endocr Relat Cancer. 2007 Jun;14(2):405-20. 
Chu IM, Hengst L, Slingerland JM. 8. The Cdk inhibitor p27 in human cancer: prognostic potential and relevance to anticancer therapy. Nat Rev Cancer. 2008 Apr;8(4):253-67.

Cosci B, Vivaldi A, Romei C, Gemignani F, Landi S, Ciampi R, Tacito A, Molinaro E, Agate L, Bottici V, Cappagli V, Viola D, Piaggi P, Vitti P, Pinchera $A$, Elisei R. In silico and in vitro analysis of rare germline allelic variants of RET oncogene associated with medullary thyroid cancer. Endocr Relat Cancer. 2011 Sep 20;18(5):603-12.

Da Silva AM, Maciel RM, Da Silva MR, Toledo SR, De Carvalho MB, Cerutti JM. A novel germ-line point mutation in RET exon 8 (Gly(533)Cys) in a large kindred with familial medullary thyroid carcinoma. J Clin Endocrinol Metab. 2003 Nov;88(11):5438-43.

de Groot JWB, Links TP, Plukker JTM, Lips C, Hofstra RM. RET as a diagnostic and therapeutic target in sporadic and hereditary endocrine tumors. Endocr Rev. 2006;27(5): 535-560.

Drosten M, Hilken G, Böckmann M, Rödicker F, Mise N, Cranston AN, Dahmen U, Ponder BA, Pützer BM. Role of MEN2A-derived RET in maintenance and proliferation of medullary thyroid carcinoma. J Natl Cancer Inst. 2004 Aug 18;96(16):1231-9.

Dvorakova S, Vaclavikova E, Ryska A, Cap J, Vlcek P, Duskova J, Kodetova D, Holub V, Novak Z, Bendlova B. Double germline mutations in the RET Proto-oncogene in MEN 2A and MEN 2B kindreds. Exp Clin Endocrinol Diabetes. 2006 Apr;114(4):192-6.

Elisei R, Cosci B, Romei C, Bottici V, Sculli M, Lari R, Barale R, Pacini F, Pinchera A. RET exon 11 (G691S) polymorphism is significantly more frequent in sporadic medullary thyroid carcinoma than in the general population. J Clin Endocrinol Metab. 2004 Jul;89(7):3579-84. 
Elisei R, Romei C, Cosci B, Agate L, Bottici V, Molinaro E, Sculli M, Miccoli $P$, Basolo F, Grasso L Pacini F, Pinchera A. RET genetic screening in patients with medullary thyroid cancer and their relatives: experience with 807 individuals at one center. J Clin Endocrinol Metab. 2007;92(12):4725-9.

Eng C. RET proto-oncogene in the development of human cancer. J Clin Oncol. 1999 Jan;17(1):380-93.

Eng C, Clayton D, Schuffenecker I, Lenoir G, Cote G, Gagel RF, van Amstel HK, Lips CJ, Nishisho I, Takai SI, Marsh DJ, Robinson BG, Frank-Raue K, Raue F, Xue F, Noll WW, Romei C, Pacini F, Fink M, Niederle B, Zedenius J, Nordenskjöld M, Komminoth P, Hendy GN, Mulligan LM, et al. The relationship between specific RET proto-oncogene mutations and disease phenotype in multiple endocrine neoplasia type 2. International RET mutation consortium analysis. JAMA. 1996 Nov 20;276(19):1575-9.

Eng C, Crossey PA, Mulligan LM, Healey CS, Houghton C, Prowse A, Chew SL, Dahia PL, O'Riordan JL, Toledo SP, et al. Mutations in the RET protooncogene and the von Hippel-Lindau disease tumour suppressor gene in sporadic and syndromic phaeochromocytomas. J Med Genet. 1995 Dec;32 (12):934-7.

Fero ML, Rivkin M, Tasch M, Porter P, Carow CE, Firpo E, Polyak K, Tsai LH, Broudy V, Perlmutter RM, Kaushansky K, Roberts JM. A syndrome of multiorgan hyperplasia with features of gigantism, tumorigenesis, and female sterility in p27(Kip1)-deficient mice. Cell. 1996 May 31;85(5):733-44. 
Frank-Raue K, Rybicki LA, Erlic Z, Schweizer H, Winter A, Milos I, Toledo SP, Toledo RA, Tavares MR, Alevizaki M, Mian C, Siggelkow H, Hüfner M, Wohllk N, Opocher G, Dvořáková S, Bendlova B, Czetwertynska M, Skasko E, Barontini M, Sanso G, Vorländer C, Maia AL, Patocs A, Links TP, de Groot JW, Kerstens MN, Valk GD, Miehle K, Musholt TJ, Biarnes J, Damjanovic S, Muresan M, Wüster C, Fassnacht M, Peczkowska M, Fauth C, Golcher H, Walter MA, Pichl J, Raue F, Eng C, Neumann HP. Risk profiles and penetrance estimations in multiple endocrine neoplasia type 2A caused by germline RET mutations located in exon 10. International RET Exon 10 Consortium. Hum Mutat. 2011 Jan;32(1):51-8.

Franklin D, Godfrey V, O’brien D, Deng C, Xiong Y. Functional collaboration between different cyclin-dependent kinase inhibitors suppresses tumor growth with distinct tissue specificity. Mol Cell Biol. 2000; 20: 6147-6158.

Franklin DS, Godfrey VL, Lee H, Kovalev GI, Schoonhoven R, Chen-Kiang S, Su L, Xiong Y. CDK inhibitors p18(INK4c) and p27(Kip1) mediate two separate pathways to collaboratively suppress pituitary tumorigenesis. Genes Dev. 1998 Sep 15;12(18):2899-911.

Fritz A, Walch A, Piotrowska K, Rosemann M, Schäffer E, Weber K, Timper A, Wildner G, Graw J, Höfler H, Atkinson MJ. Recessive transmission of a multiple endocrine neoplasia syndrome in the rat. Cancer Res. 2002; 62(11):3048-51.

Gayther SA, Song H, Ramus SJ, Kjaer SK, Whittemore AS, Quaye L, Tyrer J, Shadforth D, Hogdall E, Hogdall C, Blaeker J, DiCioccio R, McGuire V, Webb PM, Beesley J, Green AC, Whiteman DC; Australian Ovarian Cancer Study Group, Goodman MT, Lurie G, Carney ME, Modugno F, Ness RB, Edwards RP, Moysich KB, Goode EL, Couch FJ, Cunningham JM, Sellers TA, Wu AH, Pike MC, Iversen ES, Marks JR, Garcia-Closas M, Brinton L, Lissowska J, Peplonska B, Easton DF, Jacobs I, Ponder BA, Schildkraut J, Pearce CL, Chenevix-Trench G, Berchuck A, Pharoah PD Tagging single 
nucleotide polymorphisms in cell cycle control genes and susceptibility to invasive epithelial ovarian cancer. Cancer Res. 2007;67(7):3027-35.

Gimm O, Neuberg DS, Marsh DJ, Dahia PL, Hoang-Vu C, Raue F, Hinze R, Dralle $\mathrm{H}$, Eng $\mathrm{C}$. Over-representation of a germline RET sequence variant in patients with sporadic medullary thyroid carcinoma and somatic RET codon 918 mutation. Oncogene. 1999 Feb 11;18(6):1369-73.

González P, Díez-Juan A, Coto E, Alvarez V, Reguero JR, Batalla A, Andrés $V$. A single-nucleotide polymorphism in the human p27kip1 gene $(-838 C>A)$ affects basal promoter activity and the risk of myocardial infarction. BMC Biol. 2004; Apr 2;2:5.

Groot JWB, John TPL, Plukker JTM, Lips CJM., Hofstra RMW. RET as a diagnostic and therapeutic target in sporadic and hereditary endocrine tumors. Endocrine Reviews. 2006; 27(5):535-560.

Hanahan D, Weinberg RA. Hallmarks of cancer: the next generation. Cell. 2011; Mar 4;144(5):646-74.

Hazard JB, Hawk WA, Crile G Jr. Medullary (solid) carcinoma of the thyroid; a clinicopathologic entity. J Clin Endocrinol Metab. 1959 Jan;19(1):152-61.

Hengst L, Reed SI. Translational control of p27Kip1 accumulation during the cell cycle. Science. 1996 Mar 29;271(5257):1861-4.

Hershko DD. Cyclin-dependent kinase inhibitor p27 as a prognostic biomarker and potential cancer therapeutic target. Future Oncol. 2010 Dec;6(12):1837-47. doi: 10.2217/fon.10.144. Review.

Hoff AO, Cote GJ, Gagel RF. Multiple endocrine neoplasias. Annu Rev Physiol. 2000;62:377-411. Review. 
Höppner W, Dralle H, Brabant G. Duplication of 9 base pairs in the critical cysteine-rich domain of the RET proto-oncogene causes multiple endocrine neoplasia type 2A. Hum Mutat. 1998;Suppl 1:S128-30.

Höppner W, Ritter MM. A duplication of $12 \mathrm{bp}$ in the critical cysteine rich domain of the RET proto-oncogene results in a distinct phenotype of multiple endocrine neoplasia type 2A. Hum Mol Genet. 1997 Apr;6(4):587-90.

Horn RC, Ravdin IS. Carcinoma of the thyroid gland in youth. J Clin Endocrinol Metab. 1951 Oct;11(10):1166-78.

Hosmer DW, Lemeshow S. Applied Logistic Regression. 2a. ed. New York: Wiley; 2000. 320p.

Huang SC, Koch CA, Vortmeyer AO, Pack SD, Lichtenauer UD, Mannan P, Lubensky IA, Chrousos GP, Gagel RF, Pacak K, Zhuang Z. Duplication of the mutant RET allele in trisomy 10 or loss of the wild-type allele in multiple endocrine neoplasia type 2-associated pheochromocytomas. Cancer Res. 2000;60(22):6223-6.

Huang SP, Yu CC, Liu CC, Wu TT, Huang CH, Wu MT. CDKN1B V109G polymorphism frequency and prostate cancer risk in Taiwan. Urol Int. 2008;81(1):36-40.

Joshi PP, Kulkarni MV, Yu BK, Smith KR, Norton DL, Veelen W, Höppener JW, Franklin DS. Simultaneous downregulation of CDK inhibitors p18(Ink4c) and p27(Kip1) is required for MEN2A-RET-mediated mitogenesis. Oncogene. 2007 Jan 25;26(4):554-70. 
Kaldrymides P, Mytakidis N, Anagnostopoulos T, Vassiliou M, Tertipi A, Zahariou M, Rampias T, Koutsodontis G, Konstantopoulou I, Ladopoulou A, Bei T, Yannoukakos D. A rare RET gene exon 8 mutation is found in two Greek kindreds with familial medullary thyroid carcinoma: implications for screening. Clin Endocrinol (Oxf). 2006 May;64(5):561-6.

Kasprzak L, Nolet S, Gaboury L, Pavia C, Villabona C, Rivera-Fillat F, Oriola J, Foulkes WD. Familial medullary thyroid carcinoma and prominent corneal nerves associated with the germline V804M and V778I mutations on the same allele of RET. J Med Genet. 2001;38(11):784-7.

Kawamata N, Morosetti R, Miller CW, Park D, Spirin KS, Nakamaki T, Takeuchi S, Hatta Y, Simpson J, Wilcyznski S, et al. Molecular analysis of the cyclin-dependent kinase inhibitor gene p27/Kip1 in human malignancies. Cancer Res. 1995 Jun 1;55(11):2266-9.

Khoo ML, Freeman JL, Witterick IJ, Irish JC, Rotstein LE, Gullane PJ, Asa SL. Underexpression of p27/Kip in thyroid papillary microcarcinomas with gross metastatic disease. Arch Otolaryngol Head Neck Surg. 2002 Mar;128(3):253-7.

Khosla S,Patel VM,Hay ID,Schaid DJ,Grant CS, van Heerden JA, Thibodeau SN. Loss of heterozygosity suggests multiple genetic alterations in pheochromocytomas and medullary thyroid carcinomas. J Clin Invest. 1991; $87: 1691-9$.

Kibel AS, Freije D, Isaacs WB, Bova GS. Deletion mapping at 12p12-13 in metastatic prostate cancer. Genes Chromosomes Cancer. 1999 Jul;25(3): 270-6. 
Kibel AS, Suarez BK, Belani J, Oh J, Webster R, Brophy-Ebbers M, Guo C, Catalona WJ, Picus J, Goodfellow PJ. CDKN1A and CDKN1B polymorphisms and risk of advanced prostate carcinoma. Cancer Res. 2003; 63(9):2033-6.

Kirkwood B R, Sterne JAC. Essential medical statistics. 2nd ed. Blackwell Science: Massachusetts, USA; 2006. p.502.

Kiyokawa H, Kineman RD, Manova-Todorova KO, Soares VC, Hoffman ES, Ono M, Khanam D, Hayday AC, Frohman LA, Koff A. Enhanced growth of mice lacking the cyclin-dependent kinase inhibitor function of p27(Kip1). Cell. 1996 May 31;85(5):721-32.

Kloos RT, Eng C, Evans DB, Francis GL, Gagel RF, Gharib H, Moley JF, Pacini F, Ringel MD, Schlumberger M, Wells SA Jr. Medullary thyroid cancer: management guidelines of the American Thyroid Association. Thyroid. 2009 Jun;19(6):565-612.

Kodama Y, Asai N, Kawai K, Jijiwa M, Murakumo Y, Ichihara M, Takahashi M. The RET proto-oncogene: a molecular therapeutic target in thyroid cancer. Cancer Sci. 2005 Mar;96(3):143-8.

Landa I, Montero-Conde C, Malanga D, De Gisi S, Pita G, Leandro-García LJ, Inglada-Pérez L, Letón R, De Marco C, Rodríguez-Antona C, Viglietto G, Robledo M 2010 Allelic variant at -79 (C>T) in CDKN1B (p27Kip1) confers an increased risk of thyroid $c$ Hengst ancer and alters mRNA levels. Endocr Relat Cancer. 2011;17(2):317-28.

Larrea MD, Wander SA, Slingerland JM. p27 as Jekyll and Hyde: regulation of cell cycle and cell motility. Cell Cycle. 2009 Nov 1;8(21):3455-61. Epub 2009 Nov 11. 
Lenders JW, Pacak K, Walther MM, Linehan WM, Mannelli M, Friberg P, Keiser HR, Goldstein DS, Eisenhofer G. Biochemical diagnosis of pheochromocytoma: which test is best? JAMA. 2002; Mar 20;287(11):142734.

Li G, Sturgis EM, Wang LE, Chamberlain RM, Spitz MR, El-Naggar AK, Hong WK, Wei Q. Association between the V109G polymorphism of the p27 gene and the risk and progression of oral squamous cell carcinoma. Clin Cancer Res. 2004;10(12 Pt 1):3996-4002.

Liang J, Zubovitz J, Petrocelli T, Kotchetkov R, Connor MK, Han K, Lee JH, Ciarallo S, Catzavelos C, Beniston R, Franssen E, Slingerland JM. PKB/Akt phosphorylates p27, impairs nuclear import of p27 and opposes p27mediated G1 arrest. Nat Med. 2002 Oct;8(10):1153-60. Epub 2002 Sep 16.

Lindberg D, Akerström G, Westin G. Mutational analysis of p27 (CDKN1B) and p18 (CDKN2C) in sporadic pancreatic endocrine tumors argues against tumor-suppressor function. Neoplasia. 2007 Jul;9(7):533-5.

Marsh DJ, Theodosopoulos G, Martin-Schulte K, Richardson AL, Philips J, Röher HD, Delbridge L, Robinson BG. 375. Genome-wide copy number imbalances identified in familial and sporadic medullary thyroid carcinoma. $J$ Clin Endocrinol Metab. 2003 Apr;88(4):1866-72.

Marx SJ. Molecular Genetics of Multiple Endocrine Neoplasia Types 1 e 2. Nat Rev Cancer. 2005 May;5(5):367-75.

Mathew CG,Smith BA,Thorpe K,Wong Z,Royle NJ,Jeffreys AJ,Ponder BA. Deletion of genes on chromosome 1 in endocrine neoplasia. Nature 1987; 328: 524-6. 
Menko FH, van der Luijt RB, de Valk IA, Toorians AW, Sepers JM, van Diest PJ, Lips CJ. Atypical MEN type 2B associated with two germline RET mutations on the same allele not involving codon 918. J Clin Endocrinol Metab. 2002;87(1):393-7.

Miller SA, Dykes DD, Polesky HF. A simple salting out procedure for extracting DNA from human nucleated cells. Nucleic Acids Research 1988; 16(3): 1215.

Molatore S, Marinoni I, Lee M, Pulz E, Ambrosio MR, degli Uberti EC, Zatelli MC, Pellegata NS. A novel germline CDKN1B mutation causing multiple endocrine tumors: clinical, genetic and functional characterization. Hum Mutat. 2010 Nov;31(11):E1825-35.

Mulligan LM, Gardner E, Smith BA, Mathew CG, Ponder BA. Genetic events in tumour initiation and progression in multiple endocrine neoplasia type 2. Genes Chromosomes Cancer. 1993 Mar;6(3):166-77.

Mulligan LM, Kwok JB, Healey CS, Elsdon MJ, Eng C, Gardner E, Love DR, Mole SE, Moore JK, Papi L, et al. Germ-line mutations of the RET protooncogene in multiple endocrine neoplasia type 2A. Nature. 1993;363(6428): 458-60.

Mulligan LM, Marsh DJ, Robinson BG, Schuffenecker I, Zedenius J, Lips CJ, Gagel RF, Takai SI, Noll WW, Fink M, et al. Genotype-phenotype correlation in multiple endocrine neoplasia type 2: report of the International RET Mutation Consortium. J Intern Med. 1995 Oct;238(4):343-6.

Naidu R, Har YC, Taib NA. P27 V109G Polymorphism is associated with lymph node metastases but not with increased risk of breast cancer. J Exp Clin Cancer Res. 2007 Mar;26(1):133-40. 
Nakayama K, Ishida N, Shirane M, Inomata A, Inoue T, Shishido N, Horii I, Loh DY, Nakayama K. Mice lacking p27(Kip1) display increased body size, multiple organ hyperplasia, retinal dysplasia, and pituitary tumors. Cell. 1996 May 31;85(5):707-20.

Nelson DL, Cox MM. In: Lehninger Princípios de Bioquímica. Fourth Edition Sarvier. Sauders Ed. 463-465.

Nunes AB, Ezabella MC, Pereira AC, Krieger JE, Toledo SP. A novel Val648lle substitution in RET protooncogene observed in a Cys634Arg multiple endocrine neoplasia type 2A kindred presenting with an adrenocorticotropin-producing pheochromocytoma. J Clin Endocrinol Metab. 2002;87(12):5658-61.

Pagano M, Tam SW, Theodoras AM, Beer-Romero P, Del Sal G, Chau V, Yew PR, Draetta GF, Rolfe M. Role of the ubiquitin-proteasome pathway in regulating abundance of the cyclin-dependent kinase inhibitor p27. Science. 1995 Aug 4;269(5224):682-5.

Parisi MA, Kapur RP. Genetics of Hirschsprung disease. Curr Opin Pediatr. 2000 Dec;12(6):610-7. Review.

Pasquali D, Circelli L, Faggiano A, Pancione M, Renzullo A, Elisei R, Romei C, Accardo G, Coppola VR, De Palma M, Grimaldi F, Ferolla P, Colao AA, Colantuoni V. CDKN1B V109G polymorphism a new prognostic factor in sporadic medullary thyroid carcinoma. Eur J Endocrinol. 2011 Mar; 164(3): 397-404.

Pellegata NS, Quintanilla-Martinez L, Siggelkow H, Samson E, Bink K, Höfler H, Fend F, Graw J, Atkinson MJ. Germ-line mutations in p27Kip1 cause a multiple endocrine neoplasia syndrome in rats and humans. Proc Natl Acad Sci USA. 2006; 103(42):15558-63. 
Piotrowska K, Pellegata NS, Rosemann M, Fritz A, Graw J, Atkinson MJ. Mapping of a novel MEN-like syndrome locus to rat chromosome 4. Mamm Genome. 2004 Feb;15(2):135-41.

Polyak K, Kato JY, Solomon MJ, Sherr CJ, Massague J, Roberts JM, Koff A. p27Kip1, a cyclin-Cdk inhibitor, links transforming growth factor-beta and contact inhibition to cell cycle arrest. Genes Dev. 1994 Jan;8(1):9-22.

Qi XP, Ma JM, Du ZF, Ying RB, Fei J, Jin HY, Han JS, Wang JQ, Chen XL, Chen CY, Liu WT, Lu JJ, Zhang JG, Zhang XN. RET germline mutations identified by exome sequencing in a Chinese multiple endocrine neoplasia type 2A/familial medullary thyroid carcinoma family. PLoS One. 2011;6(5):e20353.

Qin Y, Yao L, King EE, Buddavarapu K, Lenci RE, Chocron ES, Lechleiter JD, Sass M, Aronin N, Schiavi F, Boaretto F, Opocher G, Toledo RA, Toledo SP, Stiles C, Aguiar RC, Dahia PL. Germline mutations in TMEM127 confer susceptibility to pheochromocytoma. Nat Genet. 2010;42:229-33.

Quedas EP, Longuini VC, Sekiya T, Coutinho FL, Toledo SP, Tannuri U, Toledo RA. RET haplotype, not linked to the C620R activating mutation, associated with Hirschsprung disease in a novel MEN2 family. Clinics (Sao Paulo). 2012;67 Suppl 1:57-61.

Raue F, Frank-Raue K. Genotype-phenotype relationship in multiple endocrine neoplasia type 2. Implications for clinical management. Hormones (Athens). 2009 Jan-Mar;8(1):23-8.

Raue F, Frank-Raue K. Update multiple endocrine neoplasia type 2. Fam Cancer. 2010 Sep;9(3):449-57. doi: 10.1007/s10689-010-9320-2. Review. 
Santos MACG, Nunes AB, Abelin N, Ezabella MCL, Toledo RA, LourençoJunior D, Hayashida CY, Fonseca IIM, Toledo SPA. Rastreamento Gênico da Neoplasia Endócrina Múltipla Tipo 2: Experiência da Unidade de Endocrinologia Genética da USP. Arq Bras Endocrinol Metab. 2006;50(1):716.

Sherr CJ, Roberts JM. CDK inhibitors: positive and negative regulators of G1-phase progression. Genes Dev. 1999 Jun 15;13(12):1501-12.

Shiraso S, Katayose Y, Yamamoto K, Mizuma M, Yabuuchi S, Oda A, Rikiyama T, Onogawa T, Yoshida H, Hayashi H, Ohtsuka H, Motoi F, Egawa S, Kato J, Unno M. Overexpression of adenovirus-mediated p27kip1 lacking the Jab1-binding region enhances cytotoxicity and inhibits xenografted human cholangiocarcinoma growth. Anticancer Res. 2009 Jun;29(6):201524.

Sipple JH. The association of pheochromocytoma with carcinoma of the thyroid gland. Am J Med. 1961; 31:163-6.

Steelman LS, Abrams SL, Whelan J, Bertrand FE, Ludwig DE, Basecke J, Libra M, Stivala F, Milella M, Tafuri A, Lunghi $P$, Bonati A, et al. Contributions of the Raf/MEK/ERK, PI3K/PTEN/Akt/mTOR and JAK/STAT pathways to leukemia. Leukemia. 2008;22:686-707.

Takai S, Tateishi, H, Nishisho I, Mikli T, Motomura K, Miyauchi A, Kato M, Ikeuchi T, Yamamoto K, Okazaki M, et al. Loss of genes on chromosome 22 in medullary thyroid carcinoma and pheochromocytoma. Jpn J Cancer Res. 1987; 78(9):894-8.

Takahashi M, Ritz J, Cooper GM. Activation of a novel human transforming gene, ret, by DNA rearrangement. Cell. 1985;42:581-8. 
Takeuchi S, Bartram CR, Miller CW, Reiter A, Seriu T, Zimmerann M, Schrappe M, Mori N, Slater J, Miyoshi I, Koeffler HP. Acute Iymphoblastic leukemia of childhood: identification of two distinct regions of deletion on the short arm of chromosome 12 in the region of TEL and KIP1. Blood. $1996 \mathrm{Apr}$ 15;87(8):3368-74.

Tessitore A, Sinisi AA, Pasquali D, Cardone M, Vitale D, Bellastella A, Colantuoni V. A novel case of multiple endocrine neoplasia type 2A associated with two de novo mutations of the RET protooncogene. J Clin Endocrinol Metab. 1999;84(10):3522-7.

Tigli H, Buyru N, Dalay N. Molecular analysis of the p27/kip1 gene in breast cancer. Mol Diagn. 2005;9(1):17-21.

Toledo RA, Lourenco DM, Coutinho FL, Quedas E, Mackowiack I, Machado MC, Montenegro F, Cunha-Neto MB, Liberman B, Pereira MA, Correa PH, Toledo SP. Novel MEN1 germline mutations in Brazilian families with multiple endocrine neoplasia type 1. Clin Endocrinol (Oxf). 2007 Sep;67(3):377-84.

Toledo RA, Wagner SM, Coutinho FL, Lourenço DM Jr, Azevedo JA, Longuini VC, Reis MT, Siqueira SA, Lucon AM, Tavares MR, Fragoso MC, Pereira AA, Dahia PL, Mulligan LM, Toledo SP. High penetrance of pheochromocytoma associated with the novel C634Y/Y791F double germline mutation in the RET protooncogene. J Clin Endocrinol Metab. 2010 Mar;95(3):1318-27.

Toledo SPA, Santos MACG, Toledo RA, Lourenço-Junior DM. Impact of RET proto-oncogene analysis on the clinical management of multiple endocrine neoplasia type 2. Clinics. 2006;61(1):59-70. 
Tomoda K, Kubota Y, Arata Y, Mori S, Maeda M, Tanaka T, Yoshida M, Yoneda-Kato N, Kato JY The cytoplasmic shuttling and subsequent degradation of p27Kip1 mediated by Jab1/CSN5 and the COP9 signalosome complex. J Biol Chem. 2002;277(3):2302-10.

Tomoda K, Kubota Y, Kato J. Degradation of the cyclin-dependent-kinase inhibitor p27Kip1 is instigated by Jab1. Nature. 1999;398(6723):160-5.

van Tiel CM, Bonta PI, Rittersma SZ, Beijk MA, Bradley EJ, Klous AM, Koch KT, Baas F, Jukema JW, Pons D, Sampietro ML, Pannekoek H, de Winter $\mathrm{RJ}$, de Vries CJ. p27kip1-838C>A single nucleotide polymorphism is associated with restenosis risk after coronary stenting and modulates p27kip1 promoter activity. Circulation. 2009 Aug 25;120(8):669-76.

van Veelen W, Klompmaker R, Gloerich M, van Gasteren CJ, Kalkhoven E, Berger R, Lips CJ, Medema RH, Höppener JW, Acton DS. P18 is a tumor suppressor gene involved in human medullary thyroid carcinoma and pheochromocytoma development. Int J Cancer. 2009;124(2):339-45.

van Veelen W, van Gasteren CJ, Acton DS, Franklin DS, Berger R, Lips CJ, Höppener JW. Synergistic effect of oncogenic RET and loss of p18 on medullary thyroid carcinoma development. Cancer Res. 2008;68(5):1329-37.

Viglietto G, Motti ML, Fusco A. Understanding p27(kip1) deregulation in cancer: down-regulation or mislocalization. Cell Cycle. 2002; NovDec;1(6):394-400. Review.

Wander SA, Zhao D, Slingerland JM. p27: a barometer of signaling deregulation and potential predictor of response to targeted therapies. Clin Cancer Res. 2011 Jan 1;17(1):12-8. Epub 2010 Oct 21.

Weber F, Eng C. Editorial: germline variants within RET: clinical utility or scientific playtoy? J Clin Endocrinol Metab. 2005 Nov;90(11):6334-6. 
Yang KP, Nguyen CV, Castillo SG, Samaan NA. Deletion mapping on the distal third region of chromosome $1 \mathrm{p}$ in multiple endocrine neoplasia type IIA. Anticancer Res 1990; 10(2B): 527-33.

Yao L, Schiavi F, Cascon A, Qin Y, Inglada-Pérez L, King EE, Toledo RA, Ercolino T, Rapizzi E, Ricketts CJ, Mori L, Giacchè M, Mendola A, Taschin E, Boaretto F, Loli P, lacobone M, Rossi GP, Biondi B, Lima-Junior JV, Kater CE, Bex M, Vikkula M, Grossman AB, Gruber SB, Barontini M, Persu A, Castellano M, Toledo SP, Maher ER, Mannelli M, Opocher G, Robledo M, Dahia PL. Spectrum and prevalence of FP/TMEM127 gene mutations in pheochromocytomas and paragangliomas. JAMA. 2010 Dec 15;304(23): 2611-9.

Ye L, Santarpia L, Cote GJ, El-Naggar AK, Gagel RF. High resolution arraycomparative genomic hybridization profiling reveals deoxyribonucleic acid copy number alterations associated with medullary thyroid carcinoma. J Clin Endocrinol Metab. 2008 Nov;93(11):4367-72. 